Alll02 616734

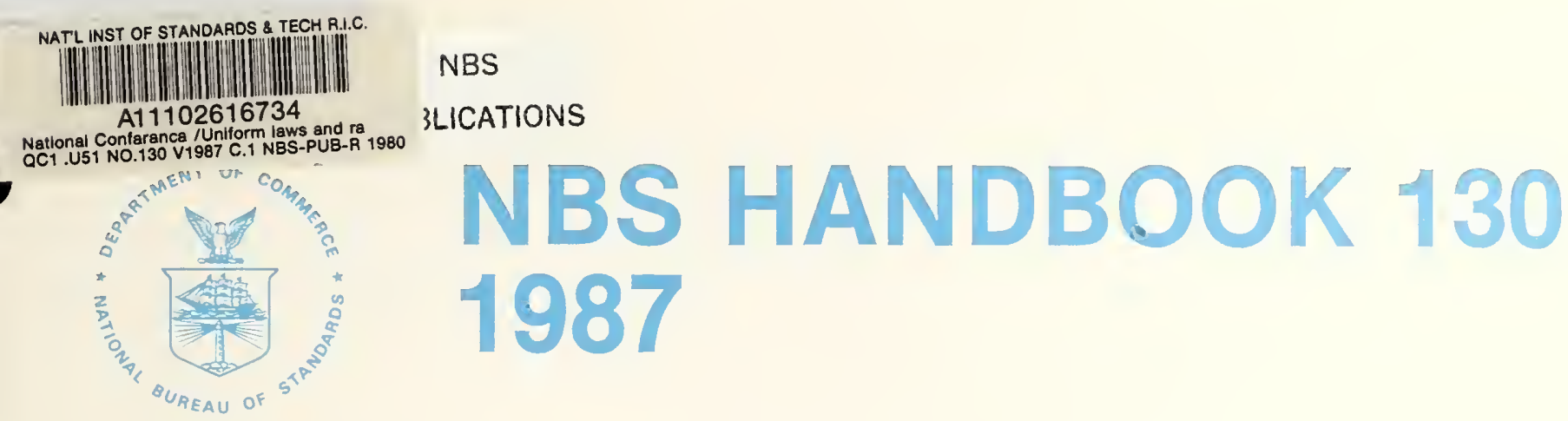

\title{
UNIFORM LAWS AND REGULATIONS
}

\section{Wewhils and Mensure: Law \\ Weigi mastar to:}

Pschaging and Labeling Heguistien Method or Sale of Commeditise Pageilation Unit Prieng Ragubilis Registration of Serrulcepersons and Agencles Regulaion Operi Dawing Requalion

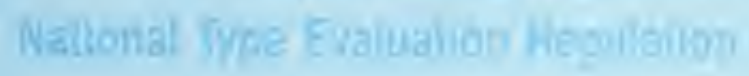
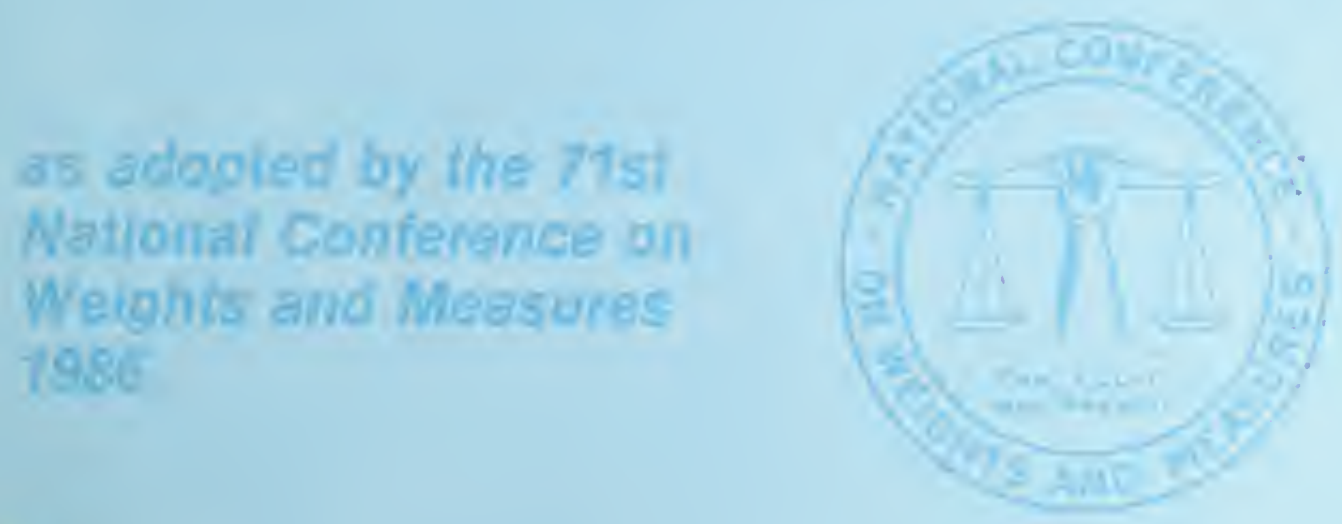

$-Q C$

1

.1151

\#130

S. DEPARTMENT OF COMMERCE / National Bureau of Standards

1987 
he National Bureau of Standards' ${ }^{\text {was }}$ established by an act of Congress on March 3, 1901. The Bureau's overall goal is to strengthen and advance the nation's science and technology and facilitate their effective application for public benefit. To this end, the Bureau conducts research and provides: (1) a basis for the nation's physical measurement system, (2) scientific and technological services for industry and government, (3) a technical basis for equity in trade, and (4) technical services to promote public safety.

The Bureau's technical work is performed by the National Measurement Laboratory, the National Engineering Laboratory, the Institute for Computer Sciences and Technology, and the Institute for Materials Science and Engineering.

\section{The National Measurement Laboratory}

Provides the national system of physical and chemical measurement; coordinates the system with measurement systems of other nations and furnishes essential services leading to accurate and uniform physical and chemical measurement throughout the Nation's scientific community, industry, and commerce; provides advisory and research services to other Government agencies; conducts physical and chemical research; develops, produces, and distributes Standard Reference Materials; and provides calibration services. The Laboratory consists of the following centers:
- Basic Standards ${ }^{2}$

- Radiation Research

- Chemical Physics

- Analytical Chemistry

\section{The National Engineering Laboratory}

Provides technology and technical services to the public and private sectors to address national needs and to solve national problems; conducts research in engineering and applied science in support of these efforts; builds and maintains competence in the necessary disciplines required to carry out this research and technical service; develops engineering data and measurement capabilities; provides engineering measurement traceability services; develops test methods and proposes engineering standards and code changes; develops and proposes new engineering practices; and develops and improves mechanisms to transfer results of its research to the ultimate user. The Laboratory consists of the following centers:
- Applied Mathematics

- Electronics and Electrical Engineering ${ }^{2}$

- Manufacturing Engineering

- Building Technology

- Fire Research

- Chemical Engineering ${ }^{2}$

\section{The Institute for Computer Sciences and Technology}

Conducts research and provides scientific and technical services to aid Federal agencies in the selection, acquisition, application, and use of computer technology to improve effectiveness and economy in Government operations in accordance with Public Law 89-306 (40 U.S.C. 759), relevant Executive Orders, and other directives; carries out this mission by managing the Federal Information Processing Standards Program, developing Federal ADP standards guidelines, and managing Federal participation in ADP voluntary standardization activities; provides scientific and technological advisory services and assistance to Federal agencies; and provides the technical foundation for computer-related policies of the Federal Government. The Institute consists of the following centers:
- Programming Science and Technology

- Computer Systems Engineering

\section{The Institute for Materials Science and Engineering}

Conducts research and provides measurements, data, standards, reference materials, quantitative understanding and other technical information fundamental to the processing, structure, properties and performance of materials; addresses the scientific basis for new advanced materials technologies; plans research around cross-country scientific themes such as nondestructive evaluation and phase diagram development; oversees Bureau-wide technical programs in nuclear reactor radiation research and nondestructive evaluation; and broadly disseminates generic technical information resulting from its programs. The Institute consists of the following Divisions:
- Ceramics

- Fracture and Deformation ${ }^{3}$

- Polymers

- Metallurgy

- Reactor Radiation 
NBS HANDBOOK 130

1987

(Superseding Handbook 130 - 1986 Edition.)

\section{UNIFORM LAWS AND REGULATIONS}

ADOPTED BY THE 71st

NATIONAL CONFERENCE ON WEIGHTS AND MEASURES 1986

Carroll S. Brickenkamp, Editor

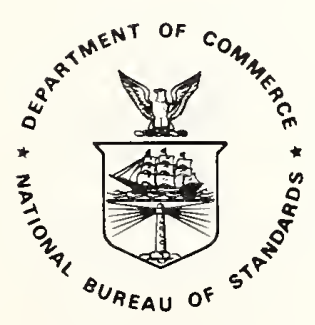

U.S. DEPARTMENT OF COMMERCE, Malcolm Baldrige, Secretary NATIONAL BUREAU OF STANDARDS, Ernest Ambler, Director Issued September 1986 
National Bureau of Standards Handbook 130, 1987 Edition Natl. Bur. Stand. (U.S.) Handb. 130, 1987 Ed., 178 pages (Sept. 1986) CODEN: NBSHAP 


\section{FOREWORD}

This handbook compiles the latest Uniform Laws and Regulations adopted by the National Conference on Weights and Measures (NCWM). At the 1983 annual meeting, the NCWM voted to change the title of Handbook 130 and the titles of the Laws and Regulations compiled in this handbook. The former title of the handbook was "Model State Laws and Regulations." "Model State" was changed to "Uniform" in the titles to reflect that these Laws and Regulations are (a) intended to be standards rather than just guidelines, and are (b) intended for adoption by political subdivisions other than States when deemed appropriate.

The compilation itself was approved by the NCWM in 1979, and this edition includes amendments adopted at the annual meeting in 1986 as well as a new index for the entire handbook. The Conference recommends adoption and promulgation by the States of these Uniform Laws and Regulations as updated in this handbook.

The National Bureau of Standards has a statutory responsibility for "cooperation with the States in securing uniformity of weights and measures laws and methods of inspection". In partial fulfillment of this responsibility, the Bureau is pleased to publish these recommendations of the National Conference.

ERNEST AMBLER

Director

National Bureau of Standards 


\section{Committee on Laws and Regulations of the 71st Conference}

Don Stagg, State of Alabama, Chairman

Trafford Brink, State of Vermont

Sidney Colbrook, State of Illiois

Leo Letey, State of Colorado

Allan Nelson, State of Connecticut

\section{Past Chairmen of the Committee}

\begin{tabular}{|c|c|c|c|}
\hline Conference & Chairman & Conference & Chairman \\
\hline 40 & $\begin{array}{l}\text { G.H. Leithauser } \\
\text { Baltimore. MD }\end{array}$ & 56 & $\begin{array}{l}\text { S.D. Andrews } \\
\text { Florida }\end{array}$ \\
\hline 41 & $\begin{array}{l}\text { G.H. Leithauser } \\
\text { Baltim ore, MD }\end{array}$ & 57 & $\begin{array}{l}\text { S.D. Andrews } \\
\text { Florida }\end{array}$ \\
\hline 42 & $\begin{array}{l}\text { F.M. Greene } \\
\text { Connecticut }\end{array}$ & 58 & $\begin{array}{l}\text { S.D. Andrews } \\
\text { Florida }\end{array}$ \\
\hline 43 & $\begin{array}{l}\text { F.M. Greene } \\
\text { Connecticut }\end{array}$ & 59 & $\begin{array}{l}\text { R.M. Leach } \\
\text { Michigan }\end{array}$ \\
\hline 44 & $\begin{array}{l}\text { G.L. Johnson } \\
\text { Kentucky }\end{array}$ & 60 & $\begin{array}{l}\text { R.L. Thompson } \\
\text { Maryland }\end{array}$ \\
\hline 45 & $\begin{array}{l}\text { R. Williams } \\
\text { Nassau County, NY }\end{array}$ & 61 & $\begin{array}{l}\text { C.H. Vincent } \\
\text { Dallas, TX }\end{array}$ \\
\hline 46 & $\begin{array}{l}\text { J.H. Lewis } \\
\text { Washington }\end{array}$ & 62 & $\begin{array}{l}\text { C.H. Vincent } \\
\text { Dallas, TX }\end{array}$ \\
\hline 47 & $\begin{array}{l}\text { J.H. Lewis } \\
\text { Washington }\end{array}$ & 63 & $\begin{array}{l}\text { J.T. Bennett } \\
\text { Connecticut }\end{array}$ \\
\hline 48 & $\begin{array}{l}\text { J.H. Lew is } \\
\text { Washington }\end{array}$ & 64 & $\begin{array}{l}\text { R.W. Probst } \\
\text { Wisconsin }\end{array}$ \\
\hline 49 & $\begin{array}{l}\text { J.H. Lewis } \\
\text { Washington }\end{array}$ & 65 & $\begin{array}{l}\text { D.I. Offner } \\
\text { St. Louis, MO }\end{array}$ \\
\hline 50 & $\begin{array}{l}\text { L. Barker } \\
\text { West Virginia }\end{array}$ & 66 & $\begin{array}{l}\text { J.J. Bartfai } \\
\text { New York }\end{array}$ \\
\hline 51 & $\begin{array}{l}\text { L. Barker } \\
\text { West Virginia }\end{array}$ & 67 & $\begin{array}{l}\text { J.J. Bartfai } \\
\text { New York }\end{array}$ \\
\hline 52 & $\begin{array}{l}\text { M. Jennings } \\
\text { Tennessee }\end{array}$ & 68 & $\begin{array}{l}\text { J.J. Bartfai } \\
\text { New York }\end{array}$ \\
\hline 53 & $\begin{array}{l}\text { W.A. Kerlin } \\
\text { California }\end{array}$ & 69 & $\begin{array}{l}\text { W.R. Mossberg } \\
\text { Los Angeles County, CA }\end{array}$ \\
\hline 54 & $\begin{array}{l}\text { J.F. Lyles } \\
\text { Virginia }\end{array}$ & 70 & $\begin{array}{l}\text { E. Skluzacek } \\
\text { Minnesota }\end{array}$ \\
\hline 55 & $\begin{array}{l}\text { J.F. Lyles } \\
\text { Virginia }\end{array}$ & & \\
\hline
\end{tabular}




\section{OUTLINE OF CONTENTS}

\section{Page}

FOREWORD

iii

1986 AMENDMENTS

vi

I. Introduction I-1

II. Uniformity of Laws and Regulations II-1

III. Uniform Laws III-1

A. Uniform Weights and Measures Law II-3

B. Uniform Weighmaster Law II-21

IV. Uniform Regulations IV-1

A. Uniform Packaging and Labeling
Regulation IV-3

B. Uniform Regulation for the Method
of Sale of Commodities IV-53

C. Uniform Unit Pricing Regulation IV-81

D. Uniform Regulation for the Voluntary Registration of Servicepersons and Service Agencies for Commercial Weighing and Measuring Devices

E. Uniform Open Dating Regulation IV-99

F. Uniform Regulation for National Type Evaluation

V. Index

$\mathrm{V}-1$

In accord with NBS policy, the meter/liter spellings are used in this document. However, the metre/litre spellings are acceptable, and are preferred by the National Conference on Weights and Measures. 


\section{AMENDMENTS}

The following table lists those laws and regulations and pages in which amendments were made by the 71st National Conference on Weights and Measures. Each law or regulation, section, or paragraph that has been added or changed is noted as "Added 1986" or "Amended 1986."

\begin{tabular}{|c|c|c|c|}
\hline Law or Regulation & Section & Action & Page \\
\hline \multicolumn{4}{|l|}{ Uniform Weights and } \\
\hline \multirow[t]{4}{*}{$\begin{array}{l}\text { Uniform Packaging and } \\
\text { Labeling Regulation }\end{array}$} & 3.1 . & $\begin{array}{l}\text { Footnote } \\
\text { Added }\end{array}$ & IV -13 \\
\hline & 4. & $\begin{array}{l}\text { Footnote } \\
\text { Added }\end{array}$ & IV -13 \\
\hline & 6.8.2.(c) & Amended & IV-22 \\
\hline & $6.10 .(d)$ & Amended & IV-24 \\
\hline \multirow{6}{*}{$\begin{array}{l}\text { Uniform Regulation for } \\
\text { the Method of Sale } \\
\text { of Commodities }\end{array}$} & 1.3. & Amended & IV -59 \\
\hline & 1.5. & Amended & IV-60 \\
\hline & 1.5 .3 & Added & IV -60 \\
\hline & 1.7 .1 & $\begin{array}{l}\text { Footnote } \\
\text { Added }\end{array}$ & IV-62 \\
\hline & 2.19 & Amended & IV -77 \\
\hline & 2.20 & Added & IV -77 \\
\hline
\end{tabular}




\section{INTRODUCTION}

A. SOURCE. - The Uniform Laws and Regulations ${ }^{1}$ in this compiled form comprise all those adopted by the National Conference on Weights and Measures (NCWM). ${ }^{2}$

The National Conference is sponsored by the National Bureau of Standards (NBS), which organization provides its secretariat and publishes its documents. The NBS also develops technical publications for use by weights and measures agencies; these publications may subsequently be endorsed or adopted by the NCWM.

The Conference Committee on Laws and Regulations (see Paragraph C), acting at the request of the Conference or upon its own initiative, prepares, with the technical assistance of the National Bureau of Standards, proposed amendments or additions to the material previously adopted by the Conference. Such amendments or additions are then presented to the Conference as a whole, where they are discussed by weights and measures officials and representatives of interested manufacturers, industries, consumer groups, and others. Eventually the proposals of the Committee, which may have been amended on the floor, are voted upon by the weights and measures officials. Following the new voting procedures adopted by the NCWM in 1978, a national consensus is required on all issues adopted by the Conference. No Uniform Law or Regulation is adopted without at least a majority of the States' representatives and at least a majority of other voting delegates favoring such adoption.

All of the Uniform Laws and Regulations given herein are recommended by the National Conference on Weights and Measures for use by States when reviewing or amending their official laws and regulations in the areas covered. A similar recommendation is made with regard to the local jurisdictions within a State in the absence of the promulgation of such laws and regulations at the State level.

1 When referring to the Uniform Laws and Regulations in Handbook 130, Laws and Regulations will be capitalized. When referring to general Federal or State laws and regulations, no capitalization will be used.

2 The National Conference on Weights and Measures (NCWM) when sitting as a voting body is made up of State and local weights and measures officials from all parts of the United States. The NCWM normally meets annually. 
B. PURPOSE. - The purpose of these Uniform Laws and Regulations is to achieve, to the maximum extent possible, standardization in weights and measures laws and regulations among the various States and local jurisdictions in order to facilitate trade between the States, permit fair competition among businesses, and provide uniform and sufficient protection to all consumers in weights and measures issues.

C. AMENDMENTS.- The Committee on Laws and Regulations of the National Conference on Weights and Measures provides the mechanism for consideration of amendments or additions to the Uniform Laws and Regulations. Recommendations for changes should be directed to the Committee on Laws and Regulations, National Conference on Weights and Measures, P. 0. Box 3137, Gaithersburg, Md., 20878 (with a copy to the Executive Secretary at the same address).

- To be considered by the Committee for action during the upcoming Conference, proposals must be presented in writing to the Committee 60 days prior to the Interim Meetings (usually the third week of January of each year).

- Proposals should contain a concise statement of the problem and clearly outline the purpose and national need for its consideration.

- Proposals should be accompanied by adequate background material, including test data, analysis of test data, or other appropriately researched and documented material from which a committee will be able either to make a suitable judgment for a firm recommendation or to consider the need for further study. When possible, solutions to problems should be proposed and stated in specific language in amendment form to Conference documents.

- Weights and measures officials are encouraged to utilize their regional associations for initial exploration of issues and to use the resources of all member States within that regional association to assist in the development of well documented proposals where applicable.

- If a proposal involves a new area of weights and measures activity, it is appropriate to make recommendations for both Uniform Regulations and test methods to provide for proper enforcement.

Additionally, when a proposal that would modify or add to Handbook 130 is presented to the Committee, the proposal should:

- Identify the pertinent portion, section, and paragraph of the existing publication (e.g., Uniform Regulation for the Method of Sale of Commodities, Section 2.8.). 
- Where applicable, provide evidence of consistency with other portions of NCWM publications (such as with other Uniform Laws and Regulations).

- Where applicable, provide evidence of consistency with Federal laws and regulations (such as with FDA or FTC regulations).

D. REVISIONS TO THE HANDBOOK.- This Handbook will be reissued annually following the annual meeting of the National Conference on Weights and Measures and will reflect changes approved by the Conference at that meeting. Each Uniform Law and Regulation will be reprinted in full each year, even if it is not changed that year, to indicate the current version clearly. (Note: Section numbering may be changed from one edition of this Handbook to another to accommodate additions or deletions.)

E. ANNOTATION.- From 1971 on, amendments or additions to sections in the Uniform Laws and Regulations are delineated at the end of each section (e.g., "amended 1982") as a service for those States that are planning to update their own laws or regulations. The references to each revision and the year will enable legislators and rule makers to study the actual wording and rationale for changes (appearing in the Annual Report of the NCWM for that year) and subsequently adopt changes in their own laws and regulations, modeling them after the Uniform Laws and Regulations. 



\section{UNIFORMITY OF LAWS AND REGULATIONS}

1.

\section{NATIONAL CONFERENCE GOAL}

The goal of the National Conference on Weights and Measures with respect to these Uniform Laws and Regulations is to achieve their acceptance in all States and local jurisdictions that have authority over such matters. The Conference stands ready to assist any jurisdiction in any way possible in securing adoption.

\section{STATUS OF PROMULGATION}

Listed on the following pages, by State, is information regarding the adoption of the Uniform Laws and Regulations. Adoption is indicated if the State has adopted the Uniform Law or Regulation in total, in part, or if the State has used it as guidance in developing a similar law or regulation.

The information is verified with each State annually; the entries are intended to represent the current status of State adoption.

There is need for judgment concerning the actual degree of adoption unless a section-by-section comparison is made between each State law or regulation and the related Uniform Laws and Regulations. This detailed comparison has been made for three regulations:

(1) Packaging and Labeling (see Annual Report of the 69th NCWM, 1984),

(2) Method of Sale (see Annual Report of the 68th NCWM, 1983), and

(3) Voluntary Registration (see Annual Report of the 67 th NCWM, 1982.) Note that the Regulation was revised in 1984 such that the data in the 1982 intercomparison is only partly valid. 


\section{SUMMARY OF STATE LAWS AND REGULATIONS FOR WEIGHTS AND MEASURES}

\begin{tabular}{|c|c|c|c|c|c|c|c|c|}
\hline \multirow[b]{2}{*}{ STATE } & \multicolumn{8}{|c|}{ UNIFORM LAWS AND REGULATIONS ADOPTED } \\
\hline & 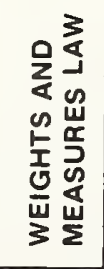 & 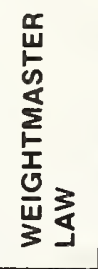 & 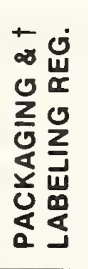 & 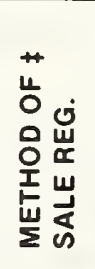 & 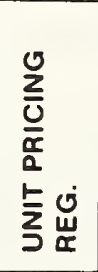 & 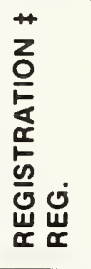 & 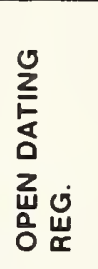 & 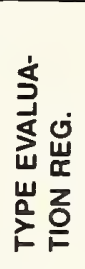 \\
\hline ALABAMA & YES & yes & yes & yes & YES & yes & yes & yes \\
\hline ALASKA & YES & NO & yes & yes & NO & NO & NO & NO \\
\hline ARIZONA & YES & YES & YES & yes & NO & yes & YES & yes \\
\hline ARKANSAS & YES & NO & YES & YES & NO & YES & YES & YES \\
\hline CALIFORNIA & YES & yes & yes & yes & NO & yes & yes* & yes \\
\hline COLORADO & yes & yes & YES & yes & NO & yes & NO & NO \\
\hline CONNECTICUT & yes & YES & yes & YES & yes* & yes* & yes* & YES \\
\hline DELAWARE & YES & YES & yes & yes & NO & NO & NO & yes \\
\hline DISTRICT OF COLUMBIA & YES & YES & NO & yes & NO & NO & No & NO \\
\hline FLORIDA & YES & NO & yes & no & yes* & YES & yes* & no \\
\hline GEORGIA & yes & yes* & yes & yes & NO & yes & yes* & yes \\
\hline HAWAII & YES & YES & yes & yes & YES & YES & YES & yes \\
\hline IDAHO & YES & YES & yes & yes & NO & YES & NO & no \\
\hline ILLINOIS & YES & NO & yes & yes & NO & yes & NO & yes* \\
\hline INDIANA & yes & yes & yes & yes & NO & NO & NO & no \\
\hline IOWA & YES & yes* & yes & yes* & NO & yes* & No & yes \\
\hline KANSAS & yes & NO & yes & yes & NO & yes & NO & no \\
\hline KENTUCKY & YES & No & yes & yes & yes* & YES & yes* & no \\
\hline LOUISIANA & yes & yes & yes* & yes & NO & NO & NO & no \\
\hline MAINE & YES & YES & YES & YES & NO & yes & No & no \\
\hline
\end{tabular}

KEY:

$$
\begin{aligned}
& \text { YES } \\
& \text { yes - Fully adopted } \\
& \text { yes* - Law or regulation in force, but NCWM standard was not } \\
& \text { considered } \\
& \text { no - No law or regulation on this subject, however NCWM } \\
& \text { No - Nondard is used as guideline } \\
& \text { No law or regulation on this subject }
\end{aligned}
$$

¥Report on status of adoption based on a paragraph-byparagraph comparison of State laws and regulations (wherever available) with the NCWM version in 1982.

tParagraph-by-paragraph comparison completed 1984.

All other summaries are based on telephone responses. 


\section{SUMMARY OF STATE LAWS AND REGULATIONS FOR WEIGHTS AND MEASURES}

\begin{tabular}{|c|c|c|c|c|c|c|c|c|}
\hline \multirow[b]{2}{*}{ STATE } & \multicolumn{8}{|c|}{ UNIFORM LAWS AND REGULATIONS ADOPTED } \\
\hline & 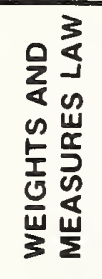 & $\begin{array}{l}\frac{x}{4} \\
5 \\
\frac{5}{5} \\
\frac{5}{5} \\
\frac{1}{5} \\
\frac{0}{w} 3 \\
\frac{3}{3}\end{array}$ & 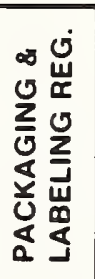 & 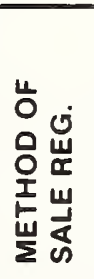 & 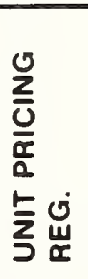 & 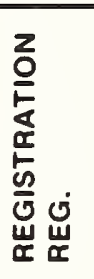 & 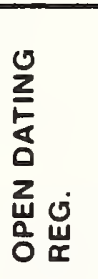 & 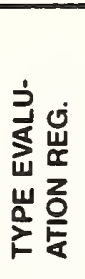 \\
\hline MARYLAND & YES & NO & yes & yes & yes* & NO & yes* & NO \\
\hline MASSACHUSETTS & yes* & yes* $^{*}$ & yes & yes & yes* & NO & NO & yes* \\
\hline MICHIGAN & yes* & YES & yes & yes & yes* & NO & YES & yes \\
\hline MINNESOTA & yes* & NO & yes & NO & NO & YES & yes* & NO \\
\hline MISSISSIPPI & YES & yes & yes & yes & yes & yes & NO & yes \\
\hline MISSOURI & yes & No & YES & YES & NO & YES & yes* & yes \\
\hline MONTANA & YES & NO & yes & yes & NO & YES & NO & NO \\
\hline NEBRASKA & YES & NO & no & no & no & YES & No & NO \\
\hline NEVADA & YES & YES & yes* & yes & NO & yes & NO & NO \\
\hline NEW HAMPSHIRE & YES & YES & YES & YES & YES & YES & YES & YES \\
\hline NEW JERSEY & yes & YES & yes & yes & yes* & yes* & yes* & yes* \\
\hline NEW MEXICO & YES & YES & NO & yes & NO & yes & yes* & NO \\
\hline NEW YORK & yes & yes & yes & yes & yes* & NO & NO & yes* \\
\hline NORTH CAROLINA & YES & YES & yes & 'yes & NO & yes & yes* & yes \\
\hline NORTH DAKOTA & YES & YES & NO & yes* & NO & yes & NO & no \\
\hline OHIO & YES & NO & yes & yes & NO & NO & yes* & YES \\
\hline OKLAHOMA & YES & NO & yes & yes* & NO & yes & yes* & NO \\
\hline OREGON & YES & NO & yes & yes & yes* & NO & yes* & no \\
\hline PENNSYLVANIA & YES & yes* & yes & yes & NO & NO & YES & yes \\
\hline PUERTO RICO & yes & YES & yes & yes* & yes* & yes & NO & NO \\
\hline
\end{tabular}




\section{SUMMARY OF STATE LAWS AND REGULATIONS FOR WEIGHTS AND MEASURES}

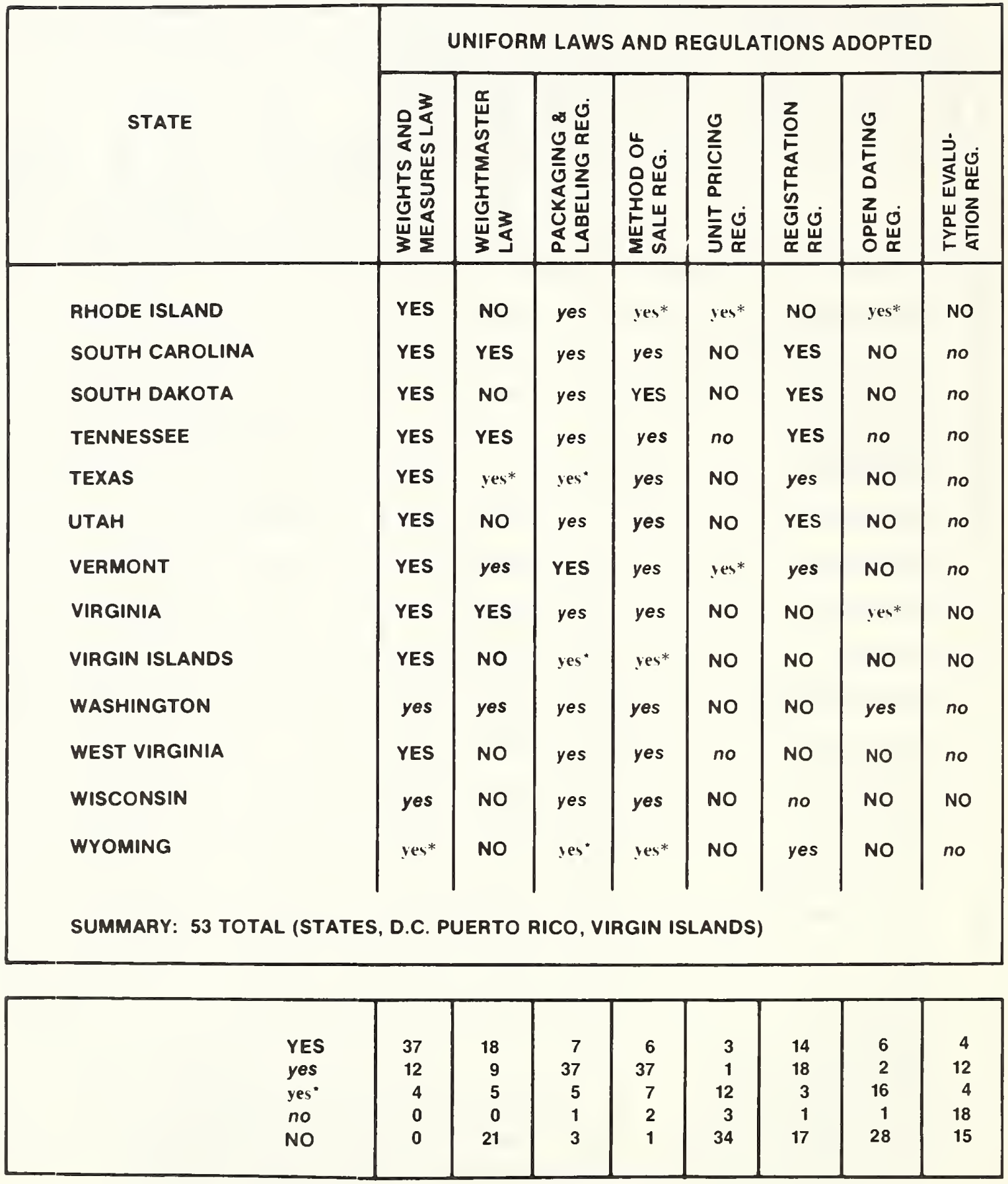




\section{UNIFORM LAWS}

\section{Page}

A. Uniform Weights and Measures Law

III-3

B. Uniform Weighmaster Law

III-21 



\section{UNIFORM WEIGHTS AND MEASURES LAW 1971}

as adopted by

The National Conference on Weights and Measures ${ }^{1}$

\section{BACKGROUND}

Recognition of the need for uniformity in weights and measures laws and regulations among the States was first noted at the second National Conference on Weights and Measures in April 1906. In the following year, basic outlines of a "Model State Weights and Measures Law" were developed. The first "Model Law", as such, was formally adopted by the Conference in 1911.

Through the years, almost without exception, each State has relied upon the NCWM Weights and Measures Law at the time it first enacted comprehensive weights and measures legislation. This has led to a great degree of uniformity in the basic weights and measures requirements throughout the country.

The original Law was regularly amended to provide for new developments in commercial practices and technology. Necessarily, this resulted in a lengthy and cumbersome document and in the need for a simplification of the basic weights and measures provisions. The 1971 National Conference on Weights and Measures adopted a thoroughly revised, simplified, modernized version of the "Model State Weights and Measures Law". The Law now can serve as a framework for all the many concerns in weights and measures administration and enforcement.

The title of the Law was changed by the 1983 NCWM. Amendments or revisions to the Law since 1971 are noted at the end of each section.

1 The National Conference on Weights and Measures is sponsored by the National Bureau of Standards in partial implementation of its statutory responsibility for "cooperation with the States in securing uniformity in weights and measures laws and methods of inspection". 
Sections 4 through 10 of the Uniform Weights and Measures Law adopt NBS Handbook 44 and Uniform Regulations in NBS Handbook 130 by citation. In addition, these sections adopt supplements to and revisions of Handbook 44 and the Uniform Regulations "except insofar as modified or rejected by regulation." Some States may not be able to lawfully enact a statute providing for automatic adoption of future supplements to or revisions of a Uniform Regulation covered by that statute. If this is determined to be the case in a given State, two alternatives are available:

(a)

Sections 4 through 10 may be enacted without the phrase "... and supplements thereto or revisions thereof..."

(b)

Sections 4 through 10 may be enacted by replacing"... except insofar as modified or rejected by regulation..." with the phrase "...as adopted, or amended and adopted, by rule of the director."

Either alternative requires action on the part of the director to adopt a current version of Handbook 44 and each Uniform Regulation each time a supplement or revision is made by the National Conference on Weights and Measures.

\section{STATUS OF PROMULGATION}

The map on the following page shows the status of promulgation of the Uniform Weights and Measures Law. 


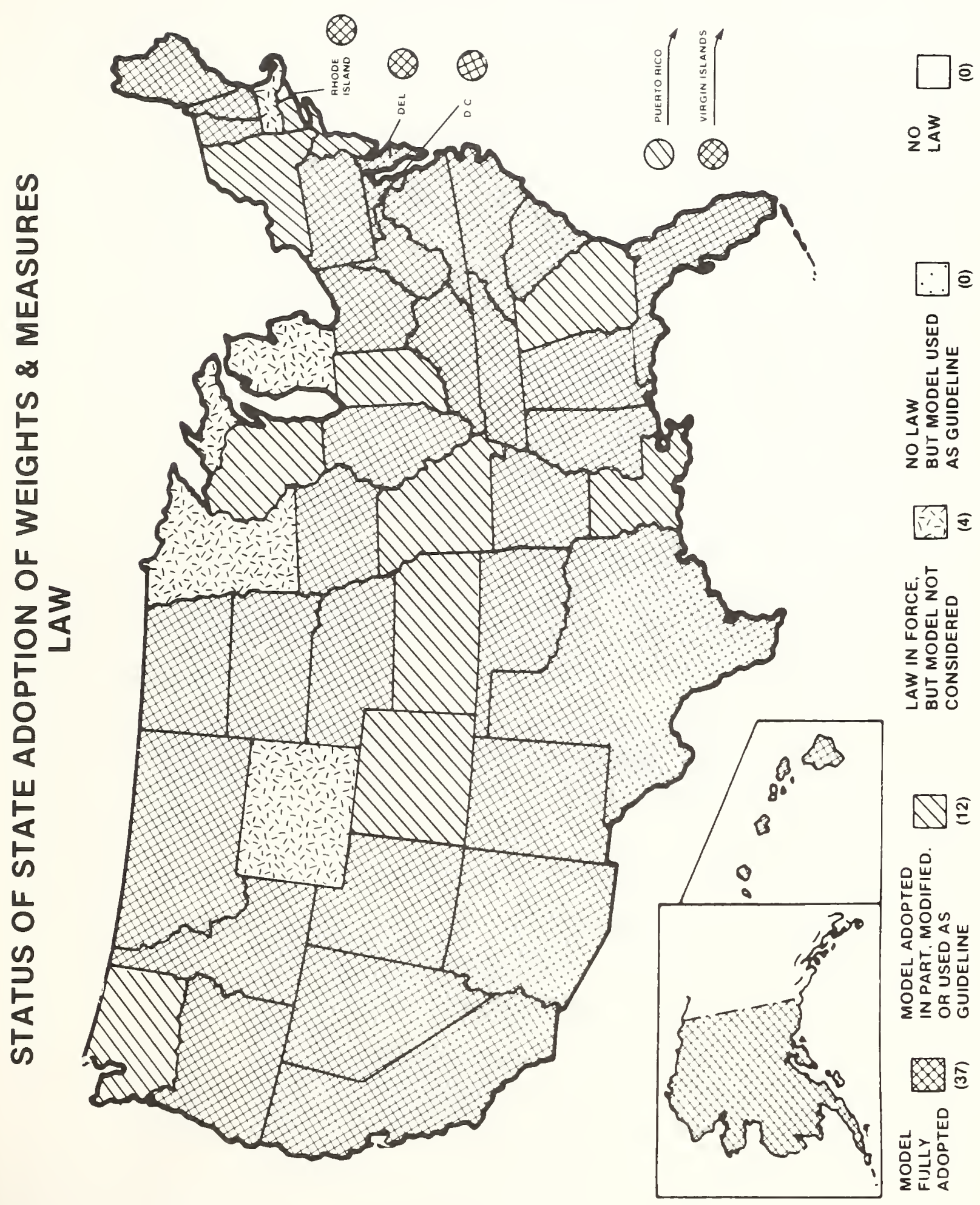





\section{TABLE OF CONTENTS}

1. DEFINITIONS

III-11

1.1. Weight(s) and (or) Measure(s)

III-11

1.2. Weight

III-11

1.3. Correct

III-11

1.4. Primary Standards

III-11

1.5. Secondary Standards

III-11

1.6. Director

III-11

1.7. Person

III-11

1.8. Sale from Bulk

III-11

1.9. Package

III-11

2. SYSTEMS OF WEIGHTS AND MEASURES

III-12

3. PHYSICAL STANDARDS

III-12

4. TECHNICAL REQUIREMENTS FOR WEIGHING AND MEASURING DEVICES

III-12

5. REQUIREMENTS FOR PACKAGING AND LABELING III-13

6. REQUIREMENTS FOR THE METHOD OF SALE OF COMMODITIES

7. REQUIREMENTS FOR UNIT PRICING

8. REQUIREMENTS FOR THE REGISTRATION OF SERVICEPERSONS AND SERVICE AGENCIES FOR COMMERCIAL WEIGHING AND MEASURING DEVICES III-14

9. REQUIREMENTS FOR OPEN DATING III-14

10. REQUIREMENTS FOR TYPE EVALUATION III-14

11. STATES WEIGHTS AND MEASURES DIVISION III-15

11.1. Assuring that weights and measures are suitable

11.2. Preventing unfair or deceptive dealing

11.3. Making calibration and certification available

11.4. Promoting uniformity

III-15

11.5. Assuring equity among buyers and sellers 
12. POWERS AND DUTIES OF THE DIRECTOR III-15

12.1. Maintain traceability of standards

III-15

12.2. Enforce the Act

III-15

12.3. Issue regulations

III-15

12.4. Establish labeling requirements

III-15

12.5. Grant exemptions

III-15

12.6. Conduct investigations

III-16

12.7. Delegate authority

III-16

12.8. Test standards

III-16

12.9. Test weights and measures sold

III-16

12.10. Test weights and measures used commercially

III-16

12.11. Test weights and measures used in State institutions

III-16

12.12. Approve or reject weights and measures

III-16

12.13. Inspect packages

III-16

12.14. Prescribe appropriate units of weight or measure

III-16

12.15. Allow reasonable variations

III-17

13. SPECIAL POLICE POWERS III-17

13.1. Power to enter III-17

13.2. Power to issue restraining orders III-17

13.3. Power to seize

III-17

13.4. Power to stop vehicles III-17

$\begin{array}{ll}\text { 13.5. Power to arrest } & \text { III-17 }\end{array}$

14. POWERS AND DUTIES OF LOCAL OFFICIALS III-17

15. MISREPRESENTATION OF QUANTITY III-18

16. MISREPRESENTATION OF PRICING III-18

$\begin{array}{ll}\text { 17. METHOD OF SALE III-18 } & \end{array}$

$\begin{array}{ll}\text { 18. SALE FROM BULK III-18 } & \end{array}$

19. INFORMATION REQUIRED ON PACKAGES III-18

20. DECLARATIONS OF UNIT PRICE ON $\begin{array}{ll}\text { RANDOM WEIGHT PACKAGES III-19 } & \text { III }\end{array}$

21. ADVERTISING PACKAGES FOR SALE III-19

22. OFFENSES AND PENALTIES III-19

23. INJUNCTION III-20 
SECTION

24. PRESUMPTIVE EVIDENCE

25. SEPARABILITY PROVISION

26. REPEAL OF CONFLICTING LAWS

27. REGULATIONS TO BE UNAFFECTED BY REPEAL OR PRIOR ENABLING STATUTE

28. EFFECTIVE DATE
PAGE

III-20

III-20

III-20

III-20

III-20 



\section{UNIFORM WEIGHTS AND MEASURES LAW 1971}

SECTION 1. DEFINITIONS. - When used in this Act:

1.1. WEIGHT(S) AND (OR) MEASURE(S). - The term "weight(s) and (or) measure(s)" means all weights and measures of every kind, instruments and devices for weighing and measuring, and any appliance and accessories associated with any or all such instruments and devices.

1.2. WEIGHT. - The term "weight" as used in connection with any commodity means net weight; except where the label declares that the product is sold by drained weight, the term means net drained weight.

(Amended 1974)

1.3. CORRECT. - The term "correct" as used in connection with weights and measures means conformance to all applicable requirements of this Act.

1.4. PRIMARY STANDARDS. - The term "primary standards" means the physical standards of the State that serve as the legal reference from which all other standards and weights and measures are derived.

1.5. SECONDARY STANDARDS. - The term "secondary standards" means the physical standards that are traceable to the primary standards through comparisons, using acceptable laboratory procedures, and used in the enforcement of weights and measures laws and regulations.

1.6. DIRECTOR. - The term "director" means the of the Department of

1.7. PERSON. - The term "person" means both plural and the singular, as the case demands, and includes individuals, partnerships, corporations, companies, societies, and associations.

1.8. SALE FROM BULK. - The term "sale from bulk" means the sale of commodities when the quantity is determined at the time of sale.

1.9. PACKAGE. - The term "package" means any commodity put up or packaged in any manner in advance of sale in units suitable for either wholesale or retail sale. 


\section{SECTION 2. SYSTEMS OF WEIGHTS AND MEASURES}

The system of weights and measures in customary use in the United States and the metric system of weights and measures are jointly recognized, and either one or both of these systems shall be used for all commercial purposes in the State. The definitions of basic units of weight and measure, the tables of weight and measure, and weights and measures equivalents as published by the National Bureau of Standards are recognized and shall govern weighing and measuring equipment and transactions in the State.

\section{SECTION 3. PHYSICAL STANDARDS}

Weights and measures that are traceable to the U.S. prototype standards supplied by the Federal Government, or approved as being satisfactory by the National Bureau of Standards, shall be the State primary standards of weights and measures, and shall be maintained in such calibration as prescribed by the National Bureau of Standards. All secondary standards may be prescribed by the director and shall be verified upon their initial receipt, and as often thereafter as deemed necessary by the director.

\section{SECTION 4. TECHNICAL REQUIREMENTS FOR WEIGHING AND MEASURING DEVICES}

The specifications, tolerances, and other technical requirements for commercial, law enforcement, data gathering, and other weighing and measuring devices as adopted by the National Conference on Weights and Measures and published in National Bureau of Standards Handbook 44, "Specifications, Tolerances, and Other Technical Requirements for Weighing and Measuring Devices," and supplements thereto or revisions thereof, shall apply to weighing and measuring devices in the State, except insofar as modified or rejected by regulation. (Amended 1975)

1 Sections 4 through 10 of the Uniform Weights and Measures Law adopt NBS Handbook 44 and Uniform Regulations in NBS Handbook 130 by citation. In addition, these sections adopt supplements to and revisions of Handbook 44 and the Uniform Regulations "except insofar as modified or rejected by a regulation". Some States may not be able to lawfully enact a statute providing for automatic adoption of future supplements to or revisions of a regulation covered by that statute. If this is determined to be the case in a given State, two alternatives are available:

(a) Sections 4 through 10 may be enacted without the phrase "...and supplements thereto or revisions thereof..."

(b) Sections 4 through 10 may be enacted by replacing "...except insofar as modified or rejected by regulation ..." with the phrase "...as adopted, or amended and adopted, by rule of the director".

Either alternative requires action on the part of the director to adopt a current version of Handbook $4 \dot{4}$ and each Uniform Regulation each time a supplement is added or revision is made by the National Conference on Weights and Measures. 


\section{SECTION 5. REQUIREMENTS FOR PACKAGING AND LABELING}

The Uniform Packaging and Labeling Regulation as adopted by the National Conference on Weights and Measures and published in the National Bureau of Standards Handbook 130 "Uniform Laws and Regulations" and supplements thereto or revisions thereof, shall apply to packaging and labeling in the State, except insofar as modified or rejected by regulation.

(Added 1983)

\section{SECTION 6. REQUIREMENTS FOR THE METHOD OF SALE OF COMMODITIES}

The Uniform Regulation for the Method of Sale of Commodities as adopted by the National Conference on Weights and Measures and published in National Bureau of Standards Handbook 130 "Uniform Laws and Regulations" and supplements thereto or revisions thereof, shall apply to the method of sale of commodities in the State, except insofar as modified or rejected by regulation.

(Added 1983)

\section{SECTION 7. REQUIREMENTS FOR UNIT PRICING}

The Uniform Unit Pricing Regulation as adopted by the National Conference on Weights and Measures and published in National Bureau of Standards Handbook 130 "Uniform Laws and Regulations" and supplements thereto or revisions thereof, shall apply to unit pricing in the State, except insofar as modified or rejected by regulation.

(Added 1983)

1 Sections 4 through 10 of the Uniform Weights and Measures Law adopt NBS Handbook 44 and Uniform Regulations in NBS Handbook 130 by citation. In addition, these sections adopt supplements to and revisions of Handbook 44 and the Uniform Regulations "except insofar as modified or rejected by a regulation". Some States may not be able to lawfully enact a statute providing for automatic adoption of future supplements to or revisions of a regulation covered by that statute. If this is determined to be the case in a given State, two alternatives are available:

(a) Sections 4 through 10 may be enacted without the phrase "...and supplements thereto or revisions thereof..."

(b) Sections 4 through 10 may be enacted by replacing "...except insofar as modified or rejected by regulation ..." with the phrase "...as adopted, or amended and adopted, by rule of the director".

Either alternative requires action on the part of the director to adopt a current version of Handbook 44 and each Uniform Regulation each time a supplement is added or revision is made by the National Conference on Weights and Measures. 
Weights and Measures Law

\section{SECTION 8. REQUIREMENTS FOR THE REGISTRATION OF SERVICE- PERSONS AND SERVICE AGENCIES FOR COMMERCIAL WEIGHING AND MEASURING DEVICES}

The Uniform Regulation for the Voluntary Registration of Servicepersons and Service Agencies for Commercial Weighing and Measuring Devices as adopted by the National Conference on Weights and Measures and published in National Bureau of Standards Handbook 130 "Uniform Laws and Regulations" and supplements thereto or revisions thereof, shall apply to the registration of servicepersons and service agencies in the State, except insofar as modified or rejected by regulation.

(Added 1983)

\section{SECTION 9. REQUIREMENTS FOR OPEN DATING}

The Uniform Open Dating Regulation as adopted by the National Conference on Weights and Measures and published in National Bureau of Standards Handbook 130 "Uniform Laws and Regulations" and supplements thereto or revisions thereof, shall apply to open dating in the State, except insofar as modified or rejected by regulation.

(Added 1983)

\section{SECTION 10. REQUIREMENTS FOR TYPE EVALUATION}

The Uniform Regulation for National Type Evaluation as adopted by the National Conference on Weights and Measures and published in National Bureau of Standards Handbook 130, "Uniform Laws and Regulations" and supplements thereto or revisions thereof, shall apply to type evaluation in the State, except insofar as modified or rejected by regulation. (Added 1985)

1 Sections 4 through 10 of the Uniform Weights and Measures Law adopt NBS Handbook 44 and Uniform Regulations in NBS Handbook 130 by citation. In addition, these sections adopt supplements to and revisions of Handbook 44 and the Uniform Regulations "except insofar as modified or rejected by a regulation". Some States may not be able to lawfully enact a statute providing for automatic adoption of future supplements to or revisions of a regulation covered by that statute. If this is determined to be the case in a given State, two alternatives are available:

(a) Sections 4 through 10 may be enacted without the phrase "...and supplements thereto or revisions thereof..."

(b) Sections 4 through 10 may be enacted by replacing "...except insofar as modified or rejected by regulation ..." with the phrase "...as adopted, or amended and adopted, by rule of the director".

Either alternative requires action on the part of the director to adopt a current version of Handbook 44 and each Uniform Regulation each time a supplement is added or revision is made by the National Conference on Weights and Measures. 


\section{SECTION 11. STATES WEIGHTS AND MEASURES DIVISION}

There shall be a State Division of Weights and Measures located for administrative purposes within the Department of (agency, etc.). The Division is charged with, but not limited to, performing the following functions on behalf of the citizens of the State:

11.1. Assuring that weights and measures in commercial service within the State are suitable for their intended use, properly installed, and accurate, and are so maintained by their owner or user.

11.2. Preventing unfair or deceptive dealing by weight or measure in any commodity or service advertised, packaged, sold, or purchased within this State.

11.3. Making available to all users of physical standards or weighing and measuring equipment the precision calibration and related metrological certification capabilities of the weights and measures facilities of the Division.

11.4. Promoting uniformity, to the extent practicable and desirable, between weights and measures requirements of this State and those of other States and Federal agencies.

11.5. Encouraging desirable economic growth while protecting the consumer through the adoption by rule of weights and measures requirements as necessary to assure equity among buyers and sellers.

(Added 1976)

\section{SECTION 12. POWERS AND DUTIES OF THE DIRECTOR}

The director shall:

12.1. Maintain traceability of the State standards to the national standards in the possession of the National Bureau of Standards.

12.2. Enforce the provisions of this Act.

12.3. Issue reasonable regulations for the enforcement of this Act, which regulations shall have the force and effect of law.

12.4. Establish labeling requirements, establish requirements for the presentation of cost-per-unit information, establish standards of weight, measure, or count, and reasonable standards of fill for any packaged commodity; and may establish requirements for open dating information.

(Added 1973)

12.5. Grant any exemptions from the provisions of this Act or any regulations promulgated pursuant thereto when appropriate to the maintenance of good commercial practices within the State. 
12.6. Conduct investigations to ensure compliance with this Act.

12.7. Delegate to appropriate personnel any of these responsibilities for the proper administration of this office.

12.8. Test annually the standards of weight and measure used by any city or county within the State, and approve the same when found to be correct.

12.9. Inspect and test weights and measures kept, offered, or exposed for sale.

12.10. Inspect and test, to ascertain if they are correct, weights and measures commercially used:

(a) in determining the weight, measure, or count of commodities or things sold, or offered or exposed for sale, on the basis of weight, measure, or count, or,

(b) in computing the basic charge or payment for services rendered on the basis of weight, measure, or count.

12.11. Test all weights and measures used in checking the receipt or disbursement of supplies in every institution, for the maintenance of which funds are appropriated by the legislature of the State.

12.12. Approve for use, and may mark, such weights and measures as are found to be correct, and shall reject and mark as rejected such weights and measures as are found to be incorrect. Weights and measures that have been rejected may be seized if not corrected within the time specified or if used or disposed of in a manner not specifically authorized. The director shall condemn and may seize the weights and measures found to be incorrect that are not capable of being made correct.

12.13. Weigh, measure, or inspect packaged commodities kept, offered, or exposed for sale, sold, or in the process of delivery, to determine whether they contain the amounts represented and whether they are kept, offered, or exposed for sale in accordance with this Act or regulations promulgated pursuant thereto. In carrying out the provisions of this section, the director shall employ recognized sampling procedures, such as are designated in National Bureau of Standards Handbook 67, "Checking Prepackaged Commodities," or in National Bureau of Standards Handbook 133, "Checking the Net Contents of Packaged Goods."

(Amended 1984)

12.14. Prescribe, by regulation, the appropriate term or unit of weight or measure to be used, whenever he determines in the case of a specific commodity that an existing practice of declaring the quantity by weight, measure, numerical count, or combination thereof, does not facilitate value comparisons by consumers, or offers an opportunity for consumer confusion. 
12.15. Allow reasonable variations from the stated quantity of contents, which shall include those caused by loss or gain of moisture during the course of good distribution practice or by unavoidable deviations in good manufacturing practice only after the commodity has entered intrastate commerce.

\section{SECTION 13. SPECIAL POLICE POWERS}

When necessary for the enforcement of this Act or regulations promulgated pursuant thereto, the director is:

13.1. Authorized to enter any commercial premises during normal business hours, except that in the event such premises are not open to the public, he shall first present his credentials and obtain consent before making entry thereto, unless a search warrant has previously been obtained.

13.2. Empowered to issue stop-use, hold, and removal orders with respect to any weights and measures commercially used, and stop-sale, hold, and removal orders with respect to any packaged commodities or bulk commodities kept, offered, or exposed for sale.

13.3. Empowered to seize, for use as evidence, without formal warrant, any incorrect or unapproved weight, measure, package, or commodity found to be used, retained, offered, or exposed for sale or sold in violation of the provisions of this Act or regulations promulgated pursuant thereto.

13.4. Empowered to stop any commercial vehicle and, after presentment of his credentials, inspect the contents, require that the person in charge of that vehicle produce any documents in his possession concerning the contents, and require him to proceed with the vehicle to some specified place for inspection.

13.5. With respect to the enforcement of this Act, the director is hereby vested with special police powers, and is authorized to arrest, without formal warrant, any violator of this Act.

\section{SECTION 14. POWERS AND DUTIES OF LOCAL OFFICIALS}

Any weights and measures official appointed for a county or city shall have the duties and powers enumerated in this Act, excepting those duties reserved to the State by law or regulation. These powers and duties shall extend to their respective jurisdictions, except that the jurisdiction of a county official shall not extend to any city for which a weights and measures official has been appointed. No requirement set forth by local agencies may be less stringent than or conflict with the requirements of the State.

(Amended 1984) 


\section{SECTION 15. MISREPRESENTATION OF QUANTITY}

No person shall sell, offer, or expose for sale less than the quantity he represents, nor take any more than the quantity he represents when as buyer he furnishes the weight or measure by means of which the quantity is deter mined.

(Amended 1975)

\section{SECTION 16. MISREPRESENTATION OF PRICING}

No person shall misrepresent the price of any commodity or service sold, offered, exposed, or advertised for sale by weight, measure, or count, nor represent the price in any manner calculated or tending to mislead or in any way deceive a person.

\section{SECTION 17. METHOD OF SALE}

Except as otherwise provided by the director, commodities in liquid form shall be sold by liquid measure or by weight, and commodities not in liquid form shall be sold only by weight, or by measure, or by count, so long as the method of sale provides accurate quantity information.

\section{SECTION 18. SALE FROM BULK}

All bulk sales in which the buyer and seller are not both present to witness the measurement, all bulk deliveries of heating fuel, and all other bulk sales specified by rule or regulation of the director, shall be accompanied by a delivery ticket containing the following information:

(a) The name and address of the buyer and seller.

(b) The date delivered.

(c) The quantity delivered and the quantity upon which the price is based, if this differs from the delivered quantity.

(d) The identity in the most descriptive terms commercially practicable, including any quality representation made in connection with the sale.

(e) The count of individually wrapped packages, if more than one.

(Amended 1983)

\section{SECTION 19. INFORMATION REQUIRED ON PACKAGES}

Except as otherwise provided in this Act or by regulations promulgated pursuant thereto, any package kept for the purpose of sale or offered or exposed for sale shall bear on the outside of the package a definite, plain, and conspicuous declaration of:

(a) The identity of the commodity in the package, unless the same can easily be identified through the wrapper or container. 
(b) The quantity of contents in terms of weight, measure, or count.

(c) The name and place of business of the manufacturer, packer, or distributor, in the case of any package kept, offered, or exposed for sale, or sold in any place other than on the premises where packed.

\section{SECTION 20. DECLARATIONS OF UNIT PRICE ON RANDOM WEIGHT PACKAGES}

In addition to the declarations required by Section 19. of this Act, any package being one of a lot containing random weights of the same commodity, at the time it is offered or exposed for sale at retail, shall bear on the outside of the package a plain and conspicuous declaration of the price per pound or kilogram ${ }^{1}$ and the total selling price of the package.

(Amended 1986)

\section{SECTION 21. ADVERTISING PACKAGES FOR SALE}

Whenever a packaged commodity is advertised in any manner with the retail price stated, there shall be closely and conspicuously associated with the retail price a declaration of quantity as is required by law or regulation to appear on the package. Where a dual declaration is required, only the declaration that sets forth the quantity in terms of the smaller unit of weight or measure need appear in the advertisement.

\section{SECTION 22. OFFENSES AND PENALTIES}

Any person who violates the following enumerated provisions or any provision of this Act or regulations promulgated pursuant thereto, for which a specific penalty has not been prescribed, shall be guilty of a misdemeanor, and upon a first conviction thereof shall be punished by a fine of not less than $\$ 50$ or more than $\$ 500$, or by imprisonment for not more than three months, or both. Upon a subsequent conviction thereof, he shall be punished by a fine of not less than $\$ 100$ or more than $\$ 1,000$ or by imprisonment for up to one year, or both. No person shall:

(a) Use or have in possession for use in commerce any incorrect weight or measure.

(b) Remove any tag, seal, or mark from any weight or measure without specific written authorization from the proper authority.

(c) Hinder or obstruct any weights and measures official in the performance of his duties.

1 Packages subject to the Federal Fair Packaging and Labeling Act must be labeled in inch-pound units of measure. Metric units may also be declared on the principal display panel and may even appear first. 


\section{SECTION 23. INJUNCTION}

The director is authorized to apply to any court of competent jurisdiction for a temporary or permanent injunction restraining any person from violating any provision of this Act.

\section{SECTION 24. PRESUMPTIVE EVIDENCE}

Whenever there shall exist a weight or measure or weighing or measuring device in or about any place in which or from which buying or selling is commonly carried on, there shall be a rebuttable presumption that such weight or measure or weighing or measuring device is regularly used for the business purposes of that place.

\section{SECTION 25. SEPARABILITY PROVISION}

If any provision of this Act is declared unconstitutional, or the applicability thereof to any person or circumstance is held invalid, the constitutionality of the remainder of the Act and the applicability thereof to other persons and circumstances shall not be affected thereby.

\section{SECTION 26. REPEAL OF CONFLICTING LAWS}

All laws and parts of laws contrary to or inconsistent with the provisions of this Act are repealed except as to offenses committed, liabilities incurred, and claims made thereunder prior to the effective date of this Act.

\section{SECTION 27. REGULATIONS TO BE UNAFFECTED BY REPEAL OF PRIOR ENABLING STATUTE}

The adoption of this Act or any of its provisions shall not affect any regulations promulgated pursuant to the authority of any earlier enabling statute unless inconsistent with this Act or modified or revoked by the director.

\section{SECTION 28. EFFECTIVE DATE}

This Act shall become effective on 


\section{UNIFORM WEIGHMASTER LAW 1965}

as adopted by

The National Conference on Weights and Measures ${ }^{1}$

\section{BACKGROUND}

The "Model State Weighmaster Law" was first proposed by the 35 th National Conference on Weights and Measures in 1950. In the following year, it was formally adopted by the National Conference and recommended to the States.

Over the years, very little change had been made to the Weighmaster Law until 1965. In that year, the format of the Weighmaster Law was revised to be in full accord with the Weights and Measures Law. It provides a means by which weights and measures officials can control the important practice of weighing bulk goods in commerce. The name was changed to "Uniform Weighmaster Law" in 1983.

\section{STATUS OF PROMULGATION}

The map on the following page shows the status of promulgation of the Uniform Weighmaster Law.

$\overline{1}_{\text {The National }}$ Conference on Weights and Measures is sponsored by the National Bureau of Standards in partial implementation of its statutory responsibility for "cooperation with the States in securing uniformity in weights and measures laws and methods of inspection." 


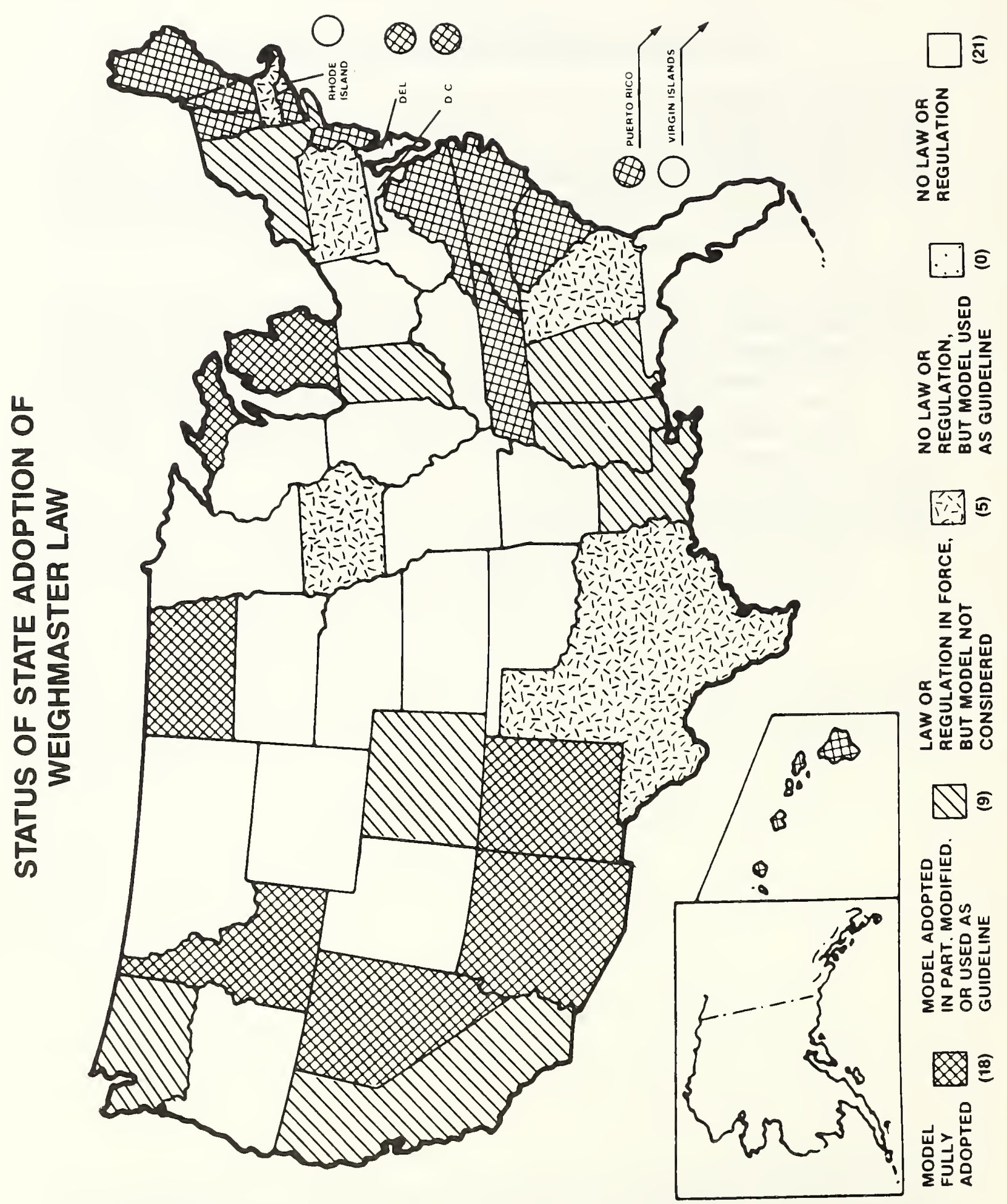




\section{TABLE OF CONTENTS}

SECTION

PAGE

1. DEFINITIONS

1.1. Licensed Public Weighmaster

III-25

1.2. Vehicle

III- 25

1.3. Director

III-25

III-25

2. ENFORCING OFFICER: RULES AND REGULATIONS III-25

3. QUALIFICATIONS FOR WEIGHMASTER

III-25

4. LICENSE APPLICATION

III-25

5. EVALUATION OF QUALIFICATIONS OF APPLICANTS: RECORDS

III-25

6. LICENSE FEES

III-26

7. LIMITED LICENSES

III-26

8. LICENSES: PERIOD, RENEWAL

III-26

9. LICENSED WEIGHMASTER: OATH, SEAL III-26

10. WEIGHT CERTIFICATE: REQUIRED ENTRIES

III-27

11. WEIGHT CERTIFICATE: EXECUTION, REQUIREMENTS III-27

12. SCALE USED: TYPE, TEST

III-27

13. SCALE USED: CAPACITY, PLATFORM SIZE, ONE-DRAFT WEIGHING

III-28

14. COPIES OF WEIGHT CERTIFICATES

III-28

15. RECIPROCAL ACCEPTANCE OF WEIGHT CERTIFICATES

III-28

16. OPTIONAL LICENSING

III-28

17. PROHIBITED ACTS

III-28

18. SUSPENSION AND REVOCATION OF LICENSE

III-28

19. OFFENSES AND PENALTIES

III-29

20. OFFENSES AND PENALTIES: MALFEASANCE

III-29

21. OFFENSES AND PENALTIES: GENERAL

III-29 
Weighmaster Law

SECTION

PAGE

22. VALIDITY OF PROSECUTIONS

III-29

23. SEPARABILITY PROVISION

III-29

24. REPEAL OF CONFLICTING LAWS

III-30

25. CITATION

III-30

26. EFFECTIVE DATE

III-30 


\section{UNIFORM WEIGHMASTER LAW}

1965

SECTION 1. DEFINITIONS. - When used in this Act:

1.1. LICENSED PUBLIC WEIGHMASTER. - The term "licensed public weighmaster" shall mean and refer to a natural person licensed under the provisions of this Act.

1.2. VEHICLE - - The term "vehicle" shall mean any device in, upon, or by which any property, produce, commodity, or article is or may be transported or drawn.

1.3. DIRECTOR - - The term "director" means the the Department of

\section{SECTION 2. ENFORCING OFFICER: RULES AND REGULATIONS}

The director is authorized to enforce the provisions of this Act and shall issue from time to time reasonable regulations for the enforcement of this Act, which regulations shall have the force and effect of law.

\section{SECTION 3. QUALIFICATIONS FOR WEIGHMASTER}

A citizen of the United States or a person who has declared his or her intention of becoming such a citizen, who is a resident of the State of , not less than 21 years of age, of good moral character, who has the ability to weigh accurately and to make correct weight certificates, and who has received from the director a license as a licensed public weighmaster, shall be styled and authorized to act as a licensed public weighmaster.

\section{SECTION 4. LICENSE APPLICATION}

An application for a license as a licensed public weighmaster shall be made upon a form provided by the director and the application shall furnish evidence that the applicant has the qualifications required by Section 3 of this Act.

\section{SECTION 5. EVALUATION OF QUALIFICATIONS OF APPLICANTS: RECORDS}

The director may adopt rules for determining the qualifications of the applicant for a license as a licensed public weighmaster. The director may pass upon the qualifications of the applicant upon the basis of the information supplied in the application, may examine such applicant orally or in writing, or both, for the purpose of determining his or her qualifications. The director shall grant licenses as licensed public weighmasters 
to such applicants as may be found to possess the qualifications required by Section 3 of this Act. The director shall keep a record of all such applications and of all licenses issued thereon.

\section{SECTION 6. LICENSE FEES}

Before the issuance of any license as a licensed public weighmaster, or any renewal thereof, the applicant shall pay to the director a fee of \$ . Such fees shall be deposited with the State Treasurer to be credited to a fund to be used by the director for the administration of this Act.

\section{SECTION \%. LIMITED LICENSES}

The director may, upon request and without charge, issue a limited license as a licensed public weighmaster to any qualified officer or employee of a city or county of this State or of a State commission, board, institution, or agency, authorizing such officer or employee to act as a licensed public weighmaster only within the scope of his official employment in the case of an officer or employee of a city or county or only for and on behalf of the State commission, board, institution, or agency in the case of an officer or employee thereof.

\section{SECTION 8. LICENSES: PERIOD, RENEWAL}

Each license as licensed public weighmaster shall be issued to expire on the thirty-first day of December of the calendar year for which it is issued: Provided, That any such license shall be valid through the thirty-first day of January of the next ensuing calendar year or until issuance of the renewal license, whichever event first occurs, if the holder thereof shall have filed a renewal application with the director on or before the fifteenth day of December of the year for which the current license was issued: And provided further, That any license issued on or after the effective date of this Act and on or before the thirty-first day of December 19, shall be issued to expire on the thirty-first day of December of the next ensuing calendar year. Renewal applications shall be in such form as the director shall prescribe.

\section{SECTION 9. LICENSED WEIGHMASTER: OATH, SEAL}

Each licensed public weighmaster shall, before entering upon his or her duties, make oath to execute faithfully his or her duties. The issuance of a license as licensed public weighmaster shall not obligate the State to pay to the licensee any compensation for his or her services as a licensed public weighmaster. Each licensed public weighmaster shall, at his or her own expense, provide himself or herself with an impression seal. His or her name and the word(s) (insert name of State) shall be inscribed around the outer margin of the seal and the words "licensed public weighmaster" shall appear in the center thereof. The seal shall be impressed upon each weight certificate issued by a licensed public weighmaster. 


\section{SECTION 10. WEIGHT CERTIFICATE: REQUIRED ENTRIES}

The director shall prescribe the form of weight certificate to be used by a licensed public weighmaster. The weight certificate shall state the date of issuance, the kind of property, produce, commodity, or article weighed, the name of the declared owner or agent of the owner or of the consignee of the material weighed, the accurate weight of the material weighed, the means by which the material was being transported at the time it was weighed, and such other available information as may be necessary to distinguish or identify the property, produce, commodity, or article from others of like kind. Such weight certificate, when so made and properly signed and sealed, shall be prima facie evidence of the accuracy of the weights shown.

\section{SECTION 11. WEIGHT CERTIFICATE: EXECUTION, REQUIREMENTS}

A licensed public weighmaster shall not enter on a weight certificate issued by him or her any weight values but such as he or she has personally determined, and shall make no entries on a weight certificate issued by some other person. A weight certificate shall be so prepared as to show clearly that weight or weights were actually determined. If the certificate form provides for the entry of gross, tare, and net weights, in any case in which only the gross, the tare, or the net weight is determined by the weighmaster he or she shall strike through or otherwise cancel the printed entries for the weights not determined or computed. If gross and tare weights are shown on a weight certificate and both of these were not determined on the same scale and on the day for which the certificate is dated, the weighmaster shall identify on the certificate the scale used for determining each such weight and the date of each such determination.

\section{SECTION 12. SCALE USED: TYPE, TEST}

When making a weight determination as provided for by this Act, a licensed public weighmaster shall use a weighing device that is of a type suitable for the weighing of the amount and kind of material to be weighed and that has been tested and approved for use by a weights and measures officer of this State within a period of 12 months immediately preceding the date of the weighing.

\section{SECTION 13. SCALE USED: CAPACITY, PLATFORM SIZE, ONE-DRAFT WEIGHING}

A licensed public weighmaster shall not use any scale to weigh a load the value of which exceeds the nominal or rated capacity of the scale. When the gross or tare weight of any vehicle or combination of vehicles is to be determined, the weighing shall be performed upon a scale having a platform of sufficient size to accommodate such vehicle or combination of vehicles fully, completely, and as one entire unit. If a combination of vehicles must be broken into separate units in order to be weighed as prescribed herein, each such separate unit shall be entirely disconnected before weighing and a separate weight certificate shall be issued for each such separate unit. 


\section{SECTION 14. COPIES OF WEIGHT CERTIFICATES}

A licensed public weighmaster shall keep and preserve for at least one year, or for such longer period as may be specified in the regulations authorized to be issued for the enforcement of this Act, a legible carbon copy of each weight certificate issued by him or her, which copies shall be open at all reasonable times for inspection by any weights and measures officer of this State.

\section{SECTION 15. RECIPROCAL ACCEPTANCE OF WEIGHT CERTIFICATES}

Whenever in any other State that licenses public weighmasters, there is statutory authority for the recognition and acceptance of the weight certificates issued by licensed weighmasters of this State, the director of this State is authorized to recognize and accept the weight certificates of such other State.

\section{SECTION 16. OPTIONAL LICENSING}

The following persons shall not be required, but shall be permitted, to obtain licenses as licensed public weighmasters: (1) a weights and measures officer when acting within the scope of his official duties; (2) a person weighing property, produce, commodities, or articles that he or his employer, if any, is either buying or selling; and (3) a person weighing property, produce, commodities, or articles in conformity with the requirements of Federal statutes or the statutes of this State relative to warehousemen or processors.

\section{SECTION 17. PROHIBITED ACTS}

No person shall assume the title licensed public weighmaster, or any title of similar import, perform the duties or acts to be performed by a licensed public weighmaster under this Act, hold himself or herself out as a licensed public weighmaster, issue any weight certificate, ticket, memorandum, or statement for which a fee is charged, or engage in the full-time or part-time business of public weighing, unless he or she holds a valid license as a licensed public weighmaster. "Public weighing," as used in this section, shall mean the weighing for any person, upon request, of property, produce, commodities, or articles other than those that the weigher or his employer, if any, is either buying or selling.

\section{SECTION 18. SUSPENSION AND REVOCATION OF LICENSE}

The director is authorized to suspend or revoke the license of any licensed public weighmaster (1) when he or she is satisfied, after a hearing upon 10 days' notice to the licensee, that the said licensee has violated any provision of this Act or of any valid regulation of the director affecting licensed public weighmasters, or (2) when a licensed public weighmaster has been convicted in any court of competent jurisdiction of violating any provision of this Act or of any regulation issued under authority of this Act. 


\section{SECTION 19. OFFENSES AND PENALTIES}

Any person who requests a licensed public weighmaster to weigh any property, produce, commodity, or article falsely or incorrectly, or who requests a false or incorrect weight certificate, or any person who issued a weight certificate simulating the weight certificate prescribed in this Act and who is not a licensed public weighmaster, shall be guilty of a misdemeanor and upon conviction for the first offense shall be punished by $a$ fine in any sum not less than twenty-five dollars or more than one hundred dollars; and upon a second or subsequent conviction such person shall be punished by a fine in any sum not less than one hundred dollars or more than five hundred dollars, or by imprisonment for not less than thirty days or more than ninety days, or by both such fine and imprisonment.

\section{SECTION 20. OFFENSES AND PENALTIES: MALFEASANCE}

Any licensed public weighmaster who falsifies a weight certificate, or who delegates his authority to any person not licensed as a licensed public weighmaster, or who preseals a weight certificate with his official seal before performing the act of weighing, shall be guilty of a misdemeanor and upon conviction shall be punished by a fine in any sum not less than fifty dollars or more than five hundred dollars, or by imprisonment for not less than thirty days or more than ninety days, or by both such fine and imprisonment.

\section{SECTION 21. OFFENSES AND PENALTIES: GENERAL}

Any person who violates any provision of this Act or any rule or regulation promulgated pursuant thereto for which no specific penalty has been provided shall be guilty of a misdemeanor and upon conviction shall be punished by a fine in any amount not less than twenty-five dollars or more than one hundred dollars.

\section{SECTION 22. VALIDITY OF PROSECUTIONS}

Prosecutions for violation of any provision of this Act are declared to be valid and proper notwithstanding the existence of any other valid general or specific Act of this State dealing with matters that may be the same as or similar to those covered by this Act.

\section{SECTION 23. SEPARABILITY PROVISION}

If any provision of this Act is declared unconstitutional, or the applicability thereof to any person or circumstance is held invalid, the constitutionality of the remainder of the Act and the applicability thereof to other persons and circumstances shall not be affected thereby. 


\section{SECTION 24. REPEAL OF CONFLICTING LAWS}

All laws and parts of laws contrary to or inconsistent with the provisions of this Act, and specifically are repealed insofar as they might operate in the future; but as to offenses committed, liabilities incurred, and claims now existing thereunder, the existing law shall remain in full force and effect.

SECTION 25. CITATION

This Act may be cited as the "Weighmaster Act of $\bullet^{\prime \prime}$

SECTION 26. EPFECTIVE DATE

This Act shall become effective on 


\section{UNIFORM REGULATIONS}

Page

A. Uniform Packaging and Labeling Regulation IV-3

B. Uniform Regulation for the Method of Sale of Commodities

IV -53

C. Uniform Unit Pricing Regulation IV-81

D. Uniform Regulation for the Voluntary Registration of Servicepersons and Service Agencies for Commercial Weighing and Measuring Devices

E. Uniform Open Dating Regulation IV-99

F. Uniform Regulation for National Type Evaluation 



\section{UNIFORM PACKAGING AND LABELING REGULATION 1978}

as adopted by

The National Conference on Weights and Measures ${ }^{1}$

\section{BACKGROUND}

The Uniform Packaging and Labeling Regulation was first adopted during the 37 th National Conference on Weights and Measures in 1952. Reporting to the Conference, the Committee on Legislation stated:

The National Conference should adopt a model package regulation for the guidance of those States authorized to adopt such a regulation under provisions of their weights and measures laws. Since so much of the work of weight and measures officials in the package field concerns food products, the importance of uniformity between the Federal Food and Drug Administration's regulations and any model regulations to be adopted by this Conference cannot be overemphasized.

Since its inception, the Uniform Packaging and Labeling Regulation has been continually revised to meet the complexities of an enormous expansion in the packaging industry-an expansion that, in late 1966, brought about the passage of the Fair Packaging and Labeling Act (FPLA). Recognizing the need for compatibility with the Federal Act, the Committee on Laws and Regulations of the 53rd National Conference in 1968 amended the "Model Packaging and Labeling Regulation" (renamed in 1983) to parallel regulations adopted by Federal agencies under FPLA. The process of amending and revising this Regulation is a continuing one, in order to keep it current with practices in the packaging field and make it compatible with appropriate Federal regulations. Amendments and additions since 1971 are noted at the end of each section.

The revision of 1978 provided for the use of metric units on labels as well as allowing metric-only labels for those commodities not covered by Federal laws or regulations.

Nothing contained in this regulation should be construed to supersede any labeling requirement specified in Federal law or to require the use of metric.

\section{STATUS OF PROMULGATION}

The map on the following page shows the status of promulgation of the Uniform Packaging and Labeling Regulation.

\footnotetext{
${ }^{1}$ The National Conference on Weights and Measures is sponsored by the National Bureau of Standards in partial implementation of its statutory responsibility for "cooperation with the States in securing uniformity in weights and measures laws and methods of inspection."
} 
Packaging and Labeling Regulation
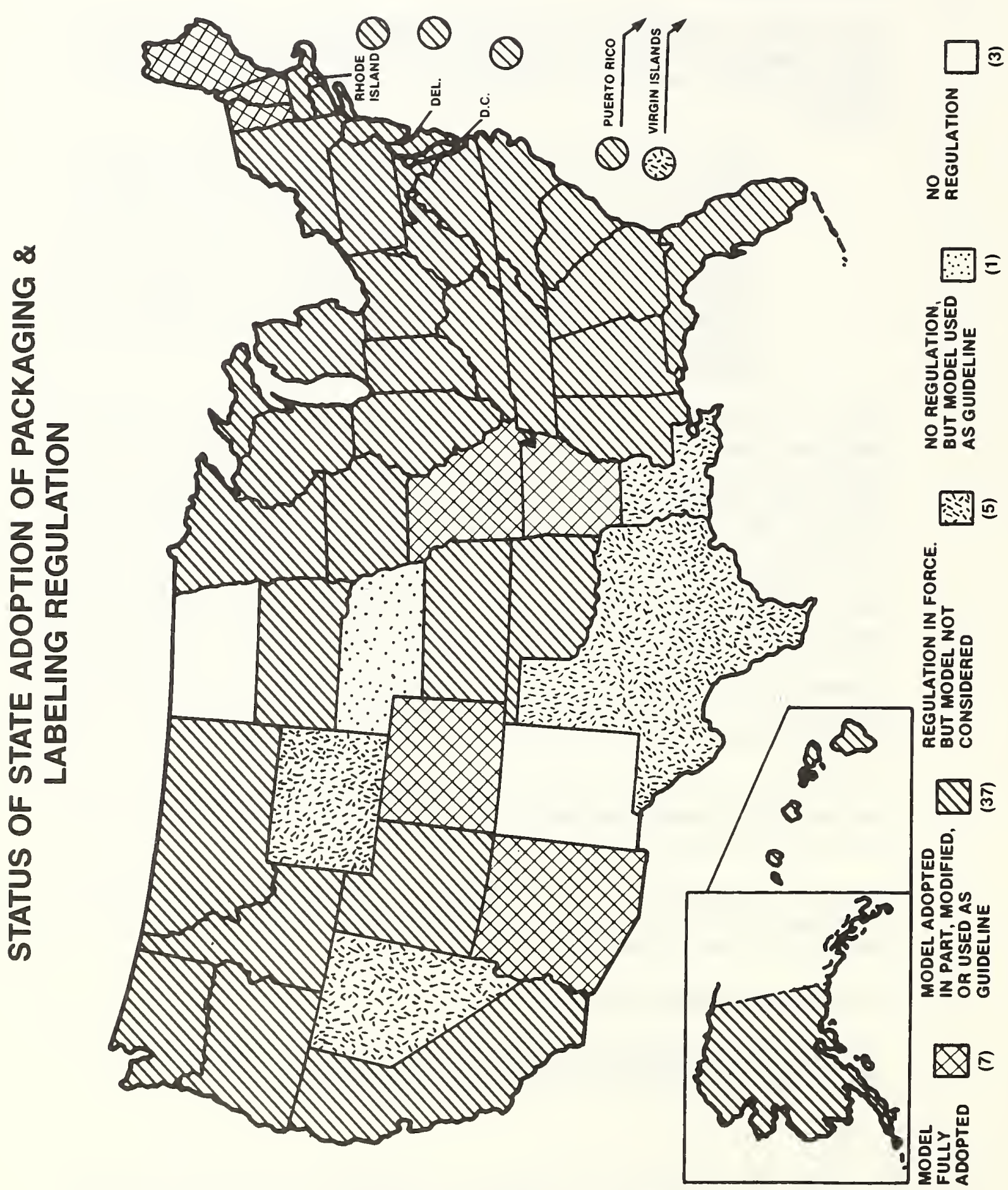
TABLE OF CONTENTS

SECTION

PAGE

1. APPLICATION

IV-11

2. DEFINITIONS

IV -11

2.1. Commodity in Package Form

IV-11

2.2. Consumer Package: Package of

IV-12

2.3. Nonconsumer Package: Package of

Nonconsumer Commodity

IV-12

2.4. Random Package IV-12

2.5. Label

IV-12

2.6. Person

IV-12

2.7. Principal Display Panel or Panels IV-12

2.8. Multi-Unit Package IV-12

3. DECLARATION OF IDENTITY: CONSUMER PACKAGE IV-13

3.1. Declaration of Identity: Consumer

Package

3.1.1. Parallel Identity Declaration:

Consumer Package

IV -13

IV-13

4. DECLARATION OF IDENTITY: NONCONSUMER PACKAGEV-13

5. DECLARATION OF REIPONSIBILITY: CONSUMER AND NONCONSUMER PACKAGES

IV-13

6. DECLARATION OF QUANTITY: CONSUMER PACKAGES IV-14

6.1. General IV-14

6.2. Largest Whole Unit

IV-14

6.3. Net Quantity

IV-14

6.3.1. Use of "Net Weight"

IV-14

6.3.2. Lines of Print or Type

IV-14

6.4. Terms: Weight, Liquid Measure, Dry Measure, or Count

IV-15

6.4.1. Combination Declaration IV -15

6.5. Inch-Pound Units Weight, Measure IV-15

6.5.1. Symbols and Abbreviations IV-16

6.5.2. Units with Two or More

Meanings

IV-16 
6.6. Metric Units:Weight, Measure IV-16 6.6.1. Symbols IV-17

6.7. Prescribed Units, Inch-Pound System

IV-18

6.7.1. Less than 1 Foot, 1 Square

IV-18

6.7.2. Weight: Dual Quantity

IV-18

6.7.3. Liquid Measure: Dual

IV-19

6.7.4. Length Measure: Lual

IV-19

6.7.5. Area Measure: Dual

IV-19

6.7.6. Four Feet, 4 Square Feet,

IV-19

6.7.7. Bidimensional Commodities

IV -19

6.8. Prescribed Units, Metric System

IV-21

6.8.1. Less than 1 Meter, 1 Square

IV-21

6.8.2. One Meter, 1 Square Meter,

IV-21

6.8.3. Bidimensional Commodities

6.9. Count: Ply

IV-22

IV -23

IV -23

6.10. Fractions

IV -24

6.11.1. Supplementary Quantity

Declarations

IV-24

6.11.2. Combined Metric and

6.11.3. Rounding

IV-24

IV-24

6.12. Qualification of Declaration

IV-24

Prohibited

IV-25

6.13. Character of Declaration: Average

IV -25

IV-25

IV-25

7.1 .

General

IV-25

7.3. Terms: Weight, Liquid Measure,
Dry Measure, or Count

IV-25

Inch-Pound Units: Weight Measure

IV-26

7.4.1. Symbols and Abbreviations

IV-26

7.5 . Metric Units: Weight, Measure

IV-27 
7.6. Character of Declaration: Average

8. PROMINENCE AND PLACEMENT:

CONSUMER PACKAGES

IV-27

8.1 .

General

IV -27

8.1.1. Location

IV -27

8.1.2. Style or Type of Lettering

IV -27

8.1.3.

Color Contrast

IV -27

8.1.4.

Free Area

IV -28

8.1.5.

Parallel Quantity Declaration

8.2. Calculation of Area of

Principal Display Panel for

Purposes of Type Size

8.2.1. Minimum Height of Numbers and Letters

8.2.2. Numbers and Letters

Proportion

IV -28

IV-28

IV-28

IV -28

9. PROMINENCE AND PLACEMENT: NONCONSUMER

PACKAGES

9.1. General

IV -29

IV-29

10. REQUIREMENTS: SPECIFIC CONSUMER COMMODITIES, NONCONSUMER COMMODITIES, PACKAGES, CONTAINERS

10.1. Display Card Package

IV-29

10.2 .

Eggs

10.3 .

Aerosols and Similar Pressurized

Containers

IV -29

IV -30

10.4. Multi-Unit Packages

IV -30

10.5. Combination Packages

IV -30

10.6 .

Variety Packages

IV -30

10.7. Cylindrical Containers

IV -30

10.8. Measurement of Container-Type

IV-31

Commodities, How Expressed

IV-31

10.8.1. General

IV -31

10.8.2. Capacity

IV -32

10.8.3. Terms

IV -33

IV -33

10.9. Textile Products, Threads, and Yarns

IV -33

10.9.1. Wearing Apparel

IV-33

10.9.3. Textiles: Variations from

IV-36

10.9.4. Exemption: Variety

Textile Packages

IV-36 
10.9.5. Sewing Threads, Handicraft Threads, and Yarns

10.10. Packaged Seed

IV -37

10.11. Bark Mulch: Variations from Declared

IV-37

10.12. Polyethylene Products:Variations

From Declared Thickness

IV-37

11. EXEMPTIONS

IV -38

11.1. General

11.2. Random Packages

IV -38

11.3. Small Confections

IV -38

11.4. Individual Servings

IV -38

11.5. Cuts, Plugs, and Twists of Tobacco

IV -38

11.6. Reusable (Returnable) Glass

IV-39

11.7. Containers

IV -39

IV -39

11.8. Packaged Commodities with Labeling

IV-39

11.9. Fluid Dairy Products, Ice Cream, and

IV-39

11.10. Single Strength and Less than Single

Strength Fruit Juice Beverages,

Imitations Thereof, and Drinking

Water

IV -40

11.11. Soft-Drink Bottles

IV -40

11.12. Multi-Unit Soft-Drink Packages

IV -41

11.13. Butter

IV -41

11.14. Eggs

IV -41

11.15. Flour

IV-41

11.16. Small Packages

IV -41

11.17. Decorative Containers

IV -42

11.18. Combination Packages

IV -42

11.19. Margarine

IV-42

11.20. Corn Flour and Corn Meal

IV -42

11.21. Prescription and Insulin-Containing

IV -42

11.22. Camera Film

IV -42

11.23.

Paints and Kindred Products

IV -43

11.24. Automotive Cooling System Antifreeze

IV -43

11.25 . Motor Oils

IV -44

11.26. Pillows, Cushions, Comforters,

Mattress Pads, Sleeping Bags, and

Similar Products

IV -44 
11.27. Commodities' Variable Weights

11.28. Packaged Commodities Sold by Count

IV -44

IV-44

11.29. Fishing Lines and Reels

IV -45

12. VARIATIONS TO BE ALLOWED

IV -45

12.1. Packaging Variations

IV-45

12.1.1. Variations from Declared

Net Quantity

IV -45

12.1.2. Variations Resulting

from Exposure

12.2. Magnitude of Permitted Variations

IV-45

IV -46

13. RETAIL SALE PRICE REPRESENTATIONS IV-46

13.1. "Cents-off" Representations IV -46

13.2. Introductory Offers IV-48

13.3. Economy Size IV-49

14. REVOCATION OF CONFLICTING REGULATIONS IV-50

$\begin{array}{ll}\text { 15. EFFECTIVE DATE IV-50 } & \text { IV }\end{array}$

Appendix: Metric/Inch-Pound Conversion Factors IV-51 



\section{UNIFORM PACKAGING AND LABELING REGULATION 1978}

\section{SECTION 1. APPLICATION}

This regulation shall apply to packages and to commodities in package form, but shall not apply to:

(a) inner wrappings not intended to be individually sold to the customer,

(b) shipping containers or wrapping used solely for the transportation of any commodities in bulk or in quantity to manufacturers, packers, or processors, or to wholesale or retail distributors, but in no event shall this exclusion apply to packages of consumer or nonconsumer commodities, as defined herein,

(Added 1971)

(c) auxiliary containers or outer wrappings used to deliver packages of such commodities to retail customers if such containers or wrappings bear no printed matter pertaining to any particular commodity,

(d) containers used for retail tray pack displays when the container itself is not intended to be sold (e.g., the tray that is used to display individual envelopes of seasonings, gravies, etc., and the tray itself is not intended to be sold), or

(e) open carriers and transparent wrappers or carriers for containers when the wrappers or carriers do not bear any written, printed, or graphic matter obscuring the label information required by this regulation.

\section{SECTION 2. DEFINITIONS}

2.1. COMMODITY IN PACKAGE FORM. - The term "commodity in package form" shall be construed to mean a commodity put up or packaged in any manner in advance of sale in units suitable for either wholesale or retail sale. An individual item or lot of any commodity not in package form as defined in this section, but on which there is marked a selling price based on an established price per unit of weight or of measure, shall be construed to be a commodity in package form. Where the term "package" is used in this regulation, it shall be construed to mean "commodity in package form" as here defined. 
2.2. CONSUMER PACKAGE: PACKAGE OF CONSUMER COMMODITY. A "consumer package" or "package of consumer commodity" shall be construed to mean a commodity in package form that is customarily produced or distributed for sale through retail sales agencies or instrumentalities for consumption by individuals or use by individuals for the purposes of personal care or in the performance of services ordinarily rendered in or about the household or in connection with personal possessions.

2.3. NONCONSUMER PACKAGE: PACKAGE OF NONCONSUMER COMMODITY. - A "nonconsumer package" or "package of nonconsumer commodity" shall be construed to mean any commodity in package form other than a consumer package, and particularly a package intended solely for industrial or institutional use or for wholesale distribution.

2.4. RANDOM PACKAGE. - The term "random package" shall be construed to mean a package that is one of a lot, shipment, or delivery of packages of the same consumer commodity with varying weights; that is, packages of the sarne consumer commodity with no fixed pattern of weight.

2.5. LABEL. - The term "label" shall be construed to mean any written, printed, or graphic matter affixed to, applied to, attached to, blown into, formed, molded into, embossed on, or appearing upon or adjacent to a consumer commodity or a package containing any consumer commodity, for purposes of branding, identifying, or giving any information with respect to the commodity or to the contents of the package, except that an inspector's tag or other nonpromotional matter affixed to or appearing upon a consumer commodity shall not be deemed to be a label requiring the repetition of label information required by this regulation.

2.6. PERSON. - The term "person" shall be construed to mean both singular and plural, and shall include any individual, partnership, company, corporation, association, and society.

2.7. PRINCIPAL DISPLAY PANEL OR PANELS. - The term "principal display panel or panels" shall be construed to mean that part, or those parts, of a label that is, or are, so designed as to most likely be displayed, presented, shown, or examined under normal and customary conditions of display and purchase. Wherever a principal display panel appears more than once on a package, all requirements pertaining to the "principal display panel" shall pertain to all such "principal display panels."

2.8. MULTI-UNIT PACKAGE. - The term "multi-unit package" shall be construed to mean a package containing two or more individual packages of the same commodity, in the same quantity, with the individual packages intended to be sold as part of the multi-unit package but capable of being individually sold in full compliance with all requirements of this regulation. 


\section{SECTION 3. DECLARATION OF IDENTITY: CONSUMER PACKAGE}

3.1. DECLARATION OF IDENTITY: CONSUMER PACKAGE. - A declaration of identity ${ }^{1}$ on a consumer package shall appear on the principal display panel, and shall positively identify the commodity in the package by its common or usual name, description, generic term, or the like.

3.1.1. PARALLEL IDENTITY DECLARATION: CONSUMER PACKAGE - A declaration of the identity on a consumer package shall appear generally parallel to the base on which the package rests as it is designed to

(Footnote added 1986) be displayed.

\section{SECTION 4. DECLARATION OF IDENTITY: NONCONSUMER PACKAGE}

A declaration of identity ${ }^{1}$ on a nonconsumer package shall appear on the outside of a package and shall positively identify the commodity in the package by its common or usual name, description, generic term, or the like.

(Footnote added 1986)

\section{SECTION 5. DECLARATION OF RESPONSIBILITY: CONSUMER AND NONCONSUMER PACKAGES}

Any package kept, offered, or exposed for sale, or sold, at any place other than on the premises where packed shall specify conspicuously on the label of the package the name and address of the manufacturer, packer, or distributor. The name shall be the actual corporate name, or, when not incorporated, the name under which the business is conducted. The address shall include street address, city, State, and ZIP Code; however, the street address may be omitted if this is shown in a current city directory or telephone directory.

If a person manufactures, packs, or distributes a commodity at a place other than his principal place of business, the label may state the principal place of business in lieu of the actual place where the commodity was manufactured or packed or is to be distributed, unless such statement would be misleading. Where the commodity is not manufactured by the person whose name appears on the label, the name shall be qualified by a phrase that reveals the connection such person has with such commodity, such as "Manufactured for and packed by " "Distributed by other wording of similar import that expresses the facts.

1 Section 19.(a) of the Uniform Weights and Measures Law (and 21 CFR 101.100 (b) (3) for non-meat and non-poultry foods) specifically exempts packages from identity statements if the identity of the commodity "can easily be identified through the wrapper or container."(Added 1986) 


\section{SECTION 6. DECLARATION OF QUANTITY: CONSUMER PACKAGES}

6.1. GENERAL. ${ }^{1}$ - The metric and inch-pound systems of weights and measures are recognized as proper systems to be used in the declaration of quantity. Units of both systems may be presented in a dual declaration of quantity.

(Amended 1985)

6.2. LARGEST WHOLE UNIT. - Where this regulation requires that the quantity declaration be in terms of the largest whole unit, the declaration shall, with respect to a particular package, be in terms of the largest whole unit of weight or measure, with any remainder expressed (following the requirements of Section 6.10. Fractions):

\section{(a) Inch-Pound Units}

(1) in common or decimal fractions of such largest whole unit, or in

(2) the next smaller whole unit, or units, with any further remainder in terms of common or decimal fractions of the smallest unit present in the quantity declaration.

(b) Metric Units, in decimal fractions of such largest whole unit.

6.3. NET QUANTITY. - A declaration of net quantity of the commodity in the package, exclusive of wrappers and any other material packed with such commodity (except as noted in Section 10.3), shall appear on the principal display panel of a consumer package and, unless otherwise specified in this regulation (see subsections 6.7. through 6.8.3.), shall be in terms of the largest whole unit.

6.3.1.

6.3.2.

(Amended 1982)
USE OF "NET WEIGHT." - The term "net weight" shall be used in conjunction with the declaration of quantity in units of weight. The term may either precede or follow the declaration of weight.

LINES OF PRINT OR TYPE. - A declaration of quantity may appear on one or more lines of print or type.

1 Packages subject to the Federal Fair Packaging and Labeling Act must be labeled in inch-pound units of measure. Metric units may also be declared on the principal display panel and may even appear first. 
6.4. TERMS: WEIGHT, LIQUID MEASURE, DRY MEASURE, OR COUNT. - The declaration of the quantity of a particular commodity shall be expressed in terms of liquid measure if the commodity is liquid, or dry measure if the commodity is dry, or in terms of weight if the commodity is solid, semisolid, viscous, or a mixture of solid and liquid, or in terms of numerical count. However, if there exists a firmly established general consumer usage and trade custom with respect to the terms used in expressing a declaration of quantity of a particular commodity, such a declaration of quantity may be expressed in its traditional terms, if such traditional declaration gives accurate and adequate information as to the quantity of the commodity.

\subsubsection{COMBINATION DECLARATION. -}

(a) A declaration of quantity in terms of weight shall be combined with appropriate declarations of the measure, count, and size of the individual units unless a declaration of weight alone is fully informative.

(b) A declaration of quantity in terms of measure shall be combined with appropriate declarations of the weight, count, and size of the individual units unless a declaration of measure alone is fully informative.

(c) A declaration of quantity in terms of count shall be combined with appropriate declarations of the weight, measure, and size of the individual units unless a

(Added 1971)

6.5. INCH-POUND UNITS: WEIGHT, MEASURE. - A declaration of quantity:

(a) in units of weight, shall be in terms of the avoirdupois pound or ounce;

(b) in units of liquid measure, shall be in terms of the United States gallon of 231 cubic inches or liquid-quart, liquid-pint, or fluid-ounce subdivisions of the gallon, and shall express the volume at $68^{\circ} \mathrm{F}$ except in the case of petroleum products and distilled spirits, for which the declaration shall express the volume at $60^{\circ} \mathrm{F}$, and except also in the case of a commodity that is normally sold and consumed while frozen, for which the declaration shall express the volume at the frozen temperature, and except also in the case of a commodity that is normally sold in the refrigerated state, for which the declaration shall express the volume at $40{ }^{\circ} \mathrm{F}$, and except also in the case of malt beverages, for which the declaration shall express the volume at $39.1{ }^{\circ} \mathrm{F}$;

(Amended 1985) 
(c) in units of linear measure, shall be in terms of the yard, foot, or inch;

(d) in units of area measure, shall be in terms of the square yard, square foot, or square inch;

(e) in units of volume measure, shall be in terms of the cubic yard, cubic foot, or cubic inch;

(f) in units of dry measure, shall be in terms of the United States bushel of 2150.42 cubic inches, or peck, dry-quart, and dry-pint subdivisions of the bushel.

6.5.1. SYMBOLS AND ABBREVIATIONS. - Any of the following symbols and abbreviations, and none other, shall be employed in the quantity statement on a package of commodity:

$\begin{array}{llll}\text { avoirdupois } & \text { avdp } & \text { ounce } & \text { oz } \\ \text { cubic } & \text { cu } & \text { pint } & \text { pt } \\ \text { feet or foot } & \text { ft } & \text { pound } & \text { lb } \\ \text { fluid } & \text { fl } & \text { quart } & \text { qt } \\ \text { gallon } & \text { gal } & \text { square } & \text { sq } \\ \text { inch } & \text { in } & \text { weight } & \text { wt } \\ \text { liquid } & \text { liq } & \text { yard } & \text { yd }\end{array}$

(There normally are no periods following, nor plural forms of, symbols. For example, "oz" is the symbol for both "ounce" and "ounces." Both upper and lower case (Added 1974, amended 1980) letters are acceptable.)

6.5.2.

UNITS OF TWO OR MORE MEANINGS. - When the term "ounce" is employed in a declaration of liquid quantity, the declaration shall identify the particular meaning of the term by the use of the term "fluid"; however, such distinction may be omitted when, by association of terms (for example, as in "20 fluid ounces, 1 pint 4 ounces"), the proper meaning is obvious. Whenever the declaration of quantity is in terms of the dry pint or dry quart, the declaration (Amended 1982) shall include the word "dry."

6.6. METRIC UNITS: WEIGHT, MEASURE. - A declaration of quantity:

(a) in units of weight shall be in terms of the kilogram, gram, or milligram; 
(b) in units of liquid measure shall be in terms of the liter or milliliter, and shall express the volume at $20{ }^{\circ} \mathrm{C}$, except in the case of petroleum products or distilled spirits, for which the declaration shall express the volume at $15^{\circ} \mathrm{C}$, and except also in the case of a commodity that is normally sold and consumed while frozen, for which the declaration shall express the volume at the frozen temperature, and except also in the case of malt beverages or a commodity that is normally sold in the refrigerated state, for which the declaration shall express the volume at $4{ }^{\circ} \mathrm{C}$;

(Amended 1985)

(c) in units of linear measure shall be in terms of the meter, centimeter, or millimeter;

(d) in units of area measure, shall be in terms of the square meter or square centimeter;

(e) in units of volume other than liquid measure, shall be in terms of the liter and milliliter, except that the terms cubic meter and cubic centimeter will be used only when specifically designated as a method of sale.

6.6.1. SYMBOLS. - Any of the following symbols for metric units, and none other, may be employed in the quantity statement on a package of commodity:

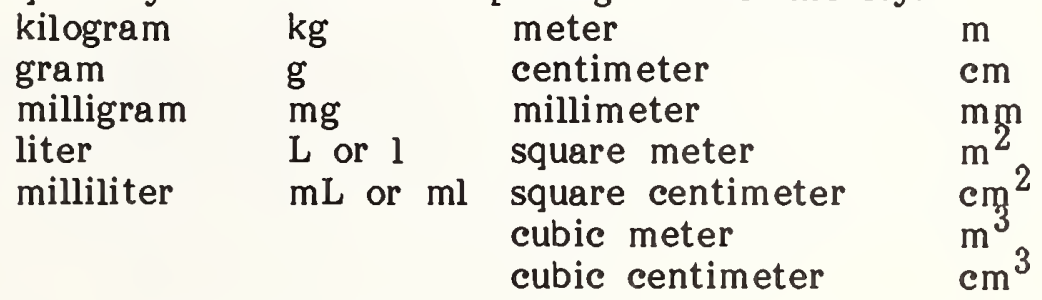

(a) Symbols, except for liter, are not capitalized unless the unit is derived from a proper name. Periods should not be used after the symbol. Symbols are always written in the singular form-do not add "s" to express the plural when the symbol is used.

(b) The "l" symbol for liter and "ml" symbol for milliliter are permitted; however, the "L" symbol and the "mL" symbol are preferred.

(Amended 1980) 


\subsection{PRESCRIBED UNITS, INCH-POUND SYSTEM. -}

6.7.1. LESS THAN 1 FOOT, 1 SQUARE FOOT, 1 POUND, OR 1 PINT. - The declaration of quantity shall be expressed in terms of

(a) in the case of length measure of less than 1 foot, inches and fractions of inches;

(b) in the case of area measure of less than 1 square foot, square inches and fractions of square inches;

(c) in the case of weight of less than 1 pound, ounces and fractions of ounces;

(d) in the case of liquid measure of less than 1 pint, fluid ounces and fractions of fluid ounces;

Provided, that the quantity declaration appearing on a random package may be expressed in terms of decimal fractions of the largest appropriate unit, the fraction being carried out to not more than three ${ }^{1}$ decimal (Amended 1984) places.

6.7 .2 .

WEIGHT: DUAL QUANTITY DECLARATION. -On packages containing 1 pound or more but less than 4 pounds, the declaration shall be expressed in ounces and, in addition, shall be followed by a declaration in parentheses, expressed in terms of the largest whole unit; Provided, that the quantity declaration appearing on a random package may be expressed in terms of pounds and decimal fractions of the pound carried out (Amended 1984) to not more than three ${ }^{1}$ decimal places.

1 Packages entering interstate commerce are restricted by Federal regulations to two decimal place quantity declarations. For example, see 9 CFR $\$ 317.2(\mathrm{~h})(5)$ for meat and meat products, 21 CFR $\$ 101.105(\mathrm{j})(2)$ f or non-meat and non-poultry foods, and 16 CFR $\$ 500.9(b)$ for certain non-food consumer commodities.

(Added 1984) 
6.7.3. LIQUID MEASURE: DUAL QUANTITY DECLARATION. -On packages containing 1 pint or more, but less than 1 gallon, the declaration shall be expressed in fluid ounces and, in addition, shall be followed by a declaration in parentheses, expressed in terms of the largest whole unit.

6.7.4. LENGTH MEASURE: DUAL QUANTITY DECLARATION. -On packages containing 1 foot or more, but less than 4 feet, the declaration shall be expressed in inches and, in addition, shall be followed by a declaration in parentheses, expressed in terms of the largest whole unit.

6.7.5. AREA MEASURE: DUAL QUANTITY DECLARATION. -On packages containing 1 square foot or more but less than 4 square feet, the declaration shall be expressed in square inches and, in addition, shall be followed by a declaration in parentheses, expressed in terms of the largest whole unit.

6.7.6. FOUR FEET, 4 SQUARE FEET, 4 POUNDS, 1 GALLON, OR MORE. - - In the case of

(a) length measure of 4 feet or more

the declaration of quantity shall be expressed in terms of feet, followed in parentheses by a declaration of yards and common or decimal fractions of the yard, or in terms of feet followed in parentheses by a declaration of yards with any remainder in terms of feet and inches. In the case of

(b) area measure of 4 square feet or more;

(c) weight of 4 pounds or more;

(d) liquid measure of 1 gallon or more

the declaration of quantity shall be expressed in terms of the largest whole unit.

6.7.7. BIDIMENSIONAL COMMODITIES. - For bidimensional commodities (including roll-type commodities) the quantity declaration shall he expressed,

(a) if less than 1 square foot, in terms of linear inches and fractions of linear inches; 
(b) if at least 1 square foot but less than 4 square feet, in terms of square inches followed in parentheses by a declaration of both the length and width, each being in terms of the largest whole unit; Provided, that

(1) no square inch declaration is required for a bidimensional commodity of 4 inches width or less,

(2) a dimension of less than 2 feet may be stated in inches within the parenthetical declaration, and

(3)

commodities consisting of usable
individual units (except roll-type
commodities with individual usable units
created by perforations, for which see
subsection 6.9 . Count: Ply.) require a
declaration of unit area but not a
declaration of total area of all such
units;

(c) if 4 square feet or more, in terms of square feet followed in parentheses by a declaration of the length and width in terms of the largest whole unit; Provided, that

(1) no declaration in square feet is required for a bidimensional commodity with a width of 4 inches or less,

(2) bidimensional commodities, with a width of 4 inches or less, shall have the length expressed in inches followed by a statement in parentheses of the length in the largest whole unit. (Example: 2 inches by 360 inches (10 yards)),

(Added 1972)

(3) a dimension of less than 2 feet may be stated in inches within the parenthetical declaration, and

(d) no declaration in square units is required for commodities for which the length and width measurements are critical in terms of end use (such as tablecloths or bedsheets) if such commodities clearly present the length and width measurements on the label. 


\subsection{PRESCRIBED UNITS, METRIC SYSTEM - -}

6.8.1. LESS THAN 1 METER, 1 SQUARE METER, 1 KILOGRAM, OR 1 LITER. - The declaration of quantity shall be expressed in terms of:

(a) in the case of length measure of less than 1 meter, centimeters or millimeters;

(Amended 1979)

(b) in the case of area measure of less than 1 square meter, square centimeters and decimal fractions of square centimeters;

(c) in the case of weight of less than 1 kilogram, grams and decimal fractions of a gram, but if less than 1 gram, then in milligrams;

(d) in the case of liquid or dry measure of less than one liter, milliliters;

Provided, that the quantity declaration appearing on a random weight package may be expressed in terms of decimal fractions of the largest appropriate unit, the fraction being carried out to not more than three 1 decimal places. (Amended 1980)

6.8.2. ONE METER, 1 SQUARE METER, 1 KILOGRAM, 1 LITER, OR MORE. -In the case of:

(a) length measure of 1 meter or more; in meters and decimal fractions to not more than two places.

(b) area measure of 1 square meter or more; in square meters and decimal fractions to not more than two places.

1 Packages subject to the Federal Fair Packaging and Labeling Act must be labeled in inch-pound units of measure. Metric units may also be declared on the principal display panel and may even appear first. Packages entering interstate commerce are restricted by Federal regulations to two decimal place quantity declarations. For example, see 9 CFR $\$ 317.2(\mathrm{~h})(5)$ for meat and meat products, 21 CFR $\$ 101.105(\mathrm{j})(2)$ for non-meat and non-poultry foods and 16 CFR $\$ 500.9$ (b) for certain nonfood consumer commodities. (Added 1984) 
(c) weight of 1 kilogram or more; in kilograms and decimal fractions to not more than two places.

(d) liquid or dry measure of 1 liter or more; in liters and decimal fractions to not more than two places.

Provided, that the quantity declaration appearing on a random weight package may be expressed in terms of kilograms and decimal fractions carried out to not more than three ${ }^{1}$ decimal places. (Added 1986)

6.8.3. BIDIMENSIONAL COMMODITIES. - For bidimensional commodities (including roll-type commodities) the quantity declaration shall be expresseci:

(a) if less than 1 square meter in terms of length and width.

(b) if 1 square meter or more, in terms of square measure followed in parentheses by a declaration of length and width; Provided, that

(1) quantity declarations on bidimensional commodities with a width of 100 millimeters or less may be expressed in terms of width and length, only.

(2) commodities consisting of usable individual units (except roll-type commodities with individual usable units created by perforations, for which see subsection 6.9. Count: Ply.) require a declaration of unit area but not a declaration of total area of all such units.

1 Packages subject to the Federal Fair Packaging and Labeling Act must be labeled in inch-pound units of measure. Metric units may also be declared on the principal display panel and may even appear first. Packages entering interstate commerce are restricted by Federal regulations to two decimal place quantity declarations. For example, see 9 CFR $\$ 317.2(\mathrm{~h})(5)$ for meat and meat products, 21 CFR $\$ 101.105(\mathrm{j})(2)$ for non-meat and non-poultry foods and $16 \mathrm{CFR} \$ 500.9(\mathrm{~b})$ for certain nonfood consumer commodities. (Added 1984, Amended 1986) 
(3) no declaration in square units is required for commodities for which the length and width measurements are critical in terms of end use (such as tablecloths or bedsheets) if such commodities clearly present the length and width measurements on the label.

6.9. COUNT: PLY. - If the commodity is in individually usable units of one or more components or plies, the quantity declaration shall, in addition to complying with other applicable quantity declaration requirements of this regulation, include the number of plies and total number of usable units.

Roll-type commodities, when perforated so as to identify individual usable units, shall not be deemed to be made up of usable units; however, such roll-type commodities shall be labeled in terms of
(a) total area measurement,
(b) number of plies,
(c) count of usable units, and
(d) dimensions of a single usable unit.

6.10. FRACTIONS. -

(a) Metric: A metric statement in a declaration of net quantity of contents of any consumer commodity may contain only decimal fractions.

(b) Inch-Pound: An inch-pound statement of net quantity of contents of any consumer commodity may contain common or decimal fractions. A common fraction shall be in terms of halves, quarters, eighths, sixteenths, or thirty-seconds, except that

$$
\begin{aligned}
& \text { if there exists a firmly established general } \\
& \text { consumer usage and trade custom of employing } \\
& \text { different common fractions in the net quantity } \\
& \text { declaration of a particular commodity, they may } \\
& \text { be employed, and }
\end{aligned}
$$

if linear measurements are required in terms of yards or feet common fractions may be in terms of thirds.

(c) Common fractions: A common fraction shall be reduced to its lowest term (Example: 2/4 becomes 1/2). 
(d) Decimal fractions: A decimal fraction shall not be carried out to more than two places, except that the quantity declaration appearing on a random package may (Amended 1986) be carried out to not more than three ${ }^{1}$ decimal places.

\subsection{SUPPLEMENTARY DECLARATIONS. -}

6.11.1. SUPPLEMENTARY QUANTITY DECLARATIONS. - The required quantity declaration may be supplemented by one or more declarations of weight, measure, or count, such declaration appearing other than on a principal display panel. Such supplemental statement of quantity of contents shall not include any term qualifying a unit of weight, measure, or count that tends to exaggerate the amount of commodity contained in the package (e.g., "giant" quart, "larger" liter, "full" gallon, "when packed," "minimum," or words of similar import).

\subsubsection{COMBINED METRIC AND INCH-POUND}

DECLARATIONS. - An equivalent statement of the net quantity of contents in terms of either the inch-pound or metric system is not regarded as a supplemental statement and such statement may also appear on the principal display panel; Provided, that it conforms to both Section 6.5. and Section 6.6.

6.11.3. ROUNDING. - In all conversions for the purpose of showing an equivalent metric or inch-pound quantity to a rounded inch-pound or metric quantity, the number of significant digits retained should be such that accuracy is neither sacrificed nor exaggerated. As a general rule, converted values should be rounded down by dropping any digit beyond the first three. (Example: 196.4 grams becomes 196 grams or 1.759 feet becomes 1.75 feet.)

6.12. QUALIFICATION OF DECLARATION PROHIBITED. - In no case shall any declaration of quantity be qualified by the addition of the words "when packed," "minimum," or "not less than," or any words of similar import, nor shall any unit of weight, measure, or count be qualified by any term (such as "jumbo," "giant," "full," or the like) that tends to exaggerate the amount of commodity.

1 Packages subject to the Federal Fair Packaging and Labeling Act must be labeled in inch-pound units of measure. Metric units may also be declared on the principal display panel and may even appear first. Packages entering interstate commerce are restricted by Federal regulations to two decimal place quantity declarations. For example, see 9 CFR $\$ 317.2(\mathrm{~h})(5)$ for meat and meat products, 21 CFR $\$ 101.105(\mathrm{j})(2)$ for non-meat and non-poultry foods and 16 CFR $\$ 500.9(b)$ for certain nonfood consumer commodities. (Added 1986) 
6.13. CHARACTER OF DECLARATION: AVERAGE. - The average quantity of contents in the packages of a particular lot, shipment, or delivery shall at least equal the declared quantity, and no unreasonable shortage in any package shall be permitted, even though overages in other packages in the same shipment, delivery, or lot compensate for such shortage.

(Added 1981)

\section{SECTION 7. DECLARATION OF QUANTITY: NONCONSUMER PACKAGES}

7.1. GENERAL. - The metric and inch-pound systems of weights and measures are recognized as proper systems to be used in the declaration of quantity. Units of both systems might be combined in a dual declaration of quantity. ${ }^{1}$

7.2. LOCATION. - A nonconsumer package shall bear on the outside a declaration of the net quantity of contents. Such declaration shall be in terms of the largest whole unit (see subsection 6.2. Largest Whole Unit).

7.3. TERMS: WEIGHT, LIQUID MEASURE, DRY MEASURE, OR COUNT. - The declaration of the quantity of a particular commodity shall be expressed in terms of liquid measure if the commodity is liquid, or in terms of dry measure if the commodity is dry, or in terms of weight if the commodity is solid, semisolid, viscous, or a mixture of solid and liquid, or in terms of numerical count. However, if there exists a firmly established general consumer usage and trade custom with respect to the terms used in expressing a declaration of quantity of a particular commodity, such declaration of quantity may be expressed in its traditional terms, if such traditional declaration gives accurate and adequate information as to the quantity of the commodity.

7.4. INCH-POUND UNITS: WEIGHT, MEASURE. - A declaration of quantity:

(a) in units of weight, shall be in terms of the avoirdupois pound or ounce;

(b) in units of liquid measure, shall be in terms of the United States gallon of 231 cubic inches or liquid-quart, liquid-pint, or fluid-ounce subdivisions of the gallon, and shall express the volume at $68{ }^{\circ} \mathrm{F}$ except in the case of petroleum products or distilled spirits, for which the declaration shall express the volume at $60^{\circ} \mathrm{F}$, and except also in the case of a commodity that is normally sold and consumed while frozen, for which

1 Although nonconsumer packages under this Regulation might bear metric declarations only, this Regulation should not be construed to supersede any labeling requirement specified in Federal law. 
the declaration shall express the volume at the frozen temperature, and except also in the case of a commodity that is normally sold in the refrigerated state, for which the declaration shall express the volume at $40{ }^{\circ} \mathrm{F}$, and except also in the case of malt beverages, for which the declaration shall express the volume at $39.1{ }^{\circ} \mathrm{F}$;

(Amended 1985)

(c) in units of linear measure, shali be in terms of the yard, foot, or inch;

(d) in units of area measure, shall be in terms of the square yard, square foot, or square inch;

(e) in units of volume measure, shall be in terms of the cubic yard, cubic foot, or cubic inch;

(f) in units of dry measure, shall be in terms of the United States bushel of 2150.42 cubic inches, or peck, dry-quart, and dry-pint subdivisions of the bushel.

7.4.1. SYMBOLS AND ABBREVIATIONS. - Any generally accepted symbol and abbreviation of a unit name may be employed in the quantity statement on a package of commodity. (For commonly accepted symbols and abbreviations, see subsection 6.5.1. Symbols and Abbreviations.)

7.5. METRIC UNITS: WEIGHT, MEASURE. - A declaration of quantity:

(a) in units of weight, shall be in terms of the kilogram, gram, or milligram;

(b) in units of liquid measure, shall be in terms of the liter or milliliter, and shall express the volume at $20{ }^{\circ} \mathrm{C}$, except in the case of petroleum products or distilled spirits, for which the declaration shall express the volume at $15^{\circ} \mathrm{C}$, and except also in the case of a commodity that is normally sold and consumed while frozen, for which the declaration shall express the volume at the frozen temperature, and except also in the case of malt beverages or a commodity that is normally sold in the refrigerated state, for which the declaration shall express the volume at $4{ }^{\circ} \mathrm{C}$;

(Amended 1985)

(c) in units of linear measure, shall be in terms of the meter, centimeter, or millimeter;

(d) in units of area measure, shall be in terms of the square meter or square centimeter; 
(e) in units of volume other than liquid measure, shall be in terms of the liter and milliliter, except that the terms cubic meter and cubic centimeter will be used only when specifically designated as a method of sale.

7.5.1. SYMBOLS. - Only those symbols as detailed in subsection 6.6.1. Symbols, and none other, may be employed in the quantity statement on a package of commodity.

7.6. CHARACTER OF DECLARATION: AVERAGE. - The average quantity of contents in the packages of a particular lot, shipment, or delivery shall at least equal the declared quantity, and no unreasonable. shortage in any package shall be permitted, even though overages in other packages in the same shipment, delivery, or lot compensate for such shortage.

\section{SECTION 8. PROMINENCE AND PLACEMENT: CONSUMER PACKAGES}

8.1. GENERAL. - All information required to appear on a consumer package shall appear thereon in the English language and shall be prominent, definite, and plain, and shall be conspicuous as to size and style of letters and numbers and as to color of letters and numbers in contrast to color of background. Any required information that is either in hand lettering or hand script shall be entirely clear and equal to printing in legibility.

8.1.1. LOCATION. - The declaration or declarations of quantity of the contents of a package shall appear in the bottom 30 percent of the principal display panel or panels. For cylindrical containers, see also subsection 10.7. for (Amended 1975) additional requirements.

8.1.2. STYLE OF TYPE OR LETTERING. - The declaration or declarations of quantity shall be in such a style of type or lettering as to be boldly, clearly, and conspicuously presented with respect to other type, lettering, or graphic material on the package, except that a declaration of net quantity blown, formed, or molded on a glass or plastic surface is permissible when all label information is blown, formed, or molded on the surface.

8.1.3. COLOR CONTRAST. - The declaration or declarations of quantity shall be in a color that contrasts conspicuously with its background, except that a declaration of net quantity blown, formed, or molded on a glass or plastic surface shall not be required to be presented in a contrasting color if no required label information is on the surface in a contrasting color. 
8.1.4. FREE AREA. - The area surrounding the quantity declaration shall be free of printed information

(a)

above and below, by a space equal to at least the height of the lettering in the declaration, and

(b) to the left and right, by a space equal to twice the width of the letter " $N$ " of the style and size of type used in the declaration.

8.1.5. PARALLEL QUANTITY DECLARATION. - The quantity declaration shall be presented in such a manner as to be generally parallel to the declaration of identity and to the base on which the package rests as it is designed to be displayed.

8.2. CALCULATION OF AREA OF PRINCIPAL DISPLAY PANEL FOR PURPOSES OF TYPE SIZE. - The area of the principal display panel shall be

(a) in the case of a rectangular container, one entire side that properly can be considered to be the principal display panel, the product of the height times the width of that side;

(b) in the case of a cylindrical or nearly cylindrical container, 40 percent of the product of the height of the of the container times the circumference; or

(c) in the case of any other shaped container, 40 percent of the total surface of the container, unless such container presents an obvious principal display panel (e.g., the top of a triangular or circular package of cheese, or the top of a can of shoe polish), in which event the area shall consist of the entire such surface.

Determination of the principal display panel shall exclude tops, bottoms, flanges at tops and bottoms of cans, and shoulders and necks of bottles or jars.

8.2.1. MINIMUM HEIGHT OF NUMBERS AND LETTERS. -The height of any letter or number in the required quantity declaration shall be not less than that shown in Table 1 with respect to the area of the panel, and the height of each number of a common fraction shall meet one-half the minimum height standards. In the case of the symbol for milliliter, the " $\mathrm{m}$ " shall meet the minimum height standard.

(Amended 1982)

8.2.2. NUMBERS AND LETTERS: PROPORTION. -No number or letter shall be more than three times as high as it is wide. 
SECTION 9. PROMINENCE AND PLACEMENT: NONCONSUMER PACKAGES

9.1. GENERAL. - All information required to appear on a nonconsumer package shall be definitely and clearly stated thereon in the English language. Any required information that is either in hand lettering or hand script shall be entirely clear and equal to printing in legibility.

TABLE 1. Minimum Height of Numbers and Letters

\begin{tabular}{lll}
\hline $\begin{array}{l}\text { Area of principal } \\
\text { display panel }\end{array}$ & $\begin{array}{l}\text { Minimum height } \\
\text { of numbers and } \\
\text { letters }\end{array}$ & $\begin{array}{l}\text { Minimum height: label } \\
\text { information blown, } \\
\text { formed, or molded on } \\
\text { surface of container }\end{array}$ \\
\hline $\begin{array}{l}5 \text { square inches } \\
\text { (in }{ }^{2} \text { and less }\end{array}$ & $1 / 8$ inch \\
$\begin{array}{l}\text { Gregter than } \\
5 \text { in and not } \\
\text { greater than } \\
25 \text { in }\end{array}$ & $1 / 16$ inch \\
$\begin{array}{l}\text { Greater than } \\
25 \text { in }{ }^{2} \text { and not } \\
\text { greater than } \\
100 \text { in }^{2}\end{array}$ & $1 / 8$ inch \\
$\begin{array}{l}\text { Greater than } \\
100 \text { in and } \\
\text { not greater } \\
\text { than } 400 \text { in } \\
\text { Greater than } \\
400 \text { in }^{2}\end{array}$ & $3 / 16$ inch \\
\hline
\end{tabular}

SECTION 10. REQUIREMENTS: SPECIFIC CONSUMER COMMODITIES, NONCONSUMER COMMODITIES, PACKAGES, CONTAINERS

(Title amended 1979)

10.1. DISPLAY CARD PACKAGE. - For an individual package affixed to a display card, or for a commodity and display card together comprising a package, the type size of the quantity declaration is governed by the dimensions of the display card. 
10.2. EGGS. - When cartons containing 12 eggs have been designed so as to permit division in half by the retail purchaser, the required quantity declaration shall be so positioned as to have its context destroyed when the carton is divided.

10.3. AEROSOLS AND SIMILAR PRESSURIZED CONTAINERS. -The declaration of quantity on an aerosol package, and on a similar pressurized package, shall disclose the net quantity of the commodity (including propellant), in terms of weight, that will be expelled when the instructions for use as shown on the container are followed.

10.4. MULTI-UNIT PACKAGES. ${ }^{1}$ - Any package containing more than one individual "commodity in package form" (see subsection 2.1.) of the same commodity shall bear on the outside of the package a declaration of

(a) the number of individual units,

(b) the quantity of each individual unit, and

(c) the total quantity of the contents of the multi-unit package: Provided, that any such declaration of total quantity shall not be required to include the parenthetical quantity statement of a dual quantity representation. (Example: soap bars, "6 Bars, Net Weight 75 grams each; Total Net Weight 450 grams)

10.5. COMBINATION PACKAGES. - Any package containing individual units of dissimilar commodities (such as an antiquing or a housecleaning kit, for example) shall bear on the label of the package a quantity declaration for each unit. (Example: sponges and cleaner: "2 sponges, each 10 centimeters $\times 15$ centimeters $\mathrm{x}$ 2 centimeters; 1 box cleaner, net weight 150 grams")

10.6. VARIETY PACKAGES. - Any package containing individual units of reasonably similar commodities (such as, for example, seasonal gift packages, variety packages of cereal) shall bear on the label of the package a declaration of the total quantity of commodity in the package. (Example: plastic tableware: 4 spoons, 4 forks, 4 knives, 12 pieces total.)

\footnotetext{
${ }^{1}$ Open multi-unit retail food packages under the authority of the Food and Drug Administration or U.S. Department of Agriculture that do not obscure the number of units or prevent examination of the labeling on each of the individual units are not required to declare the number of individual units or the total quantity of contents of the multi-unit package if the labeling of each individual unit complies with requirements so that it is capable of being sold individually. (See also Section 11.12.) (Added 1984)
} 
10.7. CYLINDRICAL CONTAINERS. - In the case of cylindrical or nearly cylindrical containers, information required to appear on the principal display panel shall appear within that 40 percent of the circumference which is most likely to be displayed, presented, shown, or examined under customary conditions of display for retail sale.

10.8. MEASUREMENT OF CONTAINER-TYPE COMMODITIES, HOW EXPRESSED. -

10.8.1. GENERAL. - Commodities designated and sold at retail to be used as containers for other materials or objects, such as bags, cups, boxes, and pans, shall be labeled with the declaration of net quantity as follows:

(a) For bag-type commodities, in terms of count followed by linear dimensions of the bag (whether packaged in a perforated roll or otherwise).

When the unit bag is characterized by two dimensions because of the absence of a gusset, the width and length will be expressed:

(1) Inch-pound units - in inches, except that a dimension of 2 feet or more will be expressed in feet with any remainder in terms of inches or common or decimal fractions of the foot. (Example: "25 BAGS, 17 inches $\times 20$ inches" or "100 BAGS, 20 inches $\times 2$ feet 6 inches" or "50 BAGS, 20 inches x 2-1/2 feet")

(2) Metric units - in millimeters except a dimension of one meter or more will be expressed in meters with the remainder in terms of decimal fractions of the meter (Examples: "25 BAGS, 500 millimeters $\mathrm{x}$ 600 millimeters" or "50 BAGS, 750 millimeters x 1.2 meters")

When the unit bag is gusseted, the dimensions will be expressed as width, depth, and length.

(3) Inch-pound units - expressed in feet with any remainder in terms of inches or the common or decimal fractions of the foot. (Examples: "25 BAGS, 17 inches $x$ 4 inches $\times 20$ inches" or "100 BAGS, 20 inches $\times 12$ inches $\times 2-1 / 2$ feet") 
(4) Metric units - in millimeters except a dimension of one meter or more will be expressed in meters with the remainder in terms of decimal fractions of the meter. (Examples: "25 BAGS, 430 millimeters $\mathrm{x}$ 100 millimeters x 500 millimeters" or "50 BAGS, 500 millimeters $\times 300$ millimeters x 1.2 meters")

(b) For other square, oblong, rectangular, or similarly shaped containers, in terms of count followed by length, width, and depth, except depth need not be listed when less than 50 millimeters or 2 inches. (Examples: "2 PANS, 8 inches $\times 8$ inches" or "2 PANS, 203 millimeters x 203 millimeters")

(c) For circular or other generally round-shaped containers, except cups, and the like, in terms of count followed by diameter and depth, except depth need not be listed when less than 50 millimeters or two inches. (Examples: "4 PANS, 8-inches diameter $x 4$ inches" or "4 PANS, 200-millimeters diameter x 100 millimeters")

(d) Notwithstanding the above requirements, the net quantity statement for containers such as cups will be listed in terms of count and liquid capacity per unit. (Examples: "24 CUPS, 6 fluid ounces capacity" or "24 CUPS, 250 milliliter capacity")

10.8.2. CAPACITY. - When the functional use of the container is related by label references in standard terms of measure to the capability of holding a specific quantity of substance or class of substances such references shall be a part of the net quantity statement and shall specify capacity as follows:

(a) Inch-Pound Units:

(1) Liquid measure for containers that are intended to be used for liquids, semisolids, viscous materials, or mixtures of solids and liquids. The expressed capacity will be stated in terms of the largest whole unit (gallon, quart, pint, ounce, with any remainder in terms of the common or decimal fraction of that unit). (Examples: Freezer Box - "4 BOXES, 1 quart capacity, 5 inches $\times 4$ inches $x 3$ inches") 
(2) Dry measure for containers that are intended to be used for solids. The expressed capacity will be stated in terms of the largest whole unit (bushel, peck), with a remainder in terms of the common or decimal fraction of that unit. (Example: Leaf Bags -"8 BAGS, 6 bushel capacity, 3 feet $\times 5$ feet")

(3) Where containers are used as liners for other more permanent containers, in the same terms as are normally used to express the capacity of the more permanent containers. (Example: Garbage Can Liners - "10 LINERS, 2 feet 6 inches $\mathrm{x} 3$ feet 9 inches. FITS UP TO 30-GALLON CANS")

(b) Metric units: Volume measure for all containers and liners. (Examples: "4 BOXES, 1 liter capacity. 150 millimeters $\times 120$ millimeters $\times 90$ millimeters"; "8 BAGS, 200 liter capacity, 85 millimeters $\times 1.5$ meters" or "10 LINERS, 750 millimeters $\times 1$ meter, FITS UP TO 120 LITER CANS")

10.8.3. TERMS. - For purposes of this section, the use of the terms "CAPACITY," "DIAMETER," and "FLUID" is optional.

\subsection{TEXTILE PRODUCTS, THREADS, AND YARNS. -}

10.9.1. WEARING APPAREL. - Wearing apparel (including nontextile apparel and accessories such as leather goods and footwear) sold as single-unit items, or if normally sold in pairs (such as hosiery, gloves, and shoes) sold as single-unit pairs, shall be exempt from the requirements for a net quantity statement by count, as required by subsection 6.4 . of this regulation.

10.9.2. TEXTILES. - Bedsheets, blankets, pillowcases, comforters, quilts, bedspreads, mattress covers and pads, afghans, throws, dresser and other furniture scarfs, tablecloths and napkins, flags, curtains, drapes, dishtowels, dish cloths, towels, face cloths, utility cloths, bath mats, carpets and rugs, pot holders, fixture and appliance covers, non-rectangular diapers, slip covers, etc., shall be exempt from the requirements of subsections 6.7.7. and 6.8.3. of this regulation; Provided, that 
(a) The quantity statement for fitted sheets and mattress covers shall state, in centimeters or inches, the length and width of the mattress for which the item is designed, such as "twin," "double," "king," etc. (Example: "Double Sheet for 135 centimeter x 190 centimeter mattress.")

(b) The quantity statement for flat sheets shall state the size designation of the mattress for which the sheet is designed, such as "twin," "double", "king", etc. The quantity statement also shall state, in centimeters or inches, the length and width of the mattress for which the sheet is designed, followed in parentheses by a statement, in centimeters or inches, of the length and width of the finished sheet. (Example: "Twin Flat Sheet for 100 centimeter $\mathrm{x}$ 190 centimeter mattress (170 centimeter x 240 centimeter finished size,") (Amended 1977)

(c) The quantity statement for pillowcases shall state the size designation of the pillow for which the pillowcase is designed, such as "youth," "standard," and "queen," etc. The quantity statement also shall state, in centimeters or inches, the length and width of the pillow for which the pillowcase is designed, followed in parentheses by a statement, in centimeters or inches, of the length and width of the finished pillowcase. (Example: "Standard Pillowcase for 50 centimeter $\times 65$ centimeter pillow (53 centimeter $\times 75$ centimeter finished size)")

(Amended 1977).

(d) The quantity statement for blankets, comforters, quilts, bedspreads, mattress pads, afghans, and throws shall state, in centimeters or inches, the length and width of the finished item. The quantity statement also may state the length of any ornamentation and the size designation of the mattress for which the item is designed, such as "twin," "double," "king," etc.

(e) The quantity statement for tablecloths and napkins shall state, in centimeters or inches, the length and width of the finished item. The quantity statement also may state parenthetically, in centimeters or inches, the length and width oi the item before hemming and properly identified as such. 
(f) The quantity statement for curtains, drapes, flags, furniture scarfs, etc., shall state, in centimeters or inches, the length and width of the finished item. The quantity statement also may state parenthetically, in centimeters or inches, the length of any ornamentation.

(g) The quantity statement for carpets and rugs shall state, in meters or feet, with any remainder in decimal fractions of the meter for metric sizes or common or decimal fractions of the foot or in inches for inch-pound sizes, the length and width of the item. The quantity statement also may state parenthetically, in centimeters or inches, the length of any ornamentation.

(h) The quantity statement for woven dish towels, dish cloths, towels, face cloths, utility cloths, bath mats, etc., shall state, in centimeters or inches, the length and width of the item. The quantity statement for such items, when knitted, need not state the dimensions.

(i) The quantity statement for textile products such as pot holders, fixture and appliance covers, non-rectangular diapers, slip covers, etc., shall be stated in terms of count and may include size designations and dimensions.

(j) The quantity statement for other than rectangular textile products identified in subsections (a) through (h) shall state the geometric shape of the product and the dimensions that are customarily used in describing such geometric shape. (Example: "Oval Tablecloth 140 centimeters $x 110$ centimeters" representing the maximum length and width in this case)

(k) The quantity statement for packages of remnants of textile products of assorted sizes, when sold by count, shall be accompanied by the term "irregular dimensions" and the minimum size of such remnants.

(Added 1971) 
10.9.3. TEXTILES: _ VARIATIONS FROM DECLARED
DIMENSIONS. -

(a) For an item with no declared dimension less than 60 centimeters or 24 inches, a minus variation greater than $3 \%$ of a declared dimension and a plus variation greater than $6 \%$ of a declared dimension should be considered unreasonable.

(b) For an item with a declared dimension less than 60 centimeters or 24 inches, a minus variation greater than $6 \%$ of that declared dimension and a plus variation greater than $12 \%$ of that declared dimension should be considered unreasonable.

(Added 1971)

10.9.4. EXEMPTION: VARIETY TEXTILE PACKAGES. Variety packages of textiles that are required by reason of subsection 6.4.1. to provide a combination declaration stating the quantity of each individual unit, shall be exempt from the requirements in this regulation for:

(a) Location (see subsection 8.1.1.),

(b) Free area (see subsection 8.1.4.), and

(c) Minimum height of numbers and letters (see subsection 8.2.1.).

(Added 1971)

10.9.5. SEWING THREADS, HANDICRAFT THREADS, AND YARNS. - Sewing and handicraft threads shall be exempt from the requirements of subsection 6.7.6. and 6.8.2. of this regulation; Provided, that

(a) The net quantity statement for inch-pound sizes of sewing and handicraft threads shall be expressed in terms of yards.

(b) The net quantity statement for yarns shall be expressed in terms of weight.

(c) Thread products may, in lieu of name and address, bear a trademark, symbol, brand, or other mark that positively identifies the manufacturer, packer, or distributor, provided that such marks, employed to identify the vendor, shall be filed with the director. 
(d) Each unit of industrial thread shall be marked to show its net length in terms of meters or yards or its net weight in terms of kilograms or grams or avoirdupois pounds or ounces, except that ready-wound bobbins that are not sold separately shall not be required to be individually marked to show the number of bobbins contained therein and the net meters or yards of thread on each bobbin.

10.10. PACKAGED SEED. - Packages of seeds intended for planting shall be labeled in full accord with this regulation except as follows:

(a) The quantity statement shall appear in the upper thirty percent of the principal display panel.

(b) The quantity statements shall be in terms of the largest whole unit of the metric system for all weights up to 7 grams, and in grams or in ounces for all other weights less than 225 grams or 8 ounces; packaged seeds weighing 225 grams or 8 ounces or more shall not be subject to Section 10.10 .

(c) The quantity statement for coated seed, encapsulated seed, pelletized seed, pre-planters, seed tapes, etc., shall be in terms of count.

(Added 1972, amended 1975)

10.11. BARK MULCH: VARIATIONS FROM DECLARED VOLUME. ${ }^{1}-$ An individual package minus variation greater than 5 percent (Added 1983)

of the declared volume shall be considered unreasonable.

10.12. POLYETHYLENE PRODUCTS: VARIATIONS FROM DECLARED THICKNESS ${ }^{1}$-Any individual thickness measurement of polyethylene sheeting, film, or bag may be as much as 20 percent below the labeled thickness (i.e., at least $80 \%$ of the labeled thickness) ${ }^{2}$.

The average thickness of a single package of polyethylene sheeting, film, or bags may be as much as 7 percent below the labeled thickness (i.e.,at least $93 \%$ of the labeled (Added 1985) thickness).

1 In addition, the average net contents of lots, shipments, or deliveries must equal or exceed the labeled net contents. See Section 12.1.

2 ASTM Standard D-4397-84, "Specification for Polyethylene Sheeting for Construction, Industrial and Agricultural Applications", 1984. 


\section{SECTION 11. EXEMPTIONS}

11.1. GENERAL. - Whenever any consumer commodity or package of consumer commodity is exempted from the requirements for dual quantity declaration, the net quantity required to appear on the package shall be in terms of the largest whole unit (except see subsection 10.4.(c)).

11.2. RANDOM PACKAGES. - A random package bearing a label conspicuously declaring

(a) the net weight,

(b) the price per kilogram or pound, and

(c) the total price

shall be exempt from the type size, dual declaration, placement, and free area requirements of this regulation. In the case of a random package packed at one place for subsequent sale at another, neither the price per unit of weight nor the total selling price need appear on the package, provided the package label includes both such prices at the time it is offered or exposed for sale at retail.

This exemption shall also apply to uniform weight packages of cheese and cheese products labeled in the same manner and by the same type of equipment as random packages exempted by this section.

11.3. SMALL CONFECTIONS. - Individually wrapped pieces of "penny candy" and other confectionery of less than 15 grams or $1 / 2$ ounce net weight per individual piece shall be exempt from the labeling requirements of this regulation when the container in which such confectionery is shipped is in conformance with the labeling requirements of this regulation. Similarly, when such confectionery items are sold in bags or boxes, such items shall be exempt from the labeling requirements of this regulation, including the required declaration of net quantity of contents, when the declaration of the bag or box meets the requirements of this regulation.

11.4. INDIVIDUAL SERVINGS. - Individual-serving-size packages of foods containing less than 15 grams or $1 / 2$ ounce or less than 15 milliliters or $1 / 2$ fluid ounce for use in restaurants, institutions, and passenger carriers, and not intended for sale at retail, shall be exempt from the required declaration of net quantity of contents specified in this regulation. 
11.5. CUTS, PLUGS, AND TWISTS OF TOBACCO AND CIGARS. - When individual cuts, plugs, and twists of tobacco and individual cigars are shipped or delivered in containers that conform to the labeling requirements of this regulation, such individual cuts, plugs, and twists of tobacco and cigars shall be exempt from such labeling requirements.

11.6. REUSABLE (RETURNABLE) GLASS CONTAINERS. - Nothing in this Regulation shall be deemed to preclude the continued use of reusable (returnable) glass containers: Provided, that such glass containers ordered after the effective date of this regulation shall conform to all requirements of this regulation.

11.7. CIGARETTES AND SMALL CIGARS. - Cartons of cigarettes and small cigars, containing ten individual packages of twenty, labeled in accordance with the requirements of this regulation, shall be exempt from the requirements set forth in subsection 8.1.1. Location, subsection 8.2.1. Minimum Height of Numbers and Letters, and subsection 10.4. Multi-Unit Packages; Provided, that such cartons bear a declaration of the net quantity of commodity in the package.

11.8. PACKAGED COMMODITIES WITH LABELING REQUIREMENTS SPECIFIED IN FEDERAL LAW. - Packages of meat and meat products, poultry products, tobacco and tobacco products, insecticides, fungicides, rodenticides, and alcoholic beverages shall be exempt from those portions of these regulations requiring dual declarations in customary units and specifying location and minimum type size of the net quantity declaration; Provided, that quantity labeling requirements for such products are specified in Federal Law, so as to follow reasonably sound principles of providing consumer information.

11.9. FLUID DAIRY PRODUCTS, ICE CREAM, AND SIMILAR FROZEN DESSERTS. -

(a) When packaged in 1/2-liquid-pint and 1/2-gallon containers, are exempt from the requirements for stating net contents of 8 fluid ounces and 64 fluid ounces, which may be expressed as $1 / 2$ pint and $1 / 2$ gallon, respectively.

(b) When packaged in 1-liquid-pint, 1-liquid-quart, and $1 / 2$-gallon containers, are exempt from the dual net contents declaration requirements of subsection 6.7.3.

(c) When measured by and packaged in measure containers as defined in "Measure Container Code of National Bureau of Standards Handbook 44," are exempt from the requirements of subsection 8.1.1. that the declaration of net contents be located within the bottom 30 percent of the principal display panel. 
(d) Milk and milk products when measured by and packaged in glass or plastic containers of 1/2-pint, 1-pint, 1-quart, $1 / 2$-gallon, and 1-gallon capacities are exempt from the placement requirement of subsection 8.1.1. that the declaration of net contents be located within the bottom 30 percent of the principal display panel; Provided, that other required label information is conspicuously displayed on the cap or outside closure, and the required net quantity of contents declaration is conspicuously blown, formed, or molded on, or permanently applied to that part of the glass or plastic container that is at or above the shoulder of the container.

\subsection{SINGLE STRENGTH AND LESS THAN SINGLE STRENGTH FRUIT JUICE BEVERAGES, IMITATIONS THEREOF, AND DRINKING WATER. -}

(a) When packaged in glass, plastic, or fluid milk type paper containers of 8- and 64-fluid-ounce capacity, are exempt from the requirements of subsection 6.5 . (b), to the extent that net contents of 8 fluid ounces and 64 fluid ounces (or 2 quarts) may be expressed as $1 / 2$ pint (or half pint) and $1 / 2$ gallon (or half gallon), respectively.

(b) When packaged in glass, plastic, or fluid milk type paper containers of 1-pint, 1-quart, and 1/2-gallon capacities, are exempt from the dual net contents declaration requirements of subsection 6.7 .4 .

(c) When packaged in glass or plastic containers of $1 / 2$-pint, 1-pint, 1-quart, 1/2-gallon, and 1-gallon capacities, are exempt from the placement requirements of subsection 8.1.1. that the declaration of net contents be located within the bottom 30 percent of the principal display panel; Provided, that other label information is conspicuously displayed on the cap or outside closure and the required net quantity of contents declaration is conspicuously blown, formed, or molded into or permanently applied to that part of the glass or plastic container that is at or above the shoulder of the container.

11.11. SOFT-DRINK BOTTLES. - Bottles of soft drinks shall be exempt from the placement requirements for the declaration of

(a) identity, when such declaration appears on the bottle closure, and

(b) quantity, when such declaration is blown, formed, or molded on or above the shoulder of the container and when all other information required by this regulation appears only on the bottle closure. 
11.12. MULTI-UNIT SOFT-DRINK PACKAGES. -- Multi-unit packages of soft drinks are exempt from the requirement for a declaration of

(a) responsibility, when such declaration appears on the individual units and is not obscured by the multi-unit packaging, or when the outside container bears a statement to the effect that such declaration will be found on the individual units inside, and

(b) identity, when such declaration appears on the individual units and is not obscured by the multi-unit packaging.

11.13. BUTTER. - When packaged in 4-ounce, 8-ounce, and 1-pound packages with continuous label copy wrapping, butter is exempt from the requirements that the statement of identity (subsection 3.1.1.) and the net quantity declaration (subsection 8.1.5.) be generally parallel to the base of the package. When packaged in 8-ounce and 1-pound units, butter is exempt from the requirement for location (subsection 8.1.1.) of net quantity declaration and, when packaged in 1-pound units, is exempt from the requirement for dual quantity declaration (subsection

(Amended 1980) 6.7.2.).

11.14. EGGS. - Cartons containing 12 eggs shall be exempt from the requirement for location (subsection 8.1.1.) of net quantity declaration. When such cartons are designed to permit division in half, each half shall be exempt from the labeling requirements of this regulation if the undivided carton conforms to all such requirements.

11.15. FLOUR. - Packages of wheat flour in conventional 2-, 5-, $10-, 25-, 50-$, and 100-pound packages shall be exempt from the requirement in this regulation for location (subsection 8.1.1.) of the net quantity declaration and, when packaged in units of 2 pounds, shall be exempt also from the requirement for a dual quantity declaration (subsection 6.7.2.).

(Amended 1980)

11.16. SMALL PACKAGES. - On a principal display panel of 5 square inches or less, the declaration of quantity need not appear in the bottom $30 \%$ of the principal display panel if that declaration satisfies the other requirements of this regulation.

(Amended 1980) 
11.17. DECORATIVE CONTAINERS. - The principal display panel of a cosmetic marketed in a "boudoir-type" container including decorative cosmetic containers of the "cartridge," "pill box," "compact," or "pencil" variety, and those with a capacity of $1 / 4$ ounce or less, may be a tear-away tag or tape affixed to the decorative container and bearing the mandatory label (Amended 1980) information as required by this regulation.

11.18. COMBINATION PACKAGES. - Combination packages are exempt from the requirements in this regulation for

(a) Location (see subsection 8.1.1.),

(b) Free area (see subsection 8.1.4.), and

(c) Minimum Height of Numbers and Letters (see subsection 8.2.1.).

11.19. MARGARINE. - Margarine in 1-pound rectangular packages, except for packages containing whipped or soft margarine or packages containing more than four sticks, shall be exempt from the requirement in this regulation for location (see subsection 8.1 .1$. ) of the net quantity declaration, and shall be exempt from the requirement for a dual quantity declaration (see subsection 6.7.2.).

(Amended 1980)

11.20. CORN FLOUR AND CORN MEAL. - Corn flour and corn meal packaged in conventional 5-, 10-, 25-, 50-, and 100-pound bags shall be exempt from the requirement in this regulation for location (see subsection 8.1.1.) of the net quantity declaration.

(Amended 1978, 1980)

11.21. PRESCRIPTION AND INSULIN-CONTAINING DRUGS. Prescription and insulin-containing drugs subject to the provisions of Section 503(b) (1) or 506 of the Federal Food, Drug, and Cosmetic Act shall be exempt from the provisions of this regulation.

11.22. CAMERA FILM. - Camera film packaged and labeled for retail sale is exempt from the net quantity statement requirements of this regulation that specify how measurement of commodities should be expressed; Provided that

(a) The net quantity of contents on packages of movie film and bulk still film is expressed in terms of the number of linear meters or feet of usable film contained therein. 
(b) The net quantity of contents on packages of movie film is expressed in terms of the running time of the exposed film for that portion of film that is of entertainment value.

"Entertainment value" is defined as that portion of a film that commences with the first frame of sound or picture, whichever comes first after the countdown sequence and ends with either: (a) the last frame of credits; or (b) the last frame of the phrase "The End", or (c) the end of sound whichever is last.

(Added 1976, amended 1979)

(c) The net quantity of contents on packages of still film is expressed in terms of the number of exposures the contents will provide. The length and width measurements of the individual exposures, expressed in millimeters or inches, are authorized as an optional statement. (Example: "36 exposures, 36 millimeters $x 24$ millimeters" or "12 exposures, $2-1 / 4$ inches $x \quad 2-1 / 4$ inches")

11.23. PAINTS AND KINDRED PRODUCTS. -

(a) Paints, varnishes, lacquers, thinners, removers, oils, resins, and solvents, when packed in 1-liquid-pint and 1-liquid-quart units shall be exempt from the dual quantity declaration requirements of subsection 6.7.3.

(b) Tint base paint may be labeled on the principal display panel, in terms of a quart or a gallon including the addition of colorant selected by the purchaser, provided that the system employed ensures that the purchaser always obtains a quart or a gallon; and further provided that in conjunction with the required quantity statement on the principal display panel, a statement indicating that the tint base paint is not to be sold without the addition of colorant is presented; and further provided that the contents of the container, before the addition of colorant, is stated in fluid ounces elsewhere on the label.

Wherever the above conditions cannot be met, containers of tint base paint must be labeled with a statement of the actual net contents prior to the addition of colorant in full accord with all the requirements of this regulation.

(Added 1972, amended 1980)

11.24. AUTOMOTIVE COOLING SYSTEM ANTIFREEZE. -Antifreeze, when packed in 1-liquid-quart units, in metal or plastic containers, shall be exempt from the dual quantity declaration requirements of subsection 6.7 .3 . 
11.25. MOTOR OILS. - Motor oils, when packed in 1-liquid-quart units, shall be exempt from the dual quantity declaration requirements of subsection 6.7.3. Additionally, motor oil in 1-liquid-quart, 1-gallon, 1-1/4-gallon, 2-gallon, and 2-1/2-gallon units, bearing the principal display panel on the body of the container, is exempt from the requirements of SECTION 3. DECLARATION OF IDENTITY: CONSUMER PACKAGE, to the extent that the Society of Automotive Engineers (SAE) viscosity number is required to appear on the principal display panel, provided the SAE viscosity number appears on the can lid and is expressed in letters and numerals in type size of at least 6 millimeters or $1 / 4$ inch.

(Amended 1974, 1980)

11.26. PILLOWS, CUSHIONS, COMFORTERS, MATTRESS PADS, SLEEPING BAGS, AND SIMILAR PRODUCTS. -- Those products, including pillows, cushions, comforters, mattress pads, and sleeping bags, that bear a permanent label as designated by the Association of Bedding and Furniture Law Officials or by the California Bureau of Home Furnishings shall be exempt from the requirements for location (Section 8.1.1.), size of letters or numbers (Section 8.2.1. and 8.2.2.), free area (Section 8.1.4.), and the declarations of identity and responsibility (Sections 3.1. and 5.); Provided, that declarations of identity, quantity, and responsibility are presented on a permanently attached label and satisfy the other requirements of this Regulation, and further provided that the information on such permanently attached label be fully observable to the (Added 1973) purchaser.

11.27. COMMODITIES VARIABLE WEIGHTS AND SIZES. -Individual packaged commodities put up in variable weights and sizes for sale intact, and intended to be weighed and marked with the correct quantity statement prior to or at the point of retail sale, are exempt from the requirements of SECTION 6. DECLARATION OF QUANTITY: CONSUMER PACKAGES, while moving in commerce and while held for sale prior to weighing and marking; Provided, that the outside container (Added 1973) bears a label declaration of the total net weight.

11.28. PACKAGED COMMODITIES SOLD BY COUNT. - When a packaged consumer commodity is properly measured in terms of count only, or in terms of count and some other appropriate unit, and the individual units are fully visible to the purchaser, such packages shall be labeled in full accord with this Regulation except that those containing six or less (Added 1973) items need not include a statement of count. 
11.29. FISHING LINES AND REELS. - Packaged fishing lines and reels are exempt from the dual quantity declaration requirements of Section 6.7.6. (a); Provided, that length of line or capacity of reel as appropriate is presented in terms of meters or yards in full accord with all other requirements of this Regulation.

(Added 1973)

\section{SECTION 12. VARIATIONS TO BE ALLOWED}

\subsection{PACKAGING VARIATIONS. -}

12.1.1. VARIATIONS FROM DECLARED NET QUANTITY. --Variations from the declared net weight, measure, or count shall be permitted when caused by unavoidable deviations in weighing, measuring, or counting the contents of individual packages that occur in good packaging practice, but such variations shall not be permitted to such extent that the average of the quantities in the packages of a particular commodity, or a lot of the commodity that is kept, offered, or exposed for sale, or sold, is below the quantity stated, and no unreasonable shortage in any package shall be permitted, even though overages in other packages in the same shipment, delivery, or lot compensate for such shortage. Variations above the declared quantity shall not be unreasonably large.

12.1.2. VARIATIONS RESULTING FROM EXPOSURE. -Variations from the declared weight or measure shall be permitted when caused by ordinary and customary exposure to conditions that normally occur in good distribution practice and that unavoidably result in change of weight or maasure, but only after the commodity is introduced into intrastate commerce: Provided, that the phrase "introduced into intrastate commerce" as used in this paragraph shall be construed to define the time and the place at which the first sale and delivery of a package is made within the State, the delivery being either

(a) directly to the purchaser or to his agent, or

(b) to a common carrier for shipment to the purchaser, and this paragraph shall be construed as requiring that, so long as a shipment, delivery, or lot of packages of a particular commodity remains in the possession or under the control of the packager or the person who introduces the package into intrastate commerce, exposure variations shall not be permitted. 
12.2. MAGNITUDE OF PERMITTED VARIATIONS. - The magnitude of variations permitted under Sections 12., 12.1., 12.1.1., and 12.1.2. of this regulation shall be those expressly set forth in this regulation and those contained in the procedures and tables of National Bureau of Standards Handbook 67, "Checking Prepackaged Commodities" or National Bureau of Standards Handbook 133, "Checking the Net Contents of Packaged Goods." (Amended 1976, 1980, 1984)

\section{SECTION 13. RETAIL SALE PRICE REPRESENTATIONS}

\section{1. "CENTS-OFF" REPRESENTATIONS. -}

(a) The term "cents-off representation" means any printed matter consisting of the words "cents-off" or words of similar import (bonus offer, 2 for 1 sale, $1 \notin$ sale, etc.), placed upon any consumer package or placed upon any label affixed or adjacent to such package, stating or representing by implication that it is being of fered for sale at a price lower than the ordinary and customary retail sale price.

(Amended 1982)

(b) Except as set forth in Section 13.2., the packager or labeler of a consumer commodity shall not have imprinted thereon a "cents-of f" representation unless:

The commodity has been sold at an ordinary and customary price in the most recent and regular course of business where the "cents-off" promotion is made.

(2) The commodity so labeled is sold at a reduction from the ordinary and customary price, which reduction is at least equal to the amount of the

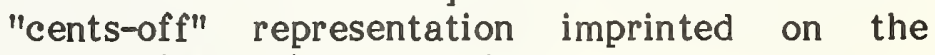
commodity package or label.

(3) Each "cents-off" representation imprinted on the package or label is limited to a phrase that reflects that the price marked by the retailer represents the savings in the amount of the "cents-off" the retailer's regular price; e.g., "Price Marked is Cents Off the Regular Price," "Price Marked is $\$$ off the Regular Price of This Package"; provided, the package or label may in addition bear in the usual pricing spot a form reflecting a space for the regular price, the represented "cents-off", and a space for the price to be paid by the consumer. 
(4) The commodity at retail presents the regular price, designated as the "regular price," clearly and conspicuously on the package or label of the commodity or ca a sign, placard, or shelf-marker placed in a position contiguous to the retail display of the "cents-off" marked commodity.

(5) a. Not more than three "cents-off" promotions of any single size commodity may be initiated in the same trade area within a 12-month period;

b. At least 30 days must lapse between "cents-off" promotions of any particular size packaged or labeled commodity in a specific trade area; and

c. Any single size commodity so labeled may not be sold in a trade area for a duration in excess of 6 months within any 12 -month period.

(6) Sales of any single size commodity so labeled in a trade area do not exceed in volume fifty percent $(50 \%)$ of the total volume of sales of such size commodity in the same trade area during any 12-month period. The 12-month period may be the calendar, fiscal, or market year provided the identical period is applied in this subparagraph and subparagraph (5) of this paragraph. Volume limits may be calculated on the basis of projections for the current year but shall not exceed 50 percent of the sales for the preceding year in the event actual sales are less than the projection for the current year.

(c) No "cents-off" promotion shall be made available in any circumstances where it is known or there is reason to know that it will be used as an instrumentality for deception or for frustration of value comparison; e.g., where the retailer charges a price that does not fully pass on to the consumers the represented price reduction or where the retailer fails to display the regular price in the display area of the "cents-off" marked product.

(d) The sponsor of a "cents-off" promotion shall prepare and maintain invoices or other records showing compliance with this section. The invoices or other records required by this section shall be open to inspection and shall be retained for a period of one year subsequent to the end of the year (calendar, fiscal, or market) in which the "cents-off" promotion occurs.

(Added 1972) 


\subsection{INTRODUCTORY OFFERS. -}

(a) The term "introductory offer" means any printed matter consisting of the words "introductory offer" or words of similar import, placed upon a package containing any new commodity or upon any label affixed or adjacent to such new commodity, stating or representing by implication that such new commodity is offered for retail sale at a price lower than the anticipated ordinary and customary retail sale price.

(b) The packager or labeler of a consumer commodity may not have imprinted thereon an introductory offer unless:

(1) The product contained in the package is new, has been changed in a functionally significant and substantial respect, or is being introduced into a trade area for the first time.

(2) Each offer on a package or label is clearly and conspicuously qualified

(3) No commodity so labeled is sold in a trade area for duration in excess of 6 months.

(4) At the time of making the introductory offer promotion, the offerer intends in good faith to offer the commodity, alone, at the anticipated ordinary and customary price for a reasonably substantial period of time following the duration of the introductory offer promotion.

(c) The packager or labeler of a consumer commodity shall not have imprinted thereon an introductory offer in the form of a "cents-off" representation unless, in addition to the requirements in paragraph (b) of this section:

(1) The package or label clearly and conspicuously and in immediate conjunction with the phrase "Introductory Offer" bears the phrase " cents-off the after-introductory offer price."

(2) The commodity so labeled is sold at a reduction from the anticipated ordinary customary price, which reduction is at least equal to the amount of the reduction from the after-introductory offer price representation on the commodity package or label. 
(d) No introductory offer with a "cents-off" representation shall be made available in any circumstance where it is known or there is reason to know that it will be used as an instrumentality for deception or for frustration of value comparison; e.g., where the retailer charges a price that does not fully pass on to consumers the represented price reduction.

(e) The sponsor of an introductory offer shall prepare and maintain invoices or other records showing compliance with this section. The invoices or other records required by this section shall be open to inspection and shall be retained for a period of one year subsequent to the

(Added 1972) period of the introductory offer.

\subsection{ECONOMY SIZE. -}

(a) The term "economy size" means any printed matter consisting of the words "economy size," "economy pack," "budget pack," "bargain size," "value size," or words of similar import placed upon any package containing any consumer commodity or placed upon any label affixed or adjacent to such commodity, stating or representing directly or by implication that a retail sale price advantage is accorded the purchaser thereof by reason of the size of that package or the quantity of its contents.

(b) The packager or labeler of a consumer commodity may not have imprinted thereon an "economy" size representation unless:

(1) At the same time the same brand of the commodity is offered in at least one other packaged size or labeled form.

(2) Only one packaged or labeled form of that brand of commodity labeled with an "economy size" representation is offered.

The commodity labeled with an "economy size" representation is sold at a price per unit of weight, volume, measure, or count that is substantially reduced (i.e., at least 5 percent) from the actual price of all other packaged or labeled units of the same brand of that commodity offered simultaneously.

(c) No "economy size" package shall be made available in any circumstances where it is known that it will be used as an instrumentality for deception; e.g., where the retailer charges a price that does not pass on to the consumer the substantial reduction in cost per unit initially granted. 
(d) The sponsor of an "economy size" package shall prepare and maintain invoices or other records showing compliance with paragraph (b) of this section. The invoices or other records required by this section shall be

(Added 1972) open to inspection and shall be retained for one year.

\section{SECTION 14. REVOCATION OF CONFLICTING REGULATIONS}

All provisions of all orders and regulations heretofore issued on this same subject that are contrary to or inconsistent with the provisions of this regulation, and specifically are hereby revoked.

\section{SECTION 15. EFFECTIVE DATE}

This regulation shall become effective on

Given under my hand and the seal of my office in the City of on this day of

SIGNED 


\section{APPENDIX: Metric/Inch-Pound Conversion Factors}

Length

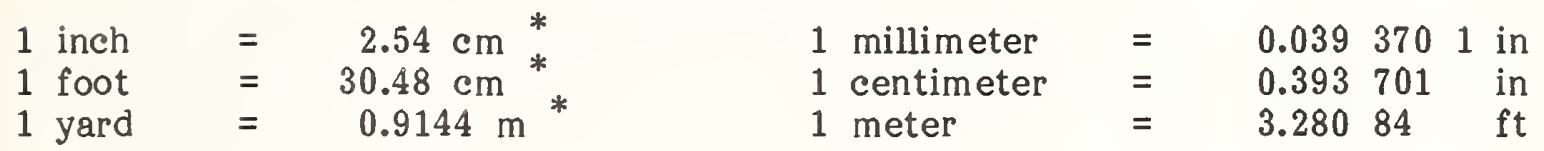

\section{$\underline{\text { Area }}$}

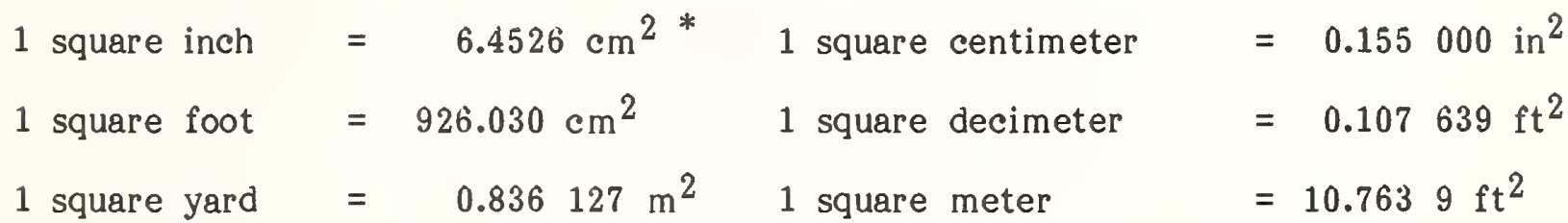

Volume or Capacity

$\begin{array}{rlrl}1 \text { cubic inch } & =16.3871 \mathrm{~cm}^{3} & 1 \text { cubic centimeter } & =0.0610237 \mathrm{in}^{3} \\ 1 \text { cubic foot } & =0.0283168 \mathrm{~m}^{3} & 1 \text { cubic decimeter } & =0.0353147 \mathrm{ft}^{3} \\ 1 \text { cubic yard } & =0.764555 \mathrm{~m}^{3} & 1 \text { cubic meter } & =35.3147 \mathrm{ft}^{3}\end{array}$

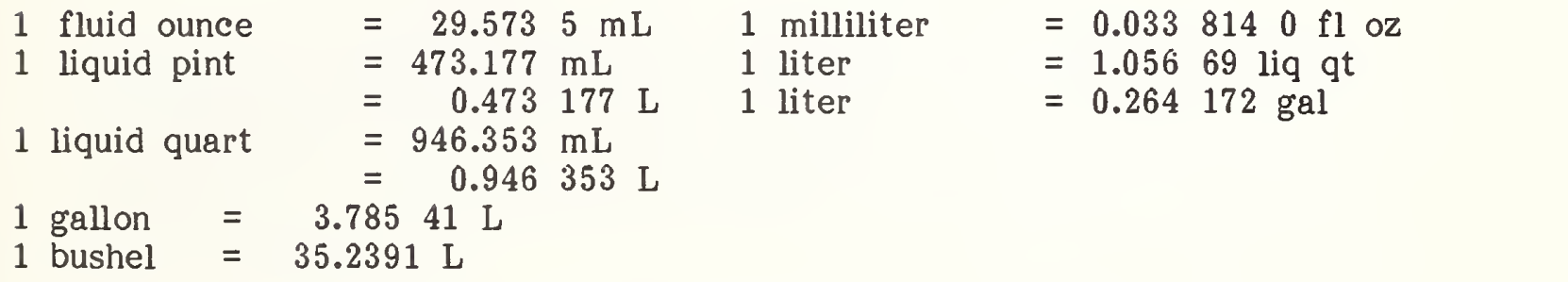

Weight (mass)

$\begin{array}{rlrll}1 \text { ounce } & =28.3495 \mathrm{~g} & 1 \text { milligram } & =0.000 & 0352740 \mathrm{oz} \\ 1 \text { pound } & 453.592 \mathrm{~g} & & =0.0154324 \text { grain } \\ & =0.453 \mathrm{~kg} & 1 \text { gram } & =0.0352740 \mathrm{oz}\end{array}$

Temperature

$\mathrm{t}_{\mathrm{O}}=\frac{5}{9}\left(\mathrm{t}_{\mathrm{O}_{\mathrm{F}}}{ }^{-32}\right)^{*} \quad \mathrm{t}_{\mathrm{O}}=1.8 \mathrm{t}_{\mathrm{C}}+32 *$

NOTE: These conversion factors are given to six significant digits in the event such accuracy is necessary. See Section 6.11.3. Rounding for information about the use of conversion factors in labeling.

\footnotetext{
*Exactly
} 



\section{UNIFORM REGULATION FOR THE METHOD OF SALE OF COMMODITIES 1979 \\ as adopted by \\ The National Conference on Weights and Measures ${ }^{1}$}

\section{BACKGROUND}

The National Conference on Weights and Measures has long been concerned with the proper units of measurement to be used in the sale of all commodities. This approach has gradually broadened to concerns of standardized package sizes and general identity of particular commodities. Requirements for individual products were at one time made a part of the Weights and Measures Law or were embodied in separate individual Model Regulations. In 1971 this "Model State Method of Sale of Commodities Regulation" was established (renamed in 1983); amendments have been adopted by the Conference almost annually since that time.

Sections with "added 1971 " dates refer to those sections that were originally incorporated in the Weights and Measures Law or in individual Model Regulations recommended by the NCWM. Subsequent dates reflect the actual amendment or addition dates.

The 1979 edition included for the first time requirements for items packaged in metric quantities as well as continuing to present requirements for inch-pound quantities. It should be stressed that nothing in this Regulation requires changing to the metric system of measurement. Metric values are given for the guidance of those wishing to adopt new metric quantities of the commodities governed by this Regulation.

This Regulation assimilates all of the actions periodically taken by the Conference with respect to certain food items, non-food items, and general method of sale concepts. Its format is such that it will permit the addition of individual items as need arises at the end of appropriate sections. Its adoption as a regulation by individual jurisdictions will eliminate the necessity for legislative considerations of necessary changes in the method of sale of particular commodities. Such items will be able to be handled through the normal regulation-making process.

\section{STATUS OF PROMULGATION}

The map on the following page shows the status of promulgation of the Uniform Regulation for the Method of Sale of Commodities.

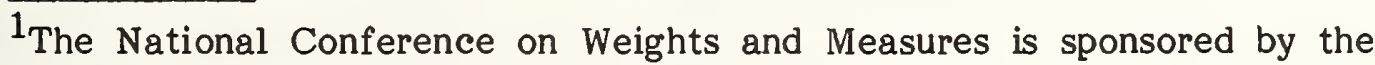
National Bureau of Standards in partial implementation of its statutory responsibility for "cooperation with the States in securing uniformity in weights and measures laws and methods of inspection." 


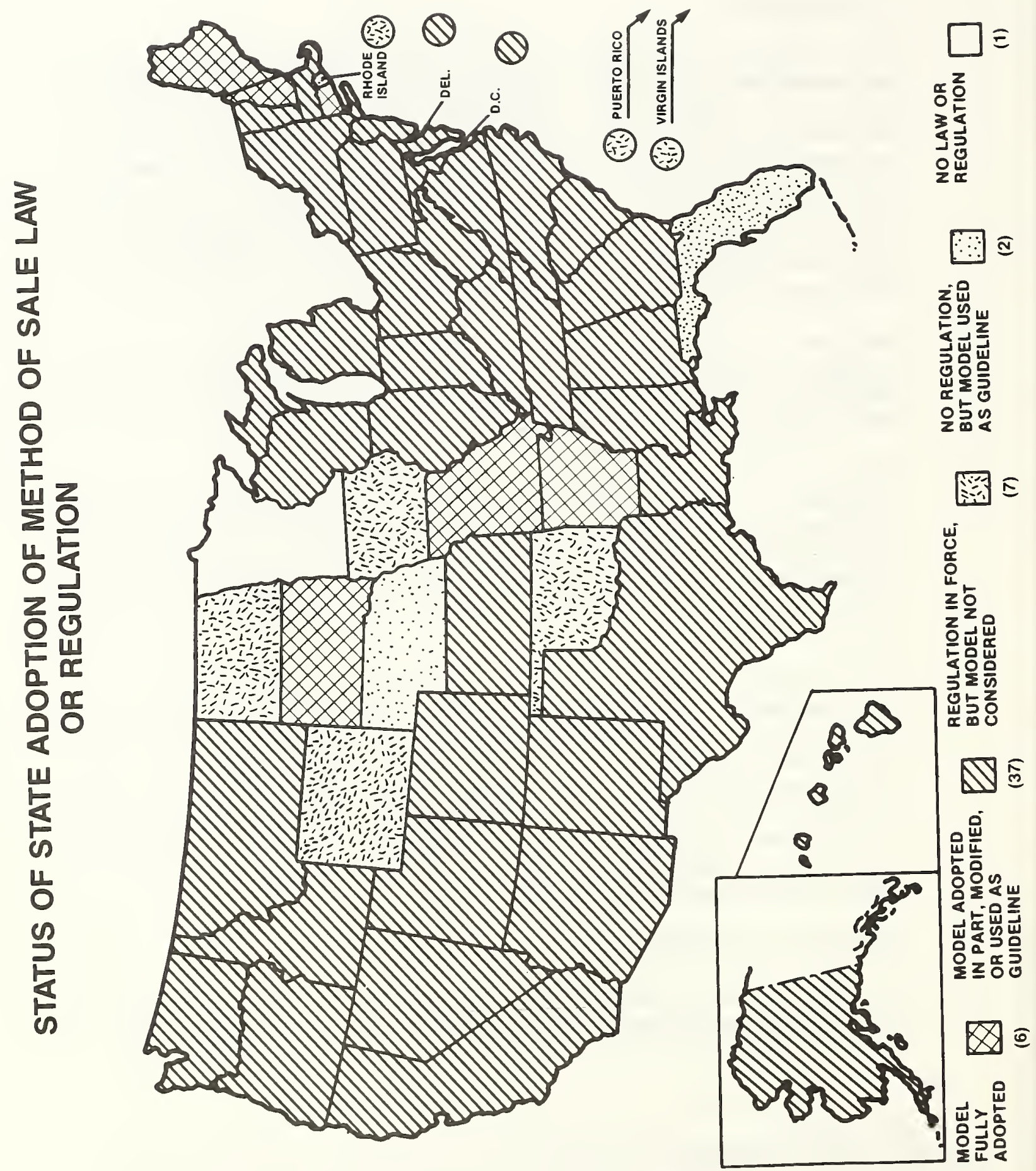




\section{TABLE OF CONTENTS}

1. FOOD PRODUCTS

IV -59

1.1. Berries and Small Fruits

IV -59

1.2. Bread

IV -59

1.3. Butter, Oleomargarine, and Margarine

IV-59

1.4. Flour, Corn Meal, and Hominy Grits

IV -60

1.5. Meat, Poultry, Fish and Seafood

IV-60

1.5.1. In Combination with

\section{Other Foods}

IV -60

1.5.2. Stuffed Fish, Seafood, Poultry,

1.5.3. Clams, Mussels, and Oysters

IV-60

IV -60

1.6. Fluid Milk Products IV-61

1.7. Other Milk Products

IV-61

1.7.1. Ice Cream and Similar Frozen Products

IV -62

1.8. Pickles

IV -62

1.9. Pricing of Bulk Food Commodities IV-62

1.10 Generic Terms for Meat Cuts IV-62

1.11 Sale of Meat by Carcass, Side or

Primal Cut IV-63

1.11.1. Prior to Delivery IV-63

1.11.2. At the Time of Delivery IV-63

1.11.3. Exemptions IV-64

1.11.4. Right of Cancellation IV-64

1.12 Ready-to-eat Food IV-64

2. NONFOOD PRODUCTS IV-65

2.1. Fence Wire Products IV 65

2.2. Coatings IV-65

2.3. Fireplace and Stove Wood IV-65

2.3.1. Definitions IV-65

2.3.1.1. Fireplace and

Stove Wood IV-65

2.3.1.2. Cord IV-65

2.3.1.3. Representation IV-65

2.3.2. Identity IV-65

2.3.3. Quantity IV-66

2.3.4. Prohibition of Terms IV-66

2.3.5. Delivery Ticket or Sales IV-66
Invoice

$\begin{array}{ll}\text { Invoice } & \text { IV-66 } \\ \text { Peat Moss } & \text { IV-66 }\end{array}$

$\begin{array}{lll}\text { 2.4. Peat and Peat Moss } & \text { IV-66 } \\ \text { 2.4.1. Declaration of Quantity } & \text { IV-67 }\end{array}$

2.4.2. Units IV-67

2.4.2.1. Weight IV-67

2.4.2.2. Cubic Measures IV-67

2.5. Prefabricated Utility Buildings IV-67 
2.6. Roofing and Roofing Material

IV -67

2.6.1. Definitions

2.6.1.1.

Square Meter

IV -68

2.6.1.2.

Square

IV -68

2.6.1.3.

Square Foot

IV -68

2.6.2. Declaration 2.6.2.1.

of Quantity

IV -68

IV -68

IV -68

2.7. Sealants

Common Fractions

IV -68

IV -69

2.8. Sod and Turf

Quantity Statement

IV -69

2.8.1. Application

IV -69

2.8.2.

Definitions

2.8.2.1.

Sod

2.8.2.2.

Turf

2.8.2.3.

Turf Plug

2.8.2.4.

Turf Sod

2.8.2.5.

2.8.3. Quantity

Turf Sprig

IV -69

IV -69

IV -69

IV -69

IV -69

IV -69

IV -69

IV-70

IV-70

2.9.1. Definitions

2.9.1.1. Dressed (Surfaced)

Lumber

IV-70

2.9.1.2.

Boards

2.9.1.3.

Timbers

IV-70

IV -70

2.9.1.4.

Dimension Lumber

IV-70

2.9.1.5.

Rough Lumber

IV-70

2.9.1.6.

Matched Lumber

2.9.1.7.

Patterned Lumber

IV -70

2.9.1.8.

Shiplapped Lumber

IV-71

IV-71

2.9.1.9.

Grade

2.9.1.10

Species

IV -71

2.9.1.11

Species Group

2.9.1.12

Representation

2.9.1.13

Minimum Dressed

IV-71

IV-71

IV-71

Sizes (Width and

2.9.2. Identity

Thickness)

IV -71

IV-71

IV-71

2.9.3. Quantity

IV-72

IV -73

IV-73

IV -73

IV-73

IV-73

IV-74

IV-74

IV-74

IV-74

IV -74 
2.13 Insulation

IV-75

2.13.1 Packaged Loose Fill Insulation Except Cellulose IV-75

2.13.2 Packaged Loose Fill

Cellulose Insulation

IV -75

2.13.3 Batt and Blanket Insulation

IV -75

2.13.4 Installed Insulation

IV-75

IV-76

2.14 Solid Fuel Products

2.15 Liquified Petroleum Gas Cylinder Tare Weights

2.15.1 Allowable Difference

IV-76

IV-76

2.15.2 Average Requirement

IV-76

IV-76

IV-76

2.16.1 Definition

2.16.1.1 Precious Metals

IV -76

IV-76

2.16.2 Quantity

IV-76

IV-77

2.18 Kerosene

IV -77

2.19 Gasoline - Alcohol Blends

IV -77

2.19.1 Method of Retail Sale

2.19.2 Documentation in Wholesale Transactions

2.20 Liquefied Petroleum Gas

IV-77

IV -77

IV-78

IV-78

3.1. Presentation of Price

3.2. Allowable Differences: Combination Quantity Declarations

IV-78

3.2.1. Beverageware: Pressed

and Blown Tumblers and

Stemware

IV-78

IV -78

3.3. Machine Vended Commodities

IV-79

3.4.1. Tare Weights and Date of Weighing

IV-79

IV-79

3.4.2. Allowable Difference

3.4.3. Verification or Change of

Stenciled Weights

IV-80

3.4.4. Reweighing and Restenciling

IV -80

4. REVOCATION OF CONFLICTING REGULATIONS IV-80

5. EFFECTIVE DATE IV-80 



\section{SECTION 1. FOOD PRODUCTS}

1.1. BERRIES AND SMALL FRUITS. - Shall be of fered and exposed for sale and sold by weight, or by volume in open measure containers having capacities per subsection 1.1(a) or subsection 1.1(b) and when sold by volume, the containers shall be deemed not to be packages for labeling purposes.

(a) Inch-Pound Capacities - $1 / 2$ dry pint, 1 dry pint, or 1 dry quart.

(b) Metric Capacities - 250 milliliters, 500 milliliters, or 1 liter.

(Added 1979, amended 1985)

(Added 1971, amended 1979, 1985)

1.2. BREAD. - Each loaf and each unit of a twin or multiple loaf made or procured for sale, kept, offered, exposed for sale, or sold, whether or not wrapped or sliced, shall have a weight per subsection 1.2(a) or subsection 1.2(b); Provided, that the provisions of this section shall not apply to biscuits, buns, or rolls of inch-pound sizes 4 ounces or less or of metric sizes 100 grams or less or to "stale bread" sold and expressly represented at the time of sale as such, and when so sold, the wrappers shall be deemed not to be packages for labeling purposes.

(a) Inch-Pound Weights $-1 / 2$ pound, 1 pound, 1-1/2 pounds, or a multiple of 1 pound.

(b) Metric Weights - 250 grams, 500 grams, 750 grams, or a multiple of 500 grams.

(Added 1979, amended 1985)

(Added 1971, amended 1979, 1980, 1985)

1.3. BUTTER, OLEOMARGARINE, ${ }^{2}$ MARGARINE, BUTTER-LIKE AND/OR MARGARINE-LIKE SPREADS - Shall be offered and exposed for sale and sold by weight per subsection 1.3(a) or subsection 1.3(b).

(a) Inch-Pound Weights - $1 / 4$ pound, $1 / 2$ pound, 1 pound, $11 / 2$ pounds, or a multiple of 1 pound. (Amended 1986)

1 Packages subject to the Federal Fair Packaging and Labeling Act must be labeled in inch-pound units of measure. Metric units may also be declared on the principal display panel and may even appear first. (Added 1982)

2 Oleomargine and margarine are not permitted in multiples of one pound, 500 grams, or multiples of 500 grams because Section $407(\mathrm{~b})(2)$ of the Federal Food, Drug, and Cosmetic Act prohibits margarine and oleomargarine packaged in sizes greater than one pound. (Added 1982) 
(b) Metric Weights - 125 grams, 250 grams, 500 grams, 750 grams, or a multiple of 500 grams.

(Added 1979, amended 1986)

"Butter-like and/or Margarine-like spreads" are those products that meet the Federal Standard of Identity for butter or margarine and oleomargarine except that they contain less than 80 percent fat and may contain other safe and suitable ingredients.

(Added 1985, amended 1986)

(Added 1971, amended 1979, 1985, 1986)

1.4. FLOUR, CORN MEAL, AND HOMINY GRITS. - Wheat flour, whole wheat flour, graham flour, self-rising wheat flour, phosphated wheat flour, bromated flour, corn flour, corn meal, and hominy grits, whether enriched or not, shall be packaged, kept, offered, or exposed for sale, or sold only in weights per subsection 1.4(a) or subsection 1.4(b); Provided that inch-pound sizes less than 2 pounds or more than 100 pounds and that metric sizes less than 1 kilogram or more than 50 kilograms shall be permitted.

(a) Inch-Pound Weights - 2, 5, 10, 25, 50, or 100 pounds.

(b) Metric Weights $-1,2.5,5,10,25$, or 50 kilograms. (Added 1979, amended 1985)

(Added 1971, amended 1979, 1985)

1.5. MEAT, POULTRY, FISH, AND SEAFOOD. ${ }^{1}$ - Shall be sold by weight, except that shellfish not included under Section 1.5.3. may be sold by weight, measure, and/or count.

1.5.1. IN COMBINATION WITH OTHER FOODS. - When meat, poultry, fish, or seafood is combined with some other food element to form a distinctive food product, the quantity representation may be in terms of the total weight of the product or combination, and a quantity representation need not be made for each element.

1.5.2. STUFFED FISH, SEAFOOD, POULTRY, OR MEAT PRODUCTS. - In the case of ready-to-cook stuffed fish, seafood, poultry, or meat products, the label must show the total net weight of the stuffed fish, seafood, poultry, or meat product and the minimum net weight of the fish, seafood, poultry or meat in the product excluding the fish, seafood, meat, or poultry that may be part of the stuffing.

1.5.3. CLAMS, MUSSELS, AND OYSTERS

1.5.3.1. Processed clams, mussels, or oysters on the half shell (fresh or frozen) shall be sold by net weight excluding the weight of the shell.

1 See Section 1.12. for additional requirements for ready-to-eat food. 
1.5.3.2. Canned (heat-processed) mussels, clams, or oysters shall be sold by net weight. A maximum of 41 percent free liquid by weight is permitted for canned oysters.

1.5.3.3. Fresh oysters, clams, or mussels removed from the shell and placed in a container shall be sold by fluid volume. A maximum of 15 percent free liquid by weight is permitted.

1.5.3.4. Whole clams, oysters, or mussels in the shell (fresh or frozen) shall be sold by weight (including the weight of the shell, but not including the liquid or ice packed with them), dry measure (e.g. bushel), and/or count. In addition, size

(Added 1986) designations may be provided.

(Added 1971, amended 1982, 1985, 1986)

1.6. FLUID MILK PRODUCTS. - All fluid milk products, including but not limited to milk, lowfat milk, skim milk, cultured milks, and cream shall be packaged for retail sale only in volumes per subsection 1.6(a), or subsection 1.6(b); Provided, that inch-pound sizes less than 1 gill and metric sizes less than 100 milliliters shall be permitted.

(a) Inch-Pound Volumes - 1 gill, $1 / 2$ liquid pint, 10 fluid ounces, 1 liquid pint, 1 liquid quart, $1 / 2$ gallon, 1 gallon, 1-1/2 gallons, 2 gallons, $2-1 / 2$ gallons, or multiples of 1 gallon.

(b) Metric Volumes - 125 milliliters, 250 milliliters, 500 milliliters, 1 liter, or multiples of 1 liter.

(Added 1979, amended 1985)

(Added 1971, amended 1979, 1982, 1985)

1.7. OTHER MILK PRODUCTS. - Cottage cheese, cottage cheese products, and other milk products that are solid, semi-solid, viscous, or a mixture of solid and liquid, as defined in the Pasteurized Milk Ordinance of the U.S. Public Health Service, as amended in 1965, shall be sold in terms of weight; Provided, that cottage cheese, cottage cheese products, sour cream, and yogurt shall be packaged for retail sale only in weights per subsection $1.7(a)$ or subsection $1.7(b)$ and Provided further, that multipack or single serving inch-pound sizes of 6 ounces or less shall be sold only in whole ounce increments, and that metric sizes of 200 grams or less shall be sold only in 25 -gram increments. 
(a) Inch-Pound Weights - 8, 12, 16, 24, 32, 64, 80, and 128 ounces avoirdupois.

(b) Metric Weights - 250, 375, 5n0, 750 grams; 1, 2, and 4 kilograms.

(Added 1979)

(Added 1971, amended 1975, 1976, 1979, 1982, 1985)

1.7.1. FACTORY PACKAGED AND HAND PACKED ICE CREAM AND SIMILAR FROZEN PRODUCTS. - Ice cream, ice milk, frozen yogurt, and similar products shall be kept, offered, or exposed for sale, or sold in terms of fluid volume.

(Added 1979, amended 1985)

1.8. PICKLES. - The declaration of net quantity of contents on pickles and pickle products, including relishes but excluding one or two whole pickles in a transparent wrapping, which may be declared by count, shall be expressed in terms of liquid measure. (Added 1971)

Sales of pickles from bulk may be by count.

1.9. PRICING OF BULK FOOD COMMODITIES. - Bulk food commodities or food commodities not in package form and sold by weight shall be priced in terms of whole units of weight and not in common or decimal fractions.

(Added 1976, amended 1985)

1.10. GENERIC TERMS FOR MEAT CUTS. - A declaration of identity for meat cuts shall be limited to generic terms, such as those listed in the Uniform Retail Meat Identity Standards.

The following abbreviations may be used:

(Added 1976)

$\begin{array}{llll}\text { BAR B Q } & \text { Barbecue } & \text { POT-RST } & \text { Pot Roast } \\ \text { BI } & \text { Bone In } & \text { RND } & \text { Round } \\ \text { BNLS } & \text { Boneless } & \text { RST } & \text { Roast } \\ \text { DBLE } & \text { Double } & \text { SHLDR } & \text { Shoulder } \\ \text { LGE } & \text { Large } & \text { SQ } & \text { Square } \\ \text { N. Y. (NY) } & \text { New York } & \text { STK } & \text { Steak } \\ \text { PK } & \text { pork } & \text { TRMD } & \text { Trimmed }\end{array}$

1 For prepackaged measure-containers, intended to be used only once, to determine in advance of sale the quantity of a commodity such as ice cream, ice milk, or sherbet on the basis of liquid measure, the size restrictions noted in Section 4.45. MEASURE-CONTAINERS of National Bureau of Standards Handbook 44, "Specifications, Tolerances, and Other Technical Requirement for Weighing and Measuring Devices" apply. Handbook 44 requires capacities of such measure containers to be a multiple of or a binary submultiple of a quart or liter, except than any capacity less than $1 / 2$ liquid pint or $1 / 4$ liter is permitted. (Added 1986) 
1.11. SALE OF MEAT BY CARCASS, SIDE, OR PRIMAL CUT. -

The seller of a carcass, side, quarter, or primal cut on a gross or hanging weight basis shall proviue to the buyer a written statement giving the following information at the times indicated: (Amended 1985)

\subsubsection{PRIOR TO DELIVERY}

(a) The name and address of the seller (firm);

(b) the date of the contract;

(c) the name and address of the buyer;

(d) the total net weight (hanging weight) of the carcass, side, or primal cut prior to cutting or processing;

(e) the USDA quality grade and yield grade of the meat to be supplied if so represented;

(f) the price per pound for each species (not including any inducements) and the total price of the sale order;

(g) the estimated cutting loss on the order in terms of percentage and weight (e.g., "40 percent, $160 \mathrm{lb")}$;

(h) a list by name and estimated count of each cut to be derived from each primal source;

(i) additional costs, listed separately, for cutting, wrapping, freezing, and finance charges, if any; and

(Added 1985)

(j) that the buyer may keep the cutting loss.

\subsubsection{AT THE TIME OF DELIVERY}

(a) The name and address of the buyer and seller;

(b) the date of delivery;

(c) the total net weight of the meat delivered;

(d) a list, by name and count, of each cut derived from each primal cut; and 
(e) a separate indication of the quantity of any meat or other commodity(s) received by the purchaser as an inducement in connection with the purchase of (Added 1985) the carcass, side, or primal cut.

1.11.3. EXEMPTIONS. - This subsection shall not apply to the sale of any carcass, side, quarter, or primal cut of meat that individually or collectively has a gross or hanging weight of fifty pounds or less. (Added 1985)

1.11.4. RIGHT OF CANCELLATION. - The buyer shall have the right to cancel any carcass, side, quarter, or primal cut meat contract until midnight of the third business day after the day on which the buyer executed the contract or after the day on which the seller provided the buyer with a fully executed copy of the contract, whichever is later. (Added 1985)

(Added 1977, amended 1980, 1985)

1.12. READY-TO-EAT FOOD. - The following may be sold by weight, measure, or count:

(a) items sold for consumption on the premises;

(b) items sold as one of three or more different elements, excluding condiments, comprising a ready-to-eat meal sold as a unit, for consumption elsewhere than on the premises where sold;

(c) ready-to-eat chicken parts cooked on the premises but not packaged in advance of sale;

(d) sandwiches when offered or exposed for sale on the premises where packed or produced and not intended for

(Added 1985) resale. 


\section{SECTION 2. NONFOOD PRODUCTS. ${ }^{1}$}

2.1. FENCE WIRE PRODUCTS. - Rolls of fence wire products shall be sold by

(a) Gauge of wire.

(b) Height in terms of inches or centimeters, if applicable.

(c) Length in terms of rods, meters or feet.

(Added 1979)

2.2. COATINGS. - Asphalt paints, coatings, and plastics shall be sold (Added 1971) in terms of liquid measure.

2.3. FIREPLACE AND STOVE WOOD. - For the purpose of this regulation, this section shall apply to the sale of all wood, natural and processed, for use as fuel.

\subsubsection{DEFINITIONS. -}

2.3.1.1. FIREPLACE AND STOVE WOOD. - Any kindling logs, boards, timbers, or other wood, split or not split, advertised, offered for sale, or sold as fuel.

2.3.1.2. CORD. - The amount of wood that is contained in a space of 128 cubic feet, when the wood is ranked and well stowed. For the purpose of this regulation, "ranked and well stowed" shall be construed to mean that pieces of wood are placed in a line or row, with individual pieces touching and parallel to each other, and stacked in a compact manner.

2.3.1.3. REPRESENTATION. - A "representation" shall be construed to mean any advertisement, offering, invoice, or the like that pertains to the sale of fireplace or stove wood.

2.3.2. IDENTITY. - A representation may include a declaration of identity that indicates the species group (Example: 50\% hickory, 50\% miscellaneous softwood). Such a representation shall indicate, within ten percent accuracy, the percentages of each group.

1 Packages subject to the Federal Fair Packaging and Labeling Act must be labeled in inch-pound units of measure. Metric units may also be declared on the principal display panel and may be even appear first.

(Added 1982) 
2.3.3. QUANTITY. - Wood, of any type, for use as fuel shall be advertised, offered for sale, and sold only by measure, using the term "cord" and fractional parts of a cord, or the cubic meter; except that wood, natural or processed, offered for sale in packaged form shall display the quantity in terms of cubic feet, to include fractions of cubic feet; or cubic meters, to include decimal fractions of cubic meters. A single log shall be sold by weight, and packages of such individual logs containing less than 4 cubic feet $(1 / 32$ cord) if sold by inch-pound volume, or less than one-tenth cubic meter if sold by (Amended 1976) metric volume, may be sold by net weight plus count.

2.3.4. PROHIBITION OF TERMS. - The terms "face cord," "rack," "pile," "truckload," or terms of similar import shall not be used when advertising, offering for sale, or selling wood for use as fuel.

2.3.5. DELIVERY TICKET OR SALES INVOICE. - A delivery ticket or sales invoice shall be presented by the seller to the purchaser whenever any nonpackaged fireplace or stove wood is sold. The delivery ticket or sales invoice shall contain at least the following information:

(a) the name and address of the vendor;

(b) the name and address of the purchaser;

(c) the date delivered;

(d) the quantity delivered and the quantity upon which the price is based, if this differs from the delivered quantity;

(e) the price of the amount delivered;

(f) the identity in the most descriptive terms commercially practicable, including any quality representation made in connection with the sale.

(Added 1975)

2.4. PEAT AND PEAT MOSS. - Applies only with respect to organic matter of geological origin, excluding coal and lignite, originating principally from dead vegetative remains through the agency of water in the absence of air and occurring in a bog, swampland, or marsh, and containing an ash content not exceeding 25 percent on a dry-weight basis (dried in an oven at $105^{\circ} \mathrm{C}\left(221{ }^{\circ} \mathrm{F}\right)$ until no further weight loss can be determined). 
2.4.1. DECLARATION OF QUANTITY. -- The declaration of quantity of peat and peat moss shall be expressed in weight units or in cubic-measure units.

2.4.2. UNITS. -

2.4.2.1. WEIGHT. - Peat and peat moss sold in terms of weight shall be offered and exposed for sale only in pounds and/or kilograms.

2.4.2.2. CUBIC MEASURE - Peat and peat moss sold in terms of cubic measures shall be offered and exposed for sale only in cubic feet and/or liters. If the commodity is labeled in terms of compressed cubic measurement, the quantity declaration shall represent the quantity in the compressed state and the quantity from which the final product was compressed (the latter declaration not exceeding the actual amount (Amended 1975, 1979, 1983) of material that can be recovered).

(Added 1971)

2.5. PREFABRICATED UTILITY BUILDINGS. -- These buildings shall be offered for retail sale on the basis of usable inside space as follows:

(a) length, measured from inside surface of wall panels at the base;

(b) width, measured from inside surface of wall panels at the base;

(c) height, measured from the base to the top of the shortest wall panel.

Inside dimensions in inch-pound units shall be declared to the nearest inch; inside dimensions in metric units shall be declared to the nearest 0.01 meter.

If total usable inside space is declared in a supplemental declaration, it shall be to the nearest cubic decimeter or cubic foot.

(Added 1975)

2.6. ROOFING AND ROOFING MATERIAL. -- Shall be sold either by the square, or by the square foot only if sold in inch-pound units, or by the square meter only if sold in metric units.

(Amended 1979) 


\subsubsection{DEFINITIONS. -}

2.6.1.1. SQUARE METER. - The term "square meter" shall mean the quantity of roofing or roofing material that, when applied according to the directions or instructions of the manufacturer, will cover one square (Added 1979) meter exclusive of side laps or side joints.

2.6.1.2. SQUARE. - The term "square" shall mean the quantity of roofing or roofing material that, when applied according to directions or instructions of the manufacturer, will cover an area of 100 square feet exclusive of side laps or side joints; Provided, that, in the case of roofing or roofing material of corrugated design, the side lap or side joint shall be one full corrugation.

2.6.1.3. SQUARE FOOT. - The term "square foot" shall mean the quantity of roofing or roofing material that, when applied according to the directions or instructions of the manufacturer, will cover one square foot (144 square inches) exclusive of side laps or side joints.

2.6.2. DECLARATION OF QUANTITY. - When the declaration of quantity on a package of roofing or roofing material contains the term "square," it shall include, plainly and conspicuously, a numerical definition of the term "square"; for example, "One square covers 100 square feet of roof area."

2.6.2.1

COMMON FRACTIONS. - The use of the common fraction one-third (1/3) is specifically authorized in the quantity statement of a package of roofing or roofing material when, and only when, used as the common fraction of the "square."

2.6.2.2. QUANTITY STATEMENT. - The primary declaration if in inch-pound units shall only be in terms of squares or square feet, and if in metric units shall only be in terms of square meters. There is no prohibition against the use of supplementary quantity declarations, such as shingle dimensions, but in no case shall the weight of the material be stated or implied. However, the use of numerical descriptions for rolls of felt (Amended 1979) roofing materiai may continue to be used. 
2.7. SEALANTS. - Calking compounds, glazing compounds, and putty shall be sold in terms of liquid measure, except that rope calk shall be sold by weight.

(Added 1971, amended 1981)

2.8. SOD AND TURF. -

2.8.1. APPLICATION. - For the purpose of this regulation this section shall apply to all sod, including turf sod, turf plugs, and turf sprigs.

2.8.2. DEFINITIONS. -

2.8.2.1. SOD. - Sod shall mean "turf sod," "turf plugs," or "turf sprigs" of a single kind or variety or a mixture of kinds and varieties.

2.8.2.2. TURF. - Turf shall mean a live population of one or more kinds of grasses, legumes, or other plant species used for lawns, recreational use, soil erosion control, or other such purposes.

2.8.2.3. TURF PLUG. - Turf plug shall mean a small section cut from live turf of those kinds of turf normally vegetatively propagated (such as zoysia grass) that when severed contain sufficient plant material to remain intact.

2.8.2.4. TURF SOD. - Shall mean a strip or section of live turf that when severed contains sufficient plant material to remain intact.

2.8.2.5. TURF SPRIG. - Shall mean a live plant, stolon, crown, or section cut from stolonifera plants used as turf.

2.8.3. QUANTITY. - Sod shall be advertised, offered for sale, and sold by measure or by a combination of count and measure as prescribed by this subsection.

(a) Turf sod.- Turf sod shall be advertised for sale and sold in terms of the square meter, square foot, or square yard, as appropriate.

(Amended 1979)

(b) Turf plugs. - Turf plugs shall be advertised for sale and sold in terms of count, combined with a statement of the plug diameter. 
(Added 1976)

(c) Turf sprigs. - Turf sprigs shall be advertised for (Amended 1979) sale and sold in terms of the liter or bushel.

2.9. SOFTWOOD LUMBER. ${ }^{1}$-- Applies to softwood boards, timbers, and dimension lumber that have been dressed on four sides, but shall not apply to rough lumber, to lumber that has been matched, patterned, or shiplapped, or to lumber remanufactured or joined so as to have changed the form or identity, such as individual assembled, or packaged millwork items.

\subsubsection{DEFINITIONS. -}

2.9.1.1. DRESSED (SURFACED) LUMBER. - Lumber that has been dressed (or surfaced) for the purpose of attaining smoothness of surface and uniformity of size.

2.9.1.2. BOARDS. - Lumber 1-1/4 inches or less in actual thickness and 1-1/2 inches or more in actual width. Lumber less than 1-1/2 inches in actual width may be classified as strips.

2.9.1.3. TIMBERS. - Lumber $1-1 / 2$ inches or more in least actual dimension. Timber may be classified as beams, stringers, posts, caps, sills, girders, purlins, etc.

2.9.1.4. DIMENSION LUMBER. - Lumber from $1-1 / 2$ inches to, but not exceeding, $4-1 / 2$ inches in actual thickness, and 1-1/2 inches or more in actual width. Dimension lumber may be classified as framing, joists, planks, rafters, studs, small timbers, etc.

2.9.1.5. ROUGH LUMBER. - Lumber that has not been dressed but that has been sawed, edged, and trimmed at least to the extent of showing saw marks in the wood on the four longitudinal surfaces of each piece for its overall length.

2.9.1.6. MATCHED LUMBER. - Lumber that has been worked with a tongue on one edge of each piece and a groove on the opposite edge to provide a close tongue-and-groove joint by fitting two pieces together; when end-matched, tiie tongue and groove are worked in the ends also.

1 Values in metric units for softwood lumber will not be added until a new standard is developed to cover metric softwood lumber. 
2.9.1.7. PATTERNED LUMBER. - Lumber that is shaped to a pattern or a molded form, in addition to being dressed, matched, or shiplapped, or any combination of these workings.

2.9.1.8. SHIPLAPPED LUMBER. - Lumber that has been worked or rabbeted on both edges of each piece to provide a close-lapped joint by fitting two pieces together.

2.9.1.9. GRADE. - The commercial designation assigned to lumber meeting specifications established by a nationally recognized grade rule writing organization.

2.9.1.10. SPECIES. - The commercial name assigned to a species of trees.

2.9.1.11. SPECIES GROUP. - The commercial name assigned to two or more individual species having similar characteristics.

2.9.1.12. REPRESENTATION. - A "representation" shall be construed to mean any advertisement, offering, invoice, or the like that pertains to the sale of lumber.

2.૭.1.13. MINIMUM DRESSED SIZES (WIDTH AND THICKNESS). - The standardized width and thickness at which lumber is dressed when manufactured in accordance with the U.S. Department of Commerce Voluntary Product Standard 20-70, "American Softwood Lumber Standard," and regional grading rules conforming to VPS 20-70 (See Table 1.)

2.9.2. IDENTITY - Representations shall include a declaration of identity that specifies the grade or grades, species or species group, and whether the lumber is unseasoned (green) or dry.

2.9.3. QUANTITY - Representations shall be in terms of the number of pieces, the minimum dressed width and thickness, the length of individual pieces, or the lineal footage, except that:

(a) the use of nominal dimensions shall be allowed when used in conjunction with the required minimum dressed sizes and actual length; 
(b) with respect to all invoices, a table of minimum dressed sizes may appear on the reverse side of the invoice, so long as appropriate reference to the table is prominently and conspicuously shown on the face of the invoice.

(Added 1971)

Table 1. Softwood Lumber Sizes

Minimum standard dressed sizes at the time of manufacture for both unseasoned (green) and dry lumber as published by the U.S. Department of Commerce in Product Standard 20-70.

\begin{tabular}{|c|c|c|}
\hline \multirow{2}{*}{$\begin{array}{l}\text { Product } \\
\text { Classification } \\
\text { (Nominal Size) }\end{array}$} & \multicolumn{2}{|c|}{$\begin{array}{l}\text { Minimum Dressed Sizes } \\
\text { (See Note 2) }\end{array}$} \\
\hline & Unseasoned & Dry \\
\hline Inches & Inches & Inches \\
\hline \multicolumn{3}{|c|}{ Dimension Lumber } \\
\hline 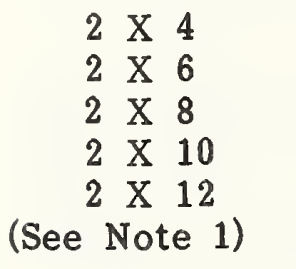 & $\begin{array}{rrr}1-9 / 16 & \mathrm{X} & 3-9 / 16 \\
1-9 / 16 & \mathrm{X} & 5-5 / 8 \\
1-9 / 16 & \mathrm{X} & 7-1 / 2 \\
1-9 / 16 & \mathrm{X} & 9-1 / 2 \\
1-9 / 16 & \mathrm{X} & 11-1 / 2\end{array}$ & $\begin{array}{rrr}1-1 / 2 & \mathrm{X} & 3-1 / 2 \\
1-1 / 2 & \mathrm{X} & 5-1 / 2 \\
1-1 / 2 & \mathrm{X} & 7-1 / 4 \\
1-1 / 2 & \mathrm{X} & 9-1 / 4 \\
1-1 / 2 & \mathrm{X} & 11-1 / 4\end{array}$ \\
\hline \multicolumn{3}{|l|}{ Board Lumber } \\
\hline $\begin{array}{rrr}1 & X & 4 \\
1 & X & 6 \\
1 & X & 8 \\
1 & X & 10 \\
1 & X & 12\end{array}$ & $\begin{array}{llr}25 / 32 & \mathrm{X} & 3-9 / 16 \\
25 / 32 & \mathrm{X} & 5-5 / 8 \\
25 / 32 & \mathrm{X} & 7-1 / 2 \\
25 / 32 & \mathrm{X} & 9-1 / 2 \\
25 / 32 & \mathrm{X} & 11-1 / 2\end{array}$ & $\begin{array}{rrr}3 / 4 & \mathrm{X} & 3-1 / 2 \\
3 / 4 & \mathrm{X} & 5-1 / 2 \\
3 / 4 & \mathrm{X} & 7-1 / 4 \\
3 / 4 & \mathrm{X} & 9-1 / 4 \\
3 / 4 & \mathrm{X} & 11-1 / 4\end{array}$ \\
\hline
\end{tabular}

Note 1. The dry thicknesses of nominal $3^{\prime \prime}$ and $4^{\prime \prime}$ lumber are $2-1 / 2^{\prime \prime}$ and 3-1/2"; unseasoned thicknesses are 2-9/16" and 3-9/16". Widths for these thicknesses are tine same as shown above.

Note 2. Product Standard 20-70 defines dry lumber as being 19 percent or less in moisture content and unseasoned lumber as being over 19 percent moisture content. The size of lumber changes approximately 1 percent for each 4 percent change in moisture content. Lumber stabilizes at approximately 15 (Added 1971) percent moisture content under normal use conditions. 
2.10. CARPETING. - Anyone who sells carpeting shall provide the purchaser with written statements at the time of sale giving the following information:

(a) The name and address of the manufacturer.

(b) The style name and roll number of the carpet.

(c) The generic name of the fiber and the type of backing material.

(d) The amount delivered (exact size shipped).

(e) The price per square yard if sold in inch-pound units, or the price per square meter if sold in metric units, and the total price.

(Added 1977)

(Amended 1979)

2.11. HARDWOOD LUMBER. - Sales of hardwood lumber measured after kiln drying shall be quoted, invoiced and delivered on the basis of net board footage, with no addition of footage for kiln drying shrinkage. Sales of hardwood lumber measured prior to kiln drying shall be quoted, invoiced, and delivered on the basis of net board footage before kiln drying. If the lumber is to be kiln dried at the request of the purchaser, the kiln drying charge shall be clearly shown and identified on the quotation and invoice.

(Added 1977)

2.12. POLYETHYLENE PRODUCTS. - Consumer products offered and exposed for sale at retail shall be sold in terms of:

2.12.1. SHEETING AND FILM. -

(a) length and width

(b) area in square feet or square meters

(Amended 1979)

(c) thickness

(d) weight

(Added 1982)

2.12.2. FOOD WRAP. -

(a) length and width

(b) area in square feet or square meters

(Amended 1979) 
2.12.3. LAWN AND TRASH BAGS. -

(a) count

(b) dimensions

(c) thickness

2.12.4. FOOD AND SANDWICH BAGS. -

(a) count

(b) dimensions

Products not intended for the retail consumer shall be offered and exposed for sale in terms of:

2.12.5. SHEETING AND FILM. -

(a) length

(b) width

(c) thickness

(d) weight

2.12.6. BAGS. -

(a) count

(b) dimensions

(c) thickness

(d) weight

2.12.7. DECLARATION OF WEIGHT. - The labeled statement of weight for polyethylene products under sections 2.12.1., 2.12.5., and 2.12.6. shall be not less than the weight calculated by using the following formula:

$\mathrm{W}=\mathrm{T} \times \mathrm{A} \times 0.03613 \times \mathrm{D}$, where

$\mathrm{W}=$ net weight in pounds

$\mathrm{T}=$ nominal thickness in inches

$A=$ nominal length in inches times nominal width in inches

$\mathrm{D}=$ density in grams per cubic centimeter as determined by ASTM Standard D1505-68 "Standard Method of Test for Density of Plastics by the Density Gradient Technique" (or lațest issue),

(Added 1982)

0.03613 is a factor for converting $\mathrm{g} / \mathrm{cm}^{3}$ to $\mathrm{lb} / \mathrm{in}^{3}$.

(Added 1977, amended 1980, 1982) 


\subsection{INSULATION}

2.13.1. PACKAGED LOOSE FILL INSULATION EXCEPT CELLULOSE. - Packaged loose-fill insulation, except cellulose, shall declare the net weight with no qualifying statement; each package must contain at least the stated weight. In addition, the following information shall be supplied on the package: minimum thickness, maximum net coverage area, number of bags per 1000 square feet, and minimum weight per square foot at $\mathrm{R}$-values of 11,19 , and 22 . This information shall also be supplied for any additional $\mathrm{R}$-values listed.

2.13.2. PACKAGED LOOSE-FILL CELLULOSE INSULATION. The principal display panel of packaged loose-fill cellulose insulation shall declare the net weight with no qualifying statement; each package must contain at least the stated weight. In addition, the following information shall be supplied on the package: minimum thickness, maximum net coverage area, number of bags per 100 square feet, and minimum weight per square foot at R-values of $13,19,24,32$, and 40 . This information shall also be supplied for any additional $\mathrm{R}$-values listed.

2.13.3. BATT AND BLANKET INSULATION. - The principal display panel of packaged batt or blanket insulation shall declare the square feet of insulation in the package, and the length and width of the batt or blanket. In addition, R-value and thickness shall be declared on the package.

2.13.4. INSTALLED INSULATION. - Installed insulation must be accompanied by a contract or receipt. For all insulation except loose fill and aluminum foil, the receipt must show the coverage area, thickness, and $\mathrm{R}$-value of the insulation installed. For loose-fill, the receipt must show those three items plus the number of bags used. For aluminum foil, the receipt must show the number and thickness of the air spaces, the direction of heat flow, and $R$-value. The receipt must be dated and signed by the installer.

Example: This is to certify that the insulation has been installed in conformance with the requirements indicated by the manufacturer to provide a value of $R-19$ using 31.5 bags of insulation to cover 1500 square feet area. Signed and dated.

(Added 1979, Amended 1983) 
2.14. SOLID FUEL PRODUCTS. - Anthracite, Semi-Anthracite, Bituminous, Semi-Bituminous, or Lignite Coal, and any other natural, manufactured, or patented fuel, not in liquid or gaseous form, except fireplace and stove wood, shall be offered, exposed (Added 1979) for sale, or sold by net weight when in package form.

2.15. LIQUIFIED PETROLEUM GAS CYLINDER TARE WEIGHTS Whenever stamped tare weights on cylinders are employed in the sale of liquified petroleum gas, the following shall apply.

2.15.1. ALLOWABLE DIFFERENCE. - The allowable difference between the actual tare weight and the stamped tare weight for a new or used cylinder shall be one percent of the actual tare weight. The tare weight shall include the weight of the cylinder (including paint), valve, and other permanent attachments. The weight of a protective cap shall not be included in tare or gross weights.

2.15.2. AVERAGE REQUIREMENT. - The tare weights of cylinders at a single place of business found to be in error predominantly in a direction favorable to the seller and near the allowable difference limit shall be considered to be not in conformance with these requirements.

(Added 1981)

2.16. PRECIOUS METALS

2.16.1. DEFINITION. -

2.16.1.1. PRECIOUS METALS. - Gold, silver, platinum, or any item composed partly or completely of these metals or their alloys and in which the market value of the metal in the item is principally the gold, silver, or platinum component.

2.16.2. QUANTITY. - The unit of measure and the method of sale of precious metals, if the price is based in part or wholly on a weight determination, shall be either troy weight or metric weight. When the measurement or method of sale is expressed in metric weight units, a conversion chart to troy units shall be prominantly displayed so as to facilitate price comparison. The conversion chart shall also display a table of troy weights indicating grains, pennyweights, and troy

(Added 1982) ounces.

2.17. BARK MULCH. - All bark mulch shall be sold, offered, or exposed for sale in terms of volume measure: in inch-pound 
(Added 1983)

units, in terms of the cubic yard or cubic foot; in metric units, in terms of the cubic meter or liter.

2.18. KEROSENE. - All kerosene kept, offered, exposed for sale, or sold shall be identified as such and will include, with the word kerosene, an indication of its compliance with the standard specification adopted by the American Society for Testing and Materials in Specification number D-3699 (1982 or latest revision).

(Added 1983)

Example: $1 \mathrm{~K}$ Kerosene; Kerosene - $2 \mathrm{~K}$.

\subsection{GASOLINE - ALCOHOL BLENDS}

2.19.1 METHOD OF RETAIL SALE. - All motor fuel kept, offered, or exposed for sale, or sold, at retail containing at least one percent by volume of ethanol, methanol, or a combination shall be identified as "with", "containing" (or similar wording) "ethanol", "methanol", or "ethanol/methanol" on the upper fifty percent of the dispenser front panel in a position clear and conspicuous from the driver's position, in a type at least one half inch in height, $1 / 16$ inch stroke (width of type).

2.19.2 DOCUMENTATION FOR DISPENSER LABELING PURPOSES.-The retailer must be provided, at the time of delivery of the fuel, on an invoice, bill of lading, shipping paper, or other documentation, the presence and maximum amount of ethanol, methanol, or any combination of ethanol/methanol (in terms of percent by volume) contained in the fuel. This documentation is only for dispenser labeling purposes; it is the responsibility of any potential blender to determine the total oxygen content of the motor fuel before blending.

(Added 1984, amended 1985, 1986)

2.20. LIQUEFIED PETROLEUM GAS. - Aii liquefied petroleum gases, including but not limited to propane, butane, and mixtures thereof, shall be kept, offered, exposed for sale, or sold by the pound, metered cubic foot ${ }^{1}$ of vapor (defined as one cubic foot at $60^{\circ} \mathrm{F}$ ), or the gallon (defined as 231 cubic inches at $60{ }^{\circ} \mathrm{F}$ ). All metered sales by the gallon, except those using meters with a maximum rated capacity of 20 gallons per minute or less, shall be accomplished by use of a meter and device that automatically compensates for temperature. (Added 1986)

1 Sources: American National Standards Institute, Inc., "American National Standard for Gas Displacement Meters (500 Cubic Feet per Hour Capacity and Under)", First Edition, 1974, and National Bureau of Standards Handbook 44, "Specifications, Tolerances, and Other Technical Requirements for Weighing and Measuring Devices". 


\section{SECTION 3. GENERAL}

3.1. PRESENTATION OF PRICE. - Whenever an advertised, posted, or labeled price per unit of weight, measure, or count for any commodity includes a fraction of a cent, all elements of the fraction shall be prominently displayed, and the numerals expressing the fraction shall be immediately adjacent to, of the same general design and style as, and at least one-half the height (Added 1976) and width of the numerals representing the whole cent.

3.2. ALLOWABLE DIFFERENCES: COMBINATION QUANTITY DECLARATIONS. - Whenever the method of sale for a bulk or packaged commodity requires the use of a statement that includes count in addition to weight, measure, or size, the following shall apply to the particular commodity:

(Added 1973)

3.2.1. BEVERAGEWARE: PRESSED AND BLOWN TUMBLERS AND STEMWARE. - The allowable difference between actual and declared capacity shall be:

(a) for inch-pound:

(1)

plus or minus $1 / 4$ fluid ounce for items of 5 fluid ounce capacity or less;

(2) plus or minus 5 percent of the stated capacity for items over 5 fluid ounce capacity.

(b) for metric:

(1) plus or minus 10 milliliters for items of 200 milliliter capacity or less;

(2) . plus or minus 5 percent of the stated capacity for items over 200 milliliter capacity.

(Amended 1980)

(Added 1974, amended 1979)

3.3. MACHINE VENDED COMMODITIES. - All vending machines dispensing packaged commodities shall indicate:

(a) product identity;

(b) net quantity; 
(c) name, address, and telephone number of responsible party.

The requirements for product identity and net quantity can be met either by display of the package or by information posted on the outside of the machine.

\section{(Added 1972)}

3.4. RAILROAD CAR TARE WEIGHTS. - Whenever stenciled tare weights on freight cars are employed in the sale of commodities or the assessment of freight charges, the following conditions and requirements shall apply:

3.4.1. All newly stenciled or restenciled tare weights shall be accurately represented to the nearest 100 pounds for inch-pound units and to the nearest 50 kilograms for metric units, and the representation shall include the date of weighing.

(Amended 1979)

3.4.2. The allowable difference between actual tare weight and stenciled tare weight on freight cars in use shall be per subsection 3.4.2(a) or subsection 3.4.2(b).

(a) Inch-Pound allowable difference:

(1) plus or minus 300 pounds for cars 50000 pounds or less;

(2) plus or minus 400 pounds for cars over 50000 pounds to and including $60 \quad 000$ pounds;

(3) plus or minus 500 pounds for cars over 60000 pounds.

(b) Metric allowable difference:

(1) plus or minus 150 kilograms for cars 25000 kilograms or less;

(2) plus or minus 200 kilograms for cars over 25000 kilograms to and including 30000 kilograms;

(3) plus or minus 250 kilograms for cars over 30000 kilograms.

(Added 1979) 
3.4.3. Tare weight determinations for verification or change of stenciled weights shall only be made on properly prepared and adequately cleaned freight cars.

3.4.4. Tank cars, covered hopper cars, flat cars equipped with multideck racks or special superstructure, mechanical refrigerator cars, and house-type cars equipped with special lading protective devices must be reweighed and restenciled only by owners or their authorized representatives:

(a) when car bears no lightweight (empty weight) stenciling;

(b) when repairs or alterations result in a change of weight in excess of the permissible lightweight tolerance.

(Added 1974, renumbered 1985)

(Added 1973, amended 1974,1979,1985)

\section{SECTION 4. REVOCATION OF CONFLICTING REGULATIONS}

All provisions of all orders and regulations heretofore issued on this same subject that are contrary to or inconsistent with the provisions of this regulation, and specifically __, are hereby revoked.

(Added 1971)

\section{SECTION 5. EFFECTIVE DATE}

This regulation shall become effective on

Given under my hand and the seal of my office in the City of , on this day of A.D. 19

Signed

(Added 1971, Amended 1973) 


\section{UNIFORM UNIT PRICING REGULATION}

$$
1971
$$

as adopted by

The National Conference on Weights and Measures ${ }^{4}$

\section{1.}

\section{BACKGROUND}

The Uniform Unit Pricing Regulation (renamed in 1983) provides a national approach to the subject for those jurisdictions choosing to adopt such a regulation.

The traditional approach of the Conference in drafting Uniform Regulations has been to design specific implementing Regulations for the enforcement of the broader requirements of the Uniform Weights and Measures Law. Given the authority of Section 12.3 and the mandate of Section 16. of this Law, as well as the trend in unit pricing, both voluntary and mandatory, the Unit Pricing Regulation is considered appropriate. Unit pricing has been a traditional concern of the weights and measures official and has been required for random weight packages for a long period of time.

2. STATUS OF PROMULGATION

The map on the following page shows the status of promulgation of the Uniform Unit Pricing Regulation.

${ }^{4}$ The National Conference on Weights and Measures is sponsored by the National Bureau of Standards in partial implementation of its statutory responsibility for "cooperation with the States in securing uniformity in weights and measures laws and methods of inspection." 
Unit Pricing Regulation

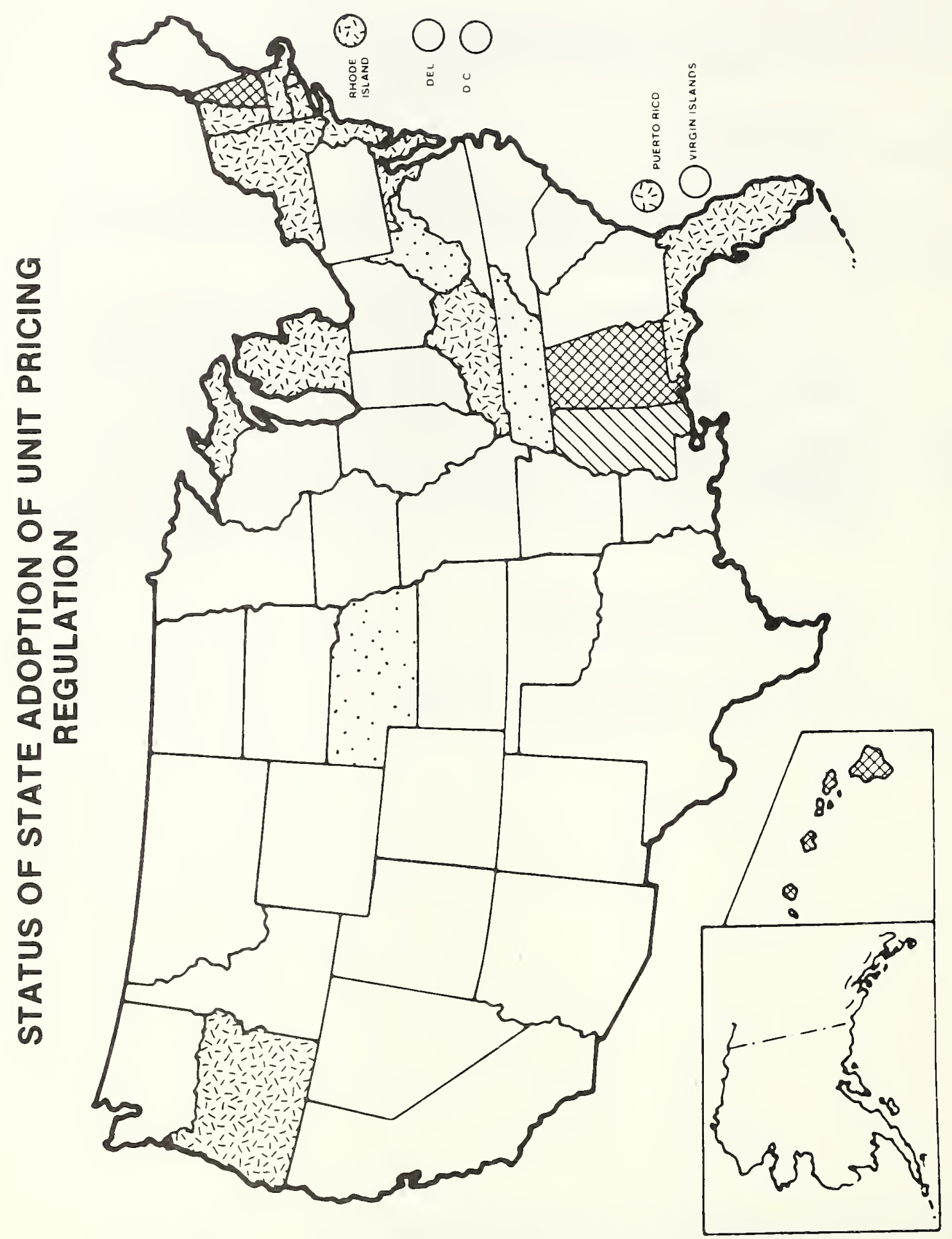

口高

zo

$\therefore$ ल

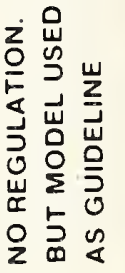

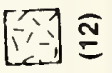

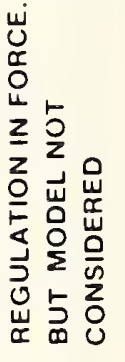

$D=$

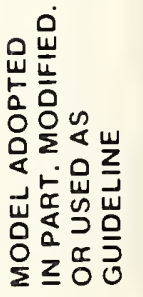

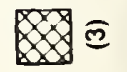

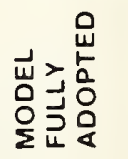


TABLE OF CONTENTS

SECTION

1. APPLICATION

2. COMMODITIES

3. EXEMPTION: SMALL PACKAGES

4. EXEMPTION: SINGLE ITEM

5. PRICING

6. PRESENTATION OF PRICE

7. EFFECTIVE DATE
PAGE

IV-85

IV-85

IV-86

IV-86

IV-86

IV-86

IV-87 


\section{UNIFORM UNIT PRICING REGULATION 1971}

\section{SECTION 1. APPLICATION}

Except for random weight packages unit priced in accord with existing regulations and uniform weight packages of cheese and cheese products unit priced in the same manner and by the same type of equipment as random weight packages, any retail establishment providing unit price information in addition to the total price, for any commodity listed herein, shall also provide the unit price information for all packaged commodities listed herein and in the manner prescribed herein.

\section{SECTION 2. COMMODITIES}

The standard of reference of all categories listed below shall be the latest edition of the "Standard Industrial Classification Manual" published by the Executive Office of the President, Office of Management and Budget.

Meat, Poultry, and Seafood Fruits and Vegetables

Fruit and Vegetable Juices and Drinks

Dry Detergents, Soap Powders, and Dry Household Cleaners

Liquid Detergents and Household Cleaners and Disinfectants

Relishes and Condiments

Liquid Soups and Condensed Liquid Soups

Cereals

Candy

Cookies and Crackers

Sanitary Paper Products

Foil, Film, and Other Rolls of Wrapping (except gift wrap)

Cooking Oils and Shortening

Salad Dressings

Soft Drinks

Jams, Jellies, Preserves, and Peanut Butter

Coffee, Tea, and Cocoa

Syrups, Table and Topping

Cheese, Natural and Processed

Rice

Pet Food

\author{
Price per pound \\ Price per pound or \\ per individual unit, \\ or whole unit of dry \\ measure \\ Price per quart \\ Price per pound \\ Price per quart \\ Price per pound or quart \\ Price per pound or quart \\ Price per pound \\ Price per pound \\ Price per pound \\ -Price per $50 \mathrm{sq} \mathrm{ft}$, or, if \\ by count, per 50 units, \\ including ply \\ Price per $50 \mathrm{sg} \mathrm{ft}$ \\ Price per quart or pound \\ Price per quart \\ Price per quart \\ Price per pound \\ Price per pound \\ Price per pound or quart \\ Price per pound \\ Price per pound \\ Price per pound
}


Toothpaste

Deodorants, Personal

Shaving Preparations

Toilet Water and Colognes

Hair Preparations
Price per ounce

Price per ounce

Price per ounce

Price per ounce

Price per ounce

\section{SECTION 3. EXEMPTION: SMALL PACKAGES}

Any of the commodities listed herein shall be exempt from these provisions when packaged in quantities of less than one ounce (avoirdupois) or one fluid ounce or when the total retail price thereof is ten cents or less.

\section{SECTION 4. EXEMPTION: SINGLE ITEM}

Any of the commodities listed herein shall be exempt from these provisions when there is only one brand in only one size appearing in a particular retail establishment.

\section{SECTION 5. PRICING}

The unit price information shall be to the nearest tenth of one cent when less than one dollar and to the nearest cent when a dollar or more.

\section{SECTION 6. PRESENTATION OF PRICE}

(a) In any retail establishment in which unit price information is provided in accordance with the provisions of the Regulation, that information may be displayed by means of a sign that offers the unit price for one or more brands and/or sizes of a given commodity, by means of a sticker, stamp, sign, label, or tag affixed to the shelf upon which the commodity is displayed, or by means of a sticker, stamp, sign, label, or tag affixed to the consumer commodity itself.

(b) Where a sign providing unit price information for one or more sizes or brands of a given commodity is used, that sign shall be provided clearly and in a nondeceptive manner in a central location as close as practical to all items to which the sign refers.

(c) If a single sign or tag does provide the unit price information for more than one brand or size of a given commodity, then the following information shall be provided:

(1) The identity and the brand name of the commodity.

(2) The quantity of the packaged commodity if more than one package size per brand is displayed.

(3) The total retail sales price.

(4) The price per appropriate unit, in accordance with SECTION 2. COMMODITIES. 


\section{SECTION 7. EFFECTIVE DATE}

(a) Not less than one-third of the commodity categories listed in section 2 of this Regulation shall be unit priced by any individual retail establishment within 90 days after this Regulation, by its terms, becomes applicable to such establishment.

(b) Full compliance with this Regulation by any individual retail establishment shall be attained within 120 days after this Regulation, by its terms, becomes applicable to such establishment. 
UNIFORM REGULATION FOR THE VOLUNTARY REGISTRATION OF SERVICEPERSONS AND SERVICE AGENCIES FOR COMMERCIAL WEIGHING AND MEASURING DEVICES 1984

as adopted by
The National Conference on Weights and Measures

1. BACKGROUND

The Uniform Regulation covering the registration of servicepersons and service agencies was developed and adopted by the National Conference on Weights and Measures in 1966, retitled in 1983, and substantially revised in 1984. It is designed to promote uniformity among those jurisdictions that provide for or are contemplating the establishment of some type of control over the servicing of commercial weighing and measuring devices. It offers to a serviceperson or to a service agency the opportunity to register, and carries with it the privilege of restoring devices to service and of placing new or used devices in service.

Two unique features of the registration plan are its voluntary nature and the provision for reciprocity. Registration is not required; however, the privileges gained make it attractive. Also, in order to provide maximum effectiveness of the program and to reduce to a minimum legal obstacles to service across State lines, provision is made for reciprocity in certification of standards and testing equipment among States.

The revised Regulation differs from the 1966 version in the following ways:

- Registration explicitly depends upon the qualifications of each applicant.

- Minimum equipment requirements ar a established by referencing the NOTES sections of Handbook 44.

- The certificate of registration automatically expires at the end of one year.

1 The National Conference on Weights and Measures is sponsored by the National Bureau of Standards in partial implementation of its statutory responsibility for "cooperation with the States in securing uniformity in weights and measures laws and methods of inspection". 
- The responsibilities of the registered serviceperson are enumerated.

- Calibration of equipment by other State weights and measures laboratories is recognized.

- Informal reciprocity with respect to other voluntary registration programs has been dropped (due to the difficulty of managing record keeping and operating procedures).

- What action or failure of action constitutes a violation of the regulation is described.

\section{STATUS OF PROMULGATION}

The map on the following page shows the status of promulgation of the Uniform Regulation for the Regulation of Servicepersons and Service Agencies, based on a comparison of State laws and regulations with the uniform regulation in 1982. Because of the 1984 revision, the map detailing status of promulgation can only be used as a rough guide at this time. 


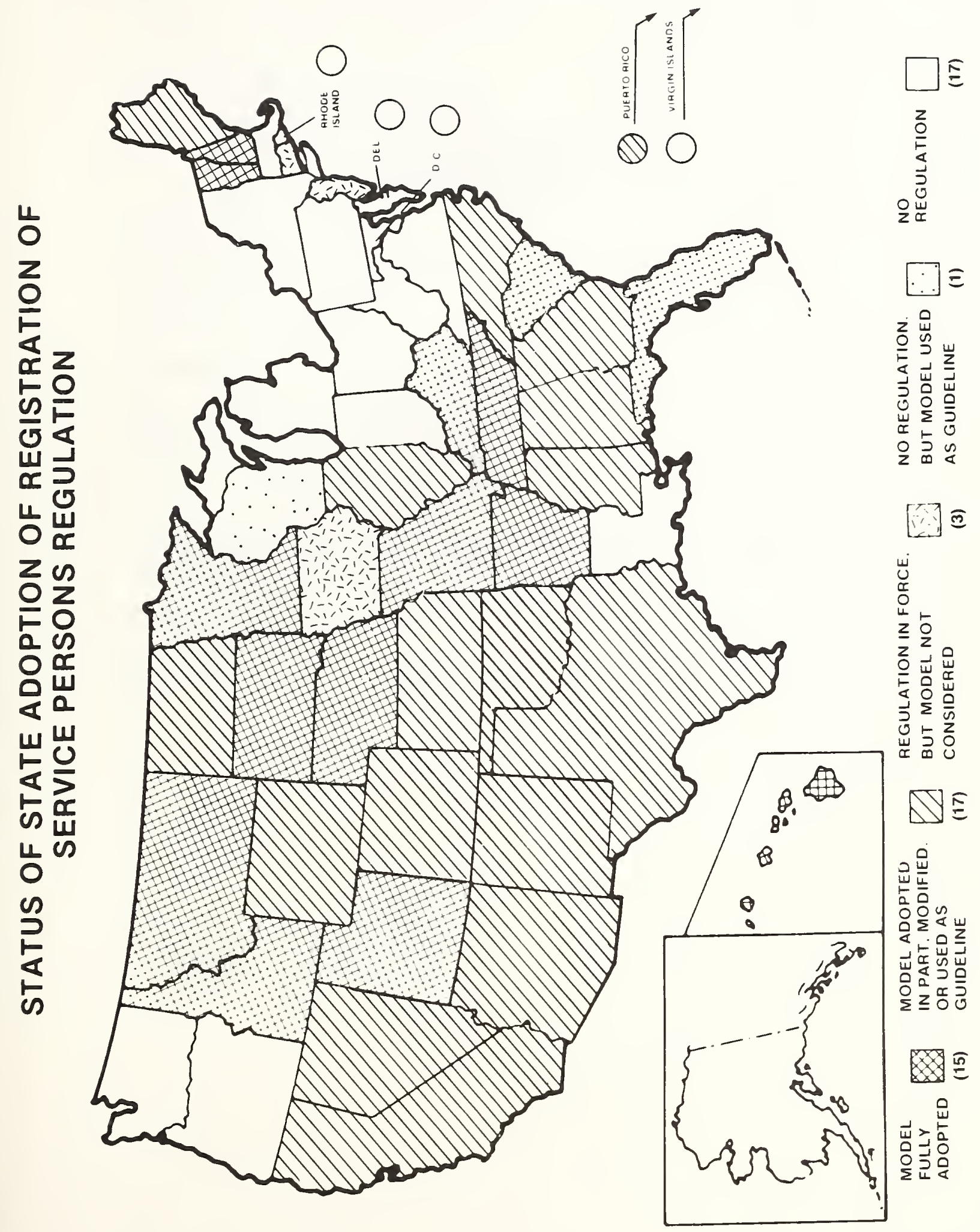




\section{TABLE OF CONTENTS}

SECTION

PAGE

1. POLICY

IV-95

2. DEFINITIONS

IV-96

2.1. Registered Serviceperson

IV -96

2.2. Registered Service Agency

IV -96

2.3. Commercial and Law-Enforcement Weighing and Measuring Device

IV-96

3. REGISTRATION FEE

IV-96

4. VOLUNTARY REGISTRATION

IV-96

5. MINIMUM EQUIPMENT

IV-97

6. CERTIFICATE OF REGISTRATION

IV-97

7. PRIVILEGES AND RESPONSIBILITIES

OF A VOLUNTARY REGISTRANT

IV-97

8. PLACED IN SERVICE REPORT

IV-97

9. EXAMINATION AND CALIBRATION OR CERTIFICATION OF STANDARDS AND TESTING EQUIPMENT

IV-98

10. REVOCATION OF CERTIFICATE OF REGISTRATION IV-98

11. PUBLICATION OF LISTS OF REGISTERED SERVICEPERSONS AND REGISTERED SERVICE AGENCIES

IV-98

12. EFFECTIVE DATE

IV-98 


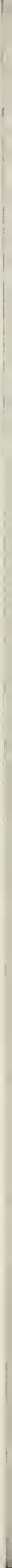




\section{UNIFORM REGULATION FOR THE VOLUNTARY REGISTRATION OF SERVICEPERSONS AND SERVICE AGENCIES FOR COMMERCIAL WEIGHING AND MEASURING DEVICES 1984}

\section{SECTION 1. POLICY}

For the benefit of the users, manufacturers, and distributors of commercial weighing and measuring devices, it shall be the policy of the Director of Weights and Measures, hereinafter referred to as "Director," to accept registration of (a) an individual and (b) an agency providing acceptable evidence that he, she, or it is fully qualified by training or experience to install, service, repair, or recondition a commercial weighing or measuring device; has a thorough working knowledge of all appropriate weights and measures laws, orders, rules, and regulations; and has possession of or available for use, and will use calibrated weights and measures standards and testing equipment appropriate in design and adequate in amount. (An employee of government shall not be eligible for registration.)

The Director will check the qualifications of each applicant. It will be necessary for an applicant to have available sufficient standards and equipment (see Section 5).

It shall also be the policy of the Department to issue to qualified applicants, whose applications for registration are approved, a "Certificate of Registration." This gives authority to remove rejection seals and tags placed on Commercial and Law-Enforcement Weighing and Measuring Devices by authorized weights and measures officials, to place in service repaired devices that were rejected, or to place in service devices that have been newly installed.

The Director is NOT guaranteeing the work or fair dealing of a Registered Serviceperson or Service Agency. He will, however, remove from the registration list any Registered Serviceperson or Service Agency that performs unsatisfactory work or takes unfair advantage of a device owner.

Registration with the Director shall be on a voluntary basis. The Director shall reserve the right to limit or reject the application of any Serviceperson or Service Agency and to revoke his, her, or its permit to remove rejection seals or tags for good cause.

This policy shall in no way preclude or limit the right and privilege of any individual or agency not registered with the Director to install, service, repair, or recondition a commercial weighing or measuring device (however, see Section 6).

(Added 1966) 


\section{SECTION 2. DEFINITIONS}

2.1. REGISTERED SERVICEPERSON. - The term "Registered Serviceperson" shall be construed to mean any individual who for hire, award, commission, or any other payment of any kind, installs, services, repairs, or reconditions a commercial weighing or measuring device, and who voluntarily applies for registration with the Director of Weights and Measures.

(Added 1966)

2.2. REGISTERED SERVICE AGENCY. - The term "Registered Service Agency" shall be construed to mean any agency, firm, company, or corporation that for hire, award, commission, or any other payment of any kind installs, services, repairs, or reconditions a commercial weighing or measuring device, and that voluntarily registers itself as such with the Director of Weights and Measures. Under agency registration, identification of individual servicepersons shall be required.

(Added 1966, amended 1984)

2.3. COMMERCIAL AND LAW-ENFORCEMENT WEIGHING AND MEASURING DEVICE. - - The term "Commercial and Law-Enforcement Weighing and Measuring Device" shall be construed to include any weight or measure or weighing or measuring device commercially used or employed in establishing the size, quantity, extent, area, or measurement of quantities, things, produce, or articles for distribution or consumption, purchased, offered, or submitted for sale, hire, or award, or in computing any basic charge or payment for services rendered on the basis of weight or measure. It shall also include any accessory attached to or used in connection with a commercial weighing or measuring device when such accessory is so designed or installed that its operation affects the accuracy of the device. It also includes weighing and measuring equipment in official use for the enforcement of law or for the collection of statistical information by government agencies.

(Added 1966, amended 1984)

\section{SECTION 3. REGISTRATION FEE}

There shall be charged by the Director an annual fee of ( $\$$ ) per Registered Serviceperson and $(\$$ ) per Registered Service Agency to cover costs at the time application for registration is made, and annually, thereafter.

(Added 1966, revised 1984)

\section{SECTION 4. VOLUNTARY REGISTRATION}

An individual or agency qualified by training or experience may apply for registration to service weighing devices or measuring devices on an application form supplied by the Director. Said form, duly signed and witnessed, shall include certification by the applicant that the individual or agency is fully qualified to install, service, repair, or recondition whatever devices for the service of which competence is being registered; 
has in possession or available for use, and will use, all necessary testing equipment and standards; and has full knowledge of all appropriate weights and measures laws, orders, rules, and regulations. An applicant also shall submit appropriate evidence or references as to qualifications. Application for registration shall be voluntary, but the Director is authorized to reject or limit any application.

(Added 1966, amended 1984)

\section{SECTION 5. MINIMUM EQUIPMENT}

Applicants must have available sufficient standards and equipment to adequately test devices as set forth in the Notes section of each applicable code in NBS Handbook 44, "Specifications, Tolerances, and Other Technical Requirements for Weighing and Measuring Devices." When applicable, this equipment will meet the specifications of National Bureau of Standards Handbook 105-1, "Specifications and Tolerances for Reference Standards and Field Standard Weights and Measures, Specifications and Tolerances for Field Standard Weights (NBS Class F)," National Bureau of Standards Handbook 105-2, "Specifications and Tolerances for Reference Standards and Field Standard Weights and Measures, Specifications and Tolerances for Field Standard Measuring Flask," or National Bureau of Standards Handbook 105-3, "Specifications and Tolerances for Reference Standards and Field Standard Weights and Measures, Specifications and Tolerances for Graduated Neck Type Volumetric Field Standards." See also Section 9. (Added 1984)

\section{SECTION 6. CERTIFICATE OF REGISTRATION}

The Director will review and check the qualifications of each applicant. The Director shall issue to the applicant a "Certificate of Registration," including an assigned registration number if it is determined that the applicant is qualified. The "Certificate of Registration" will expire one year from the date of issuance.

(Added 1966, amended 1984)

\section{SECTION 7. PRIVILEGES AND RESPONSIBILITIES OF A VOLUNTARY REGISTRANT}

A bearer of a Certificate of Registration shall have the authority to remove an official rejection tag or mark placed on a weighing or measuring device by the authority of the Director; place in service, until such time as an official examination can be made, a weighing or measuring device that has been officially rejected; and place in service, until such time as an official examination can be made, a new or used weighing or measuring device. The Registered Serviceperson or Service Agency is responsible for installing, repairing, and adjusting devices such that the devices are adjusted as closely as practicable to zero error. (Added 1966, amended 1984)

\section{SECTION 8. PLACED IN SERVICE REPORT}

The Director shall furnish each Registered Serviceperson and Registered Service Agency with a supply of report forms to be known as "Placed in Service Reports." Such a form shall be executed in triplicate, shall include the assigned registration number, and shall be signed by a 
Registered Serviceperson or by a serviceperson representing a Registered Agency for each rejected device restored to service and for each newly installed device placed in service. Within 24 hours after a device is restored to service, or placed in service, the original of the properly executed Placed in Service Report, together with any official rejection tag removed from the device, shall be mailed to the Director at_ (address) - The duplicate copy of the report shall be handed to the owner or operator of the device, and the triplicate copy of the report shall be retained by the Registered Serviceperson or Agency.

(Added 1966)

\section{SECTION 9. EXAMINATION AND CALIBRATION OR CERTIFICATION OF STANDARDS AND TESTING EQUIPMENT}

A registered Serviceperson and a Registered Service Agency shall submit, at least annually to the Director, for examination and certification, any standards and testing equipment that are used, or are to be used, in the performance of the service and testing functions with respect to weighing and measuring devices for which competence is registered. A Registered Serviceperson or Agency shall not use in servicing commercial weighing or measuring devices any standards or testing equipment that have not been certified by the Director. Equipment calibrated by another State weights and measures laboratory that can show traceahility to the National Bureau of Standards will also be recognized as equipment suitable for use by Registered Servicepersons or Service Agencies in this State. (Added 1966, revised 1984)

\section{SECTION 10. REVOCATION OF CERTIFICATE OF REGISTRATION}

The Director is authorized to suspend or revoke a Certificate of Registration for good cause which shall include but not be limited to: taking of unfair advantage of an owner of a device; failure to have test equipment or standards certified; failure to use adequate testing equipment, failure to adjust Commercial or Law-Enforcement Devices to comply with Handbook 44 subsequent to service or repair.

(Added 1966, revised 1984)

SECTION 11. PUBLICATION OF LISTS OF REGISTERED SERVICEPERSONS AND REGISTERED SERVICE AGENCIES

The Director shall publish, from time to time as he deems appropriate, and may supply upon request, lists of Registered Servicepersons and Registered Service Agencies.

(Added 1966)

SECTION 12. EFFECTIVE DATE

This regulation shall become effective on

(Added 1966) 


\title{
UNIFORM OPEN DATING REGULATION 1985
}

\author{
as adopted by \\ The National Conference on Weights and Measures ${ }^{5}$
}

\section{BACKGROUND}

Numerous State and local jurisdictions have provided for, or are considering, mandatory open dating of certain packaged commodities. Additionally, many commodities in the marketplace are now voluntarily open dated. Lack of uniformity between jurisdictions could impede the orderly flow of commerce.

In 1985 the National Conference on Weights and Measures, in concert with the Association of Food and Drug Officials, wrote a new Uniform Regulation. It resolved the differences which existed between the versions previously developed by the two organizations independently.

The Uniform Regulation of 1973 (published in the 1985 Edition of this Handbook) and the new Uniform Regulation (published in this edition) are similar in the details of marking and overall intent.

However, the new version is unique in that it provides two options for implementation by the States. One requires open dating on all perishable foods. The other permits voluntary open dating of such foods. In the latter (voluntary) case, the open dating must then conform to the uniform regulation. Footnotes to Sections 1(a) and 3.1. indicate the alternative wording for the voluntary version of the Regulation.

\section{STATUS OF PROMULGATION}

The map on the following page shows the status of promulgation of the Uniform Open Dating Regulation of 1973. Future editions of the Handbook will report the status of promulgation of the new Regulation.

${ }^{5}$ The National Conference on Weights and Measures is sponsored by the National Bureau of Standards in partial implementation of its statutory responsibility for "cooperation with the States in securing uniformity in weights and measures laws and methods of inspection". 


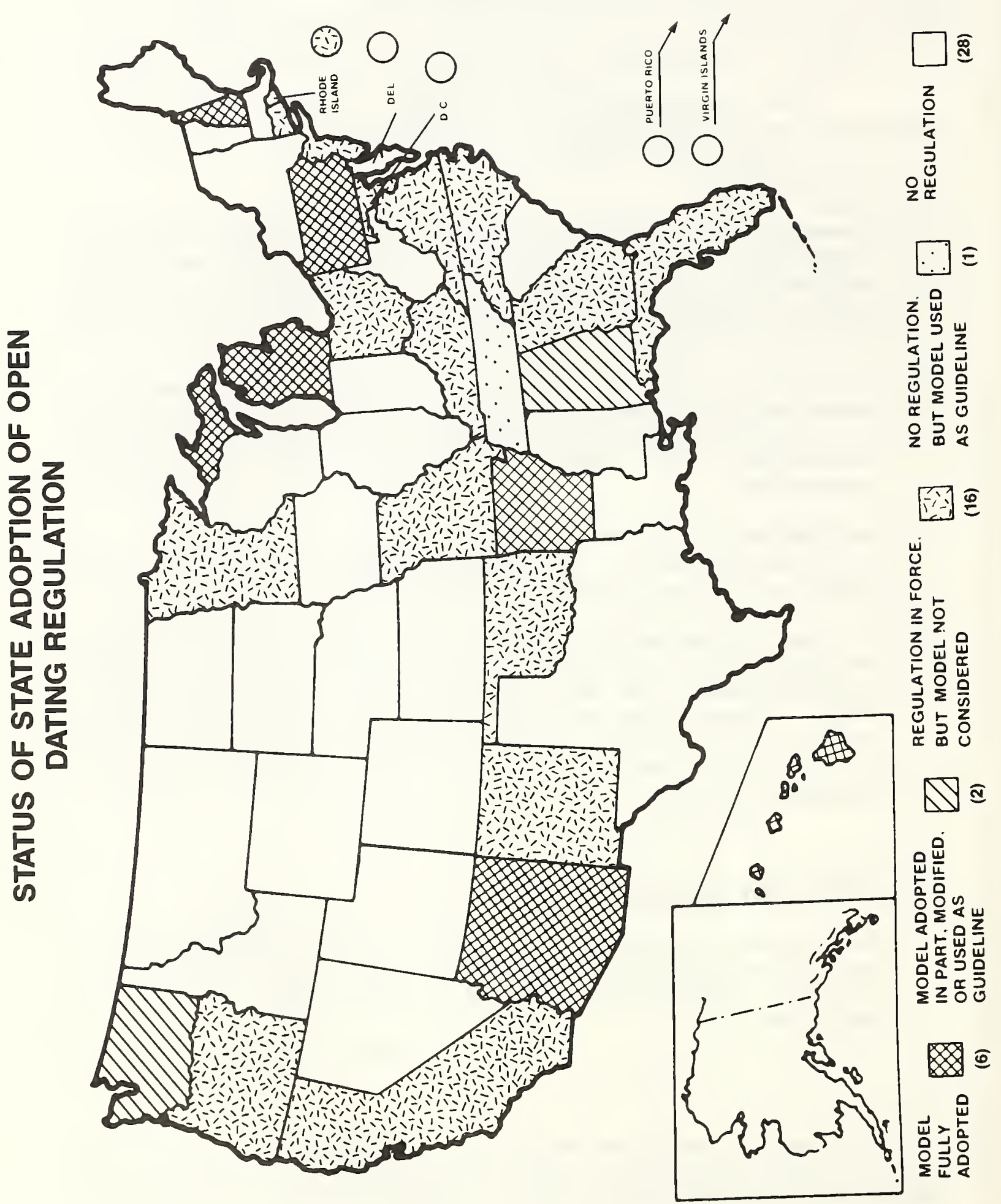


TABLE OF CONTENTS

SECTION

PAGE

1. PURPOSE, SCOPE, AND APPLICATION IV-103

1.1. Purpose

1.2. Scope and Application

IV -103

IV-103

2. DEFINITIONS
2.1. "Sell By" Date
2.2. Perishable Food
IV -103
2.3 Semiperishable Food
IV -103
2.4. Long Shelf-Life Food
IV-104
2.5. Prepackaged
IV-104
2.6. "Best If Used By" Date
IV-104
2.7. Person
IV-104
IV-104

IV-103

3. SALE OF PERISHABLE FOOD AND DATE IV-104 DETERMINATION

3.1. "Sell By" Date

3.2. Sale After Expiration of "Sell By" Date

IV-104

3.3. Determination of "Sell By" Date

IV-104

3.4. Manner of Expressing Date

IV-105

IV-105

4. SALE OF SEMI-PERISHABLE AND

LONG SHELF-LIFE FOOD

4.1. "Best If Used By" Date

IV-106

4.2. Sale After Expiration of

"Best If Used By" Date

IV-106

4.3. Manner of Expressing Date

IV-106

IV-106

5. Placement of the DAte

IV-106

6. FACTORS FOR THE DATE DETERMINATION IV-107

7. RECORDS

IV-107

8. EXEMPTIONS

IV-107

9. PRE-EMPTION OF LOCAL, COUNTY, AND MUNICIPAL ORDINANCE

IV-107

10. EFFECTIVE DATE

IV-107 


\section{UNIFORM OPEN DATING REGULATION ${ }^{1}$ 1985}

\section{SECTION 1. PURPOSE, SCOPE, AND APPLICATION}

1.1. PURPOSE. ${ }^{1}$ The purpose of this regulation is to prescribe mandatory uniform date labeling of prepackaged, perishable foods, and to prescribe optional uniform date labeling that must be used whenever a packager elects to use date labeling on prepackaged foods that are not perishable. Open dating is intended for use and understanding by both distributors and consumers when judging food qualities.

1.2. SCOPE AND APPLICATION. This regulation prescribes the manner of date labeling, the method of determining the appropriate date, required records, responsible persons, and the foods subject to this regulation. This regulation provides for the permissible sale of a regulated food after the expiration of the date on the label. This regulation does not apply to any food that is not prepackaged or is exempted by Section 8 .

\section{SECTION 2. DEFINITIONS}

2.1. "SELL .BY" DATE. - " 'Sell by' date" means a recommended last date of sale that permits a subsequent period before deterioration of qualities described in 2.2., 2.3., and 2.4.

2.2. PERISHABLE FOOD. - "Perishable food" means any food having a significant risk of spoilage, loss of value, or loss of palatability within 60 days of the date of packaging.

1 Alternatively, this regulation may be adopted to require uniformity of open dating of perishable foods whenever a packager voluntarity elects to use date labeling. In such instance, Section 1.1. is reworded in the following manner:

1.1. PURPOSE. The purpose of this regulation is to prescribe uniform date labeling that must be used whenever a packager elects to use date labeling on a prepackaged food. Open date labeling is intended for use and understanding by both distributors and consumers when judging food qualities. 
2.3. SEMI-PERISHABLE FOOD. - "Semi-perishable food" means any food for which a significant $r$ isk of spoilage, loss of value, or loss of palatability occurs only after a minimum of 60 days, but within 6 months, after the date of packaging.

2.4. LONG SHELF-LIFE FOOD. - "Long shelf-life food" means any food for which a significant risk of spoilage, loss of value, or loss of palatability does not occur sooner than 6 months after the date of packaging including foods preserved by freezing, dehydrating, or being placed in a hermetically sealed container.

2.5. PREPACKAGED. - "Prepackaged" means packaged prior to being displayed or offered for retail sale.

2.6. "BEST IF USED BY" DATE. - "Best if used by" date means a date prior to deterioration of qualities described in 2.3. and 2.4.

2.7. PERSON. - "Person" means an individual, partnership, association, or corporation.

SECTION 3. SALE OF PERISHABLE FOOD AND DATE DETERMINATION.

3.1. "SELL BY" DATE. 1 - A retail food establishment shall not sell or offer for sale a prepackaged perishable food unless it is identified with a "sell by" date as prescribed by this regulation.

\subsection{SALE AFTER EXPIRATION OF "SELL BY" DATE. -}

3.2.1. ADVERTISEMENT. - Perishable food shall not be offered for sale after the "sell by" date unless it is wholesome and advertised in a conspicuous manner as being offered for sale after the recommended last date of sale. The placement of a sign, sticker, or tag is acceptable for such advertising if it is easily readable and clearly identifies the perishable food as having passed the recommended last date of sale.

3.2.2. RESPONSIBILITY FOR ADVERTISEMENT. - The retailer or final seller is responsible for the advertisement, described in 3.2.1., of a perishable food offered for sale after the recommended last date of sale.

1 Alternatively, this regulation may be adopted to require uniformity of open dating of perishable foods whenever a packager voluntarity elects to use date labeling. In such instance, section 3.1. is reworded in the following manner:

3.1. "SELL BY" DATE. If a retail food establishment elects to sell or offer for sale a prepackaged perishable food identified with a "sell by" date, the "sell by" date used must be as prescribed by this regulation. 


\subsection{DETERMINATION OF "SELL BY" DATE。-}

3.3.1. REASONABLE PERIOD FOR CONSUMPTION. -A manufacturer, processor, packer, repacker, retailer, or other person who prepackages perishable food, shall determine a date that allows a reasonable period after sale for consumption of the food without physical spoilage, loss of value, or loss of palatability. A reasonable period for consumption shall consist of at least one third of the approximate total shelf life of the perishable food.

3.3.2. RESPONSIBILITY FOR "SELL BY" DATE. - A retailer who purchases prepackaged perishable food may upon written agreement with the person prepackaging such food determine, identify, and be responsible for the "sell by" date placed on or attached to each package of such food.

\subsection{MANNER OF EXPRESSING DATE. -}

3.4.1. MONTH AND DAY, OR DAY OF WEEK. - A person described in section 3.3.1. or 3.3.2. shall place or attach to each package of perishable food a date by month and day. However, bakery products with a shelf-life of not more than 7 days may be dated with the day of the week representing the last recommended day of sale.

3.4.2. THE TERM "SELL BY"。 - The "sell by" date shall be displayed with the term "sell by" or words of similar import immediately preceding or immediately over the designated date unless a prominent notice is on the label describing the date as a "sell by" date and indicating the location of the date.

3.4.3. ABBREVIATION OF WEEKDAY. - If the day of the week is solely designated as provided in section 3.4.1., the name of the day may be abbreviated by the use of either the first two or first three letters of the name of the day.

3.4.4. EXPRESSION OF MONTH AND DAY. - Except as provided for in section 3.4.1., the date shall be designated by the first three letters of the month followed by a numeral indicating the calendar day or designated by the month represented numerically followed by a numeral designation of the calendar day. The month and day designation shall be separated by a period, slash, dash, or spacing. When a numeral designation of the first nine days of the month is used, the number shall include a zero as the first digit; for example, 01 or 03. 
3.4.5. EXPRESSION OF THE YEAR. - The "sell by" date may include the year following the day if such year is expressed as a two or four digit number separated as described in section 3.4.4.

\section{SECTION 4. SALE OF SEMI-PERISHABLE AND LONG SHELF-LIFE FOOD.}

4.1. "BEST IF USED BY" DATE. - A manufacturer, processor, packer, repacker, or other person who prepackages semi-perishable or long shelf-life food may place upon or attach to the package an open date proviciing it is designated by the "best if used by" date.

4.2. SALE AFTER EXPIRATION OF "BEST IF USED BY" DATE. - A retail food establishment may sell or of fer for sale food beyond the designated "best if used by" date providing the food is wholesome and the sensory physical quality standards for that food have not significantly diminished.

4.3. MANNER OF EXPRESSING DATE. - The "best if used by" date as required by section 4.1. shall be placed upon or attached to each container or package and be limited to the terms "best if used by" or words of similar import followed by or immediately over the date designated by the month and year unless a prominent notice is on the label describing the date as a "best if used by" date and indicating the location of the date. The date shall be designated by the first three letters of the month followed by a numeral indicating the year. The use of the day of the month is permissible provided that the day of the month is placed prior to the month; for example, 30 Jun 81 .

\section{SECTION 5. PLACEMENT OF THE DATE}

The date, whether "sell by" or "best if used by," shall be printed, stamped, embossed, perforated, or otherwise shown on the package, label on the package, or tag attached to the package in a manner that is easily readable and separate from other information, graphics, or lettering so as to be clearly visible to a prospective purchaser. The date shall not be superimposed on other required information or obscured by other information, graphics, or pricing. Regardless of the type size used, the date shall be easily readable. These requirements do not preclude a supplemental notice elsewhere on a package describing and/or indicating the location of the date. 


\section{SECTION 6. FACTORS FOR THE DATE DETERMINATION}

A person who, as provided for in this regulation, places either the "sell by" date or "best if used by" date shall determine the date by taking into consideration the food quality, characteristics, formulation, processing impact, packaging or container and other protective wrapping or coating, customary transportation, and storage and display conditions. For purposes of calculating this date, home storage conditions shall be considered to be similar to those in the usual retail store except that the date for refrigerated food may be calculated by using a home storage temperature standard of 40 degrees Fahrenheit ( 4.4 degrees Celsius).

\section{SECTION 7. RECORDS}

A person responsible for establishing the date for perishable, semi-perishable, and long shelf-life food shall keep a record of the method used for the determination of that date. A record revision is necessary whenever a factor affecting date determination is altered. Such record shall be retained for not less than 6 months after the most recent "sell by" or "best if used by" date and be available during normal business hours for examination upon request by (insert agency name).

\section{SECTION 8. EXEMPTIONS}

8.1. This regulation does not apply to perishable fruits or vegetables in a container permitting sensory examination.

8.2. This regulation does not apply to prepackaged perishable foods open dated according to requirements of Federal law or regulation.

SECTION 9. PRE-EMPTION OF LOCAL, COUNTY, AND MUNICIPAL ORDINANCE

A municipality or county shall not adopt or impose standards or requirements other than those provided for in this regulation.

\section{SECTION 10. EPFECTIVE DATE}

This regulation shall become effective on and after (insert appropriate date). 


\title{
UNIFORM REGULATION FOR NATIONAL TYPE EVALUATION
} 1983

\author{
as adopted by \\ The National Conference on Weights and Measures ${ }^{1}$
}

\section{BACKGROUND}

The Uniform Regulation for National Type Evaluation is a necessary adjunct to recognize and enable participation in the National Type Evaluation Program administered by the National Bureau of Standards. The Regulation specifically authorizes: type evaluation; recognition of a National Bureau of Standards "Certificate of Conformance" of type; the State Measurement Laboratory to operate as a Participating Laboratory, if authorized by the National Bureau of Standards under its program of certification of State Measurement Laboratories; and, the State to charge fees to those persons who seek type evaluation of weighing and measuring devices.

\section{INTENT}

It is the intent of this regulation to have all States use the National Type Evaluation Program, as approved by the National Conference on Weights and Measures, as their examining procedure.

\section{STATUS OF PROMULGATION}

The map on the following page shows the status of promulgation of the Uniform Regulation for National Type Evaluation.

1 The National Conference on Weights and Measures is sponsored by the National Bureau of Standards in partial implementation of its statuatory responsibility for "cooperation with the States in securing uniformity in weights and measures laws and methods of inspection. 
Type Evaluation Regulation

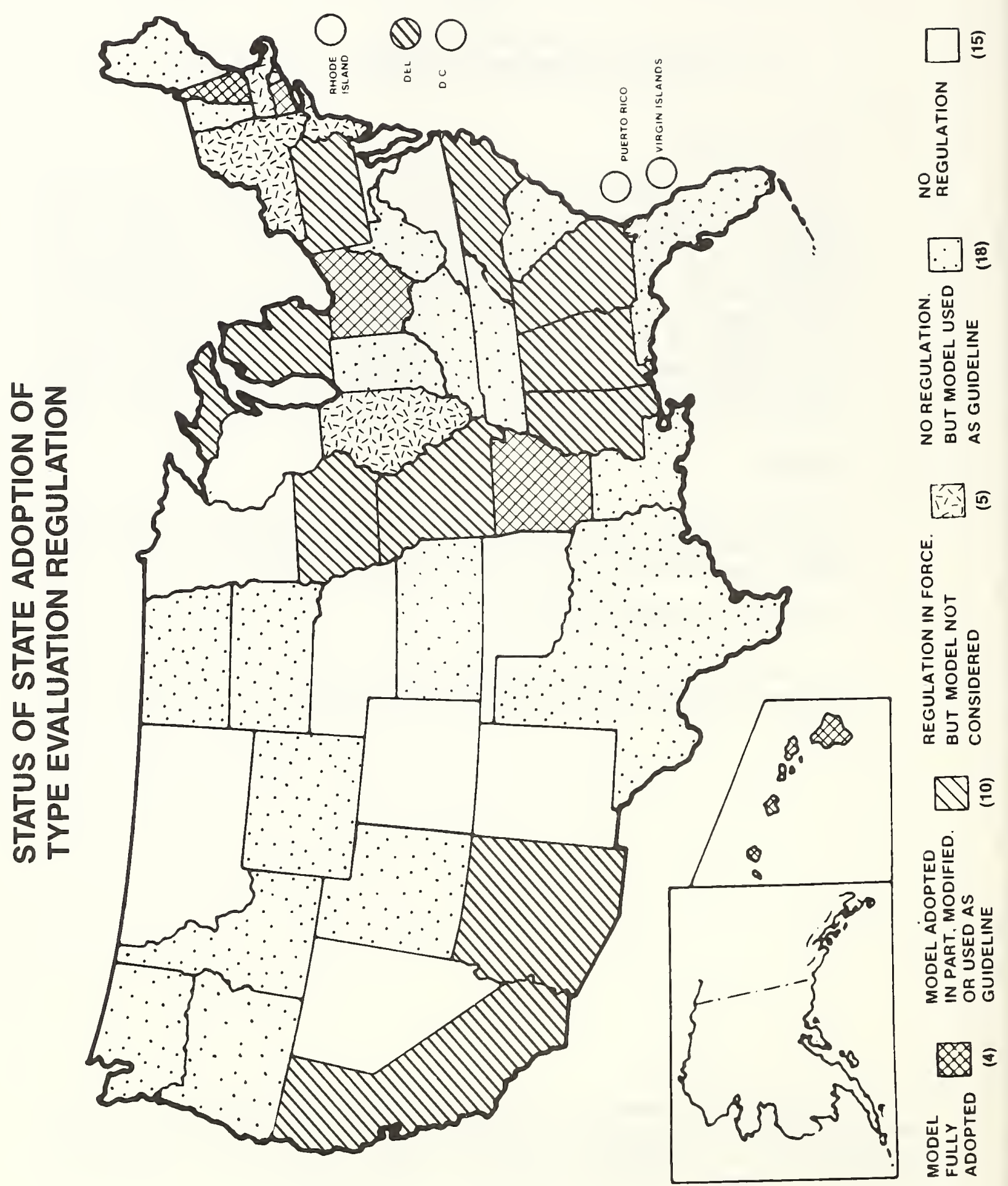




\section{TABLE OF CONTENTS}

SECTION

PAGE

1. APPLICATION

IV-113

2. DEFINITIONS

IV -113

2.1. National Type Evaluation Program

IV -113

2.2. Type Evaluation

IV -113

2.3. Type

IV -113

2.4. Participating Laboratory

IV -113

2.5. Certificate of Conformance

IV-114

2.6. Director

IV-114

3. CERTIFICATE OF CONFORMANCE

IV-114

4. PARTICIPATING LABORATORY

IV -114

5. REVOCATION OF CONFLICTING REGULATIONS

IV-114

6. EFFECTIVE DATE

IV -114 


\section{UNIFORM REGULATION FOR NATIONAL TYPE EVALUATION 1983}

\section{SECTION 1. APPLICATION}

This regulation shall apply to all classes of devices and/or equipment as covered in National Bureau of Standards Handbooks 44, 105-1, 105-2, and $105-3$.

\section{SECTION 2. DEFINITIONS}

2.1. NATIONAL TYPE EVALUATION PROGRAM. - The term "National Type Evaluation Program" shall be construed to mean a program of cooperation between the National Bureau of Standards, the National Conference on Weights and Measures, the States, and the private sector for determining, on a uniform basis, conformance of a type with the relevant provisions of National Bureau of Standards Handbook 44, "Specifications, Tolerances, and Other Technical Requirements for Weighing and Measuring Devices," National Bureau of Standards Handbook 105-1, "Specifications and Tolerances for Reference Standards and Field Standard Weights and Measures, Specifications and Tolerances for Field Standard Weights (NBS Class F)," National Bureau of Standards Handbook 105-2, "Specifications and Tolerances for Reference Standards and Field Standard Weights and Measures, Specifications and Tolerances for Field Standard Measuring Flask," or National Bureau of Standards Handbook 105-3, "Specifications and Tolerances for Reference Standards and Field Standard Weights and Measures, Specifications and Tolerances for Graduated Neck Type Volumetric Field Standards."

2.2. TYPE EVALUATION. - The term "type evaluation" shall be construed to mean the testing, examination, and/or evaluation of a type by a Participating Laboratory under the National Type Evaluation Program.

2.3. TYPE. - The term "type" shall be construed to mean a model or models of a particular measurement system, instrument, element, or a field standard that positively identifies the design. A specific type may vary in its measurement ranges, size, performance, and operating characteristics as specified in the Certificate of Conformance.

2.4. PARTICIPATING LABORATORY. - The term "Participating Laboratory" shall be construed to mean any State Measurement Laboratory that has been certified by the National Bureau of Standards, in accordance with its program for the Certification of Capability of State Measurement Laboratories, to conduct a type evaluation under the National Type Evaluation Program. 
2.5. CERTIFICATE OF CONFORMANCE.. - The term "Certificate of Conformance" shall be construed to mean a document issued by the National Bureau of Standards based on testing in participating laboratories, said document constituting evidence of conformance of a type with the requirements of National Bureau of Standards Handbooks 44, 105-1, 105-2, or 105-3.

2.6. DIRECTOR. - The term "Director" means the of the Department of

\section{SECTION 3. CERTIFICATE OF CONFORMANCE}

The Director may require any weight or measure, or any weighing or measuring instrument or device to be issued a Certificate of Conformance prior to use for commercial or law enforcement purposes. ${ }^{6}$

\section{SECTION 4. PARTICIPATING LABORATORY}

The Director is authorized to operate a Participating Laboratory as part of the National Type Evaluation Program. In this regard, the Director is authorized to charge and collect fees for type evaluation services.

\section{SECTION 5. REVOCATION OF CONFLICTING REGULATIONS}

All Provisions of all orders and regulations heretofore issued on this same subject that are contrary to or inconsistent with the provisions of this regulation, and specifically , are hereby revoked.

\section{SECTION 6. EFFECTIVE DATE}

This regulation shall become effective on

Given under my hand and the seal of my office in the City of on this day of , 19 .

${ }^{6}$ See G-A.1., Section 1.14. General Code, National Bureau of Standards Handbook 44 for definition of commercial and law enforcement equipment. 


\section{INDEX TO HANDBOOK}

Key to abbreviations of Laws and Regulations:

$\begin{array}{ll}\text { UWML } & \text { Uniform Weights and Measures Law } \\ \text { UWL } & \text { Uniform Weighmaster Law } \\ \text { UPLR } & \text { Uniform Packaging and Labeling Regulation } \\ \text { UMSCR } & \text { Uniform Regulation for Method of Sale of Commodities } \\ \text { UODR } & \text { Uniform Regulation for Open Dating } \\ \text { UUPR } & \text { Uniform Regulation for Unit Pricing } \\ \text { URVRS } & \text { Uniform Regulation for the Voluntary Registration } \\ \text { URNTE } & \text { Uniform Regulation for National Type Evaluation }\end{array}$

Abbreviation of weekday, in open dating

Abbreviations and symbols

Ability to make correct weight certificates

Ability to weigh accurately

Accurate

$\begin{array}{lll}\text { UODR } & 3.4 .3 . & \text { IV-105 } \\ \text { UPLR } & 6.5 .1 . & \text { IV-16 } \\ \text { UWL } & 3 . & \text { III-25 } \\ \text { UWL } & 3 . & \text { III-25 } \\ \text { U'NML } & 11.1 . & \text { III-15 } \\ & & \\ \text { UWML } & 11.5 . & \text { III-15 } \\ \text { UWML } & 11.2 . & \text { III-15 } \\ \text { UODR } & 3.2 .1 . & \text { IV-104 } \\ & & \\ \text { UMSCR } & 2.9 .1 .12 . & \text { IV-71 } \\ \text { UWML } & 21 . & \text { III-19 }\end{array}$

Adoption of weights and measures requirements

Advertised commodity or service

Advertisement of sale after sell by date

Advertisement, offering, invoice, softwood lumber

Advertising packages for sale

Aerosols and similar pressurized containers

UPLR $\quad 10.3$.

IV -30

UPLR

10.9.2.(d)

IV-34

UWL

3.

III-25

Age requirements

UWML

12.15 .

III-17

UPLR

12.1.2.

IV -45

Allowable difference:

LPG cylinders

Railroad car tare weights

UMSCR

2.15.1.

IV-76

Combination quantity

declaration

UMSCR

3.4.2.

IV -79

Stemware, tumblers

UMSCR

3.2 .

IV -78

UMSCR

3.2.1.

IV-78 
American Softwood Lumber Standard

$\begin{array}{lll}\text { UMSCR } & 2.9 .1 .13 . & \text { IV-71 } \\ \text { UWML } & 12.8 . & \text { III-16 } \\ \text { UMSCR } & 2.14 . & \text { IV-76 } \\ \text { UPLR } & 13.2 . & \text { IV-48 } \\ \text { UPLR } & 11.24 . & \text { IV-43 } \\ \text { UPLR } & 10.9 .2 .(\mathrm{i}) & \text { IV-35 } \\ \text { UWL } & 4 . & \text { III-25 }\end{array}$

Annual testing of standards

Anthracite, bituminous,

lignite coal

Anticipated ordinary customary price

Antifreeze, labeling exemption

Appliance covers, textile

Application form

UWL

4.

III-25

Application

Open Dating Regulation

Packaging and Labeling Regulation

UODR

1.2

IV-103

UPLR

1.

IV-11

Unit Pricing Regulation

Approve city or county standards

Approve correct weights and meas

UUPR

1.

IV -85

UWML

12.8 .

III-16

UWML

12.12 .

III-16

Area measure, dual quantity declaration

$\begin{array}{lll}\text { UPLR } & 6.7 .5 . & \text { IV-19 } \\ \text { UWML } & 13.5 . & \text { III-17 } \\ \text { UMSCR } & 2.2 & \text { IV-65 } \\ \text { UPLR } & 11.26 . & \text { IV-44 } \\ \text { UMSCR } & 2.18 . & \text { IV-77 }\end{array}$

Arrest

Asphalt paints, coatings, plastics

Association of Bedding and Furniture Law Officials

ASTM D-3699, Kerosene

ASTM D-1505-68, Density of Plastics

$\begin{array}{lll}\text { UMSCR } & 2.12 .7 . & \text { IV }-74\end{array}$

Authorization to enter commercial premises

Automotive cooling system antifreeze

Auxiliary containers without printed matter

Availability of physical standards

UWML $\quad$ I3.1. III-17

$\begin{array}{lll}\text { UPLR } & 11.24 . & \text { IV-43 }\end{array}$

$\begin{array}{lll}\text { UPLR } & \text { I(c) }\end{array}$

UWML 11.3. III-15

Average quantity of contents

UPLR 6.13. IV-25

$\begin{array}{lll}\text { UPLR } & \text { 7.6. IV-27 }\end{array}$

Average of the quantities in the packages

UPLR 12.1.1. IV-45

Average requirement for $L P G$ cylinders

UMSCR

2.15.2.

IV-76

Avoirdupois pound or ounce

UPLR

6.5.(a)

IV-15 
Bags, gusset or no gusset

Bags, polyethylene, nonconsumer

Bargain size, value size, economy size

Bark mulch, method of sale, unit of measure

Bark mulch: variations from declared volume

Basis of weight, measure, or count

Bath mats

Batt and blanket insulation

Bedsheets

Bedsheets or tablecloths, metric system

Bedspreads

Berries and small fruits

Best if used by date, definition

Best if used by day

Beverageware, pressed and blown tumblers, stemware

Bidimensional commodities

Bidimensional commodities, metric system

Biscuits, buns, or rolls

Bituminous Coal

Blanket and batt insulation

Blankets

Blown, formed, molded declaration

Boards of softwood lumber, definition

Boards, timbers, kindling logs as fuel

Bonus offer, 2 for 1 sale, 1 cent sale

$\begin{array}{lll}\text { UPLR } & 10.8 .1 .(\mathrm{a}) & \text { IV-31 } \\ \text { UMSCR } & 2.12 .6 . & \text { IV-74 } \\ \text { UPLR } & 13.3 . & \text { IV-49 } \\ \text { UMSCR } & 2.17 . & \text { IV-76 } \\ \text { UPLR } & 10.11 . & \text { IV-37 }\end{array}$

UWML 12.10. III-16

UPLR 10.9.2.(h) IV-35

UMSCR 2.13.3. IV-75

UPLR 10.9.2. IV-33

6.7.7.(d) IV -20

UPLR 6.8.3.(b)(3) IV-23

UPLR 10.9.2.(d) IV-34

UMSCR 1.1. IV-59

UODR 2.6. IV-104

UODR 4.1. IV-106

$\begin{array}{lll}\text { UMSCR } & \text { 3.2.1. IV }-78\end{array}$

UPLR 6.7.7. IV-19

UPLR 6.8.3. IV-22

UMSCR 1.2. IV-59

UMSCR 2.14. IV-76

UMSCR 2.13.3. IV-75

UPLR 10.9.2.(d) IV-34

UPLR 8.1.3. IV-27

8.1.2. IV -27

UMSCR 2.9.1.2. IV-70

UMSCR 2.3.1.1. IV-65

$\begin{array}{lll}\text { UPLR } & \text { 13.1. }\end{array}$ 


\section{Bottles of soft drinks \\ Bottles of soft drinks, multi-unit \\ Boxes, pans, bags, cups, cotainers \\ Bread \\ Budget pack, bargain size, value size}

Bulk food commodities, pricing Bulk meat sales

Bulk Sales

Carpeting

Gasoline

Firewood

Insulation

Meat

Buns, rolls, or biscuits

Bushel

Butter, labeling exemptions

Butter, oleomargarine, and margarine

$\begin{array}{lll}\text { UPLR } & 11.11 . & \text { IV-40 } \\ \text { UPLR } & 11.12 . & \text { IV-41 } \\ \text { UPLR } & 10.8 .1 . & \text { IV-31 } \\ \text { UMSCR } & 1.2 . & \text { IV-59 } \\ \text { UPLR } & 13.3 . & \text { IV-49 } \\ \text { UMSCR } & 1.9 . & \text { IV-62 } \\ \text { UMSCR } & 1.11 . & \text { IV-63 } \\ \text { UWML } & 18 . & \text { III-18 } \\ \text { UMSCR } & 2.10 . & \text { IV-73 } \\ \text { UMSCR } & 2.19 . & \text { IV-77 } \\ \text { UMSCR } & 2.3 .5 . & \text { IV-66 } \\ \text { UMSCR } & 2.13 .4 & \text { IV-75 } \\ \text { UiMSCR } & 1.11 . & \text { IV-63 } \\ \text { UMSCR } & 1.2 . & \text { IV-59 } \\ \text { UPLR } & 6.5 .(f) & \text { IV-16 } \\ \text { UPLR } & 11.13 . & \text { IV-41 } \\ \text { UMSCR } & 1.3 . & \text { IV-59 }\end{array}$

Calculation of principal display panel area

Calibration capabilities

Calibration of service agency standards

California Bureau of Home Furnishings

Calking compounds, glazing compounds, sealants

$\begin{array}{lll}\text { UPLR } & 8.2 . & \text { IV-8 } \\ \text { UWML } & 11.3 . & \text { III-15 } \\ \text { URVRS } & 9 . & \text { IV-98 } \\ \text { UPLR } & 11.26 . & \text { IV-44 } \\ \text { UMSCR } & 2.7 . & \text { IV-69 } \\ \text { UPLR } & 11.22 . & \text { IV-42 } \\ \text { UUPR } & 2 . & \text { IV-85 } \\ \text { UPLR } & 11.3 . & \text { IV-38 } \\ \text { UPLR } & 10.8 .2 . & \end{array}$

Camera Film, labeling exemptions Candy

Candy, small confections, labeling exemptions

Capacity of container

Capacity of scale used by weighmaster
13.

III-27 
Capitalization of symbols

Carcass meat sales

Carpeting

Carpets

Cartons of 12 eggs

Cartons of cigarettes and small cigars

Centimeter, millimeter, or meter

Cents-off representations

Cereals

Certificate of Conformance

Certificate of registration

Character of declaration: average

Charging a fee for weighing without license

Cheese packages, labeling exemptions

Cheese, natural and processed

Cigarettes and small cigars

Cigars, and cuts, plugs, and twists of tobacco

Circular, round-shaped containers

Citation of weighmaster law

Citizenry requirements

Coal, solid fuel products

Coated seed

Coatings, asphalt paints, plastics

Cocoa, tea, and coffee

Coffee, tea, and cocoa

Colognes and toilet water

Color contrast, consumer package

Combination declaration

Combination packages

Combination quantity declarations

$\begin{array}{lll}\text { UPLR } & 6.6 .1 .(\mathrm{a}) & \text { IV-17 } \\ \text { UMSCR } & 1.11 . & \text { IV-63 } \\ \text { UMSCR } & 2.10 . & \text { IV-73 } \\ \text { UPLR } & 10.9 .2 .(\mathrm{g}) & \text { IV-35 } \\ \text { UPLR } & 11.14 . & \text { IV-41 } \\ & 10.2 & \text { IV-30 }\end{array}$

$\begin{array}{lll}\text { UPLR } & 11.7 . & \text { IV-39 } \\ \text { UPLR } & 6.6 .(\mathrm{c}) & \text { IV-17 } \\ \text { UPLR } & 13.1 . & \text { IV-46 } \\ \text { UUPR } & 2 . & \text { IV-85 } \\ \text { URNTE } & 2.5 & \text { IV-114 } \\ & & \text { IV-97 } \\ \text { URVRS } & 6 . & \\ \text { UPLR } & 6.13 . & \text { IV-25 } \\ & 7.6 . & \text { IV-27 } \\ & 12.1 .1 . & \text { IV-45 }\end{array}$

UWL $17 . \quad$ III-28

UPLR 11.2. IV-38

UUPR $2 . \quad$ IV-85

$\begin{array}{lll}\text { UPLR } & \text { 11.7. }\end{array}$

$\begin{array}{lll}\text { UPLR } & \text { 11.5. IV-39 }\end{array}$

UPLR 10.8.1.(c) IV-32

UWL 25 . III-30

UWL $3 . \quad$ IV-25

$\begin{array}{lll}\text { UMSCR } & \text { 2.14. IV-76 }\end{array}$

$\begin{array}{lll}\text { UPLR } & 10.10 & \text { IV-37 }\end{array}$

UMSCR 2.2. IV -65

UUPR $2 . \quad$ IV-85

$\begin{array}{lll}\text { UUPR } & 2 . & \text { IV-85 }\end{array}$

$\begin{array}{lll}\text { UUPR } & 2 . & \text { IV-85 } \\ \text { UPLR } & 8.1 .3 . & \text { IV-27 } \\ \text { UPLR } & 6.4 .1 . & \text { IV-15 } \\ \text { UPLR } & 10.5 . & \text { IV-30 } \\ & 11.18 & \text { IV-42 } \\ \text { UMSCR } & 3.2 . & \text { IV-78 }\end{array}$


Combined metric and inch-pound declarations

Comforters

Comforters, mattress pads, pillows cushions

Commercial and law-enforcement $w$ and $m$ device

Commercial weights and measures

Commodities

Commodities in liquid form

Commodities variable weights and sizes

Commodity in package form

Common fractions

$\begin{array}{lll}\text { UPLR } & 6.11 .2 . & \text { IV-24 } \\ \text { UPLR } & 10.9 .2 .(\mathrm{d}) & \text { IV-34 } \\ \text { UPLR } & 11.26 . & \text { IV-44 } \\ \text { URVRS } & 2.3 . & \text { IV-96 } \\ \text { UWML } & 12.10 . & \text { III-16 } \\ \text { UWML } & 12.10 . & \text { III-16 } \\ \text { UWML } & 17 . & \text { III-18 } \\ \text { UPLR } & 6.4 & \text { IV-15 } \\ \text { UPLR } & 11.27 . & \text { IV-44 } \\ \text { UPLR } & 2.1 . & \text { IV-11 } \\ \text { UPLR } & 6.10 .(\mathrm{c}) & \text { IV-23 } \\ & & \\ \text { UMSCR } & 2.6 .2 .1 . & \text { IV-68 } \\ \text { UPLR } & 6.2 .(\mathrm{a})(1) & \text { IV-14 } \\ \text { UPLR } & 3.1 . & \text { IV-13 } \\ \text { UMSCR } & 2.4 .2 .2 . & \text { IV-67 } \\ \text { UWML } & 12.10 . & \text { III-16 }\end{array}$

Common fractions in quantity statements, roofing

Common or decimal fractions

Common or usual name

Compressed peat or peat moss

Computing the charge or payment for services

UWML $\quad 12.10$.

III-16

Condemnation of weights and measures

$\begin{array}{lll}\text { UWML } & 12.12 . & \text { III-16 } \\ \text { UUPR } & 2 . & \text { IV-85 } \\ \text { UUPR } & 2 . & \text { IV-85 } \\ \text { UWML } & 12.6 . & \text { III-16 } \\ \text { UPLR } & 11.3 . & \text { IV-38 }\end{array}$

Condensed soups

Condiments and relishes

Conduct investigations

Confections, small, labeling exemptions

UWML 12.14. III-16

Consumer confusion

Consumer package

Consumer package declaration of identity

Consumer packages declaration of quantity

Consumer protection

UPLR 2.2 .

IV-12

UPLR 3.1. IV-13

UPLR 6.

UWML 11.5. III-15

Consumer usage

Consumption by individuals

UPLR 6.4. IV-15

UPLR 2.2. IV-12

Containers for retail tray pack display

UPLR 1.(d) IV-11

Containers, bags, cups, boxes, pans

Cookies and crackers

UPLR

10.8.1.

IV-31

UUPR $2 . \quad$ IV-85 
Cooking oils and shortening

Copies of weight certificates

Cord of wood

Corn flour and corn meal, labeling exemptions

Corn meal, hominy grits, and flour

\section{Correct}

Correct weights and measures

Cost-per-unit information requirements

Cottage cheese, products, sour cream yogurt

Count combined with weight, measure, or size

Count of packages, bulk sales

Count, labeling exemptions

Count, ply

Covered hopper cars, flat cars, refrigerator cars

Crackers and cookies

Cream, milk, lowfat milk, skim milk, cultured milk

Credentials

Cubic measure for peat and peat moss

Cubic meter or cubic centimeter

Cubic yard, cubic foot, cubic inch

Cultured milk, cream, milk, lowfat milk, skim milk

Cups

Curtains

Cushions, comforters, mattress pads, etc.

Cuts, plugs, and twists of tobaceo and cigars

Cylindrical container, area of PDP calculations

Cylindrical containers

$\begin{array}{lll}\text { UUPR } & 2 . & \text { IV-85 } \\ \text { UWL } & 14 . & \text { III-28 } \\ \text { UMSCR } & 2.3 .1 .2 . & \text { IV-65 } \\ \text { UPLR } & 11.20 . & \text { IV-42 } \\ \text { UMSCR } & 1.4 . & \text { IV-60 } \\ \text { UWML } & 1.3 . & \\ \text { UWML } & 12.12 . & \text { III-11 } \\ \text { UWML } & 11.4 . & \text { III-16 } \\ \text { UMSCR } & 1.7 . & \text { III-15 } \\ \text { UPLR } & 6.4 .1 .(c) & \text { IV-61 } \\ \text { UWML } & 18 .(e) & \text { III-18 } \\ \text { UPLR } & 11.28 . & \text { IV-44 } \\ \text { UPLR } & 6.9 . & \text { IV-23 } \\ \text { UMSCR } & 3.4 .4 . & \text { IV-80 } \\ \text { UUPR } & 2 . & \text { IV-85 }\end{array}$

UMSCR

1.6.

IV-61

UWML 13.4 .

III-17

UMSCR

2.4.2.2.

IV -67

UPLR

6.6.(e)

IV-17

UPLR

6.5.(e)

IV-16

UMSCR

1.6.

IV-61

UPLR

10.8.1.(d)

IV-32

UPLR

10.9.2.(f)

IV-35

UPLR

11.26 .

IV-44

UPLR

11.5.

IV-39

UPLR

UPLR

8.2.(b)

IV -28

10.7

IV-31 
Deceptive commodity or service

Decimal fractions

Declaration of identity, bulk sales

Declaration of identity, meat cuts

Declaration of identity: Consumer package

Declaration of identity: nonconsumer package

Declaration of quantity for: bulk sales

peat and peat moss

packages

roofing materials

advertisements

consumer packages

nonconsumer packages

Declaration of responsibility

Declaration of unit price on random packages

Declaration of weight, polyethylene products

Decorative containers, labeling exemptions

Delegation of responsibilities

Delivery ticket

Deliver ticket or sales invoice
for carpeting
for gasoline
for firewood
for insulation
for meat

Deodorants, personal

Detergents, soap powders, household cleaners

$\begin{array}{lll}\text { UWML } & 11.2 . & \text { III-15 } \\ \text { UPLR } & 6.10 .(\mathrm{d}) & \text { IV-24 } \\ \text { UWML } & 18 .(\mathrm{d}) & \text { III-18 } \\ \text { UMSCR } & 1.10 . & \text { IV-62 } \\ \text { UPLR } & 3.1 ., 3 . & \text { IV-13 } \\ \text { UWML } & 19 . & \text { III-18 }\end{array}$

$\begin{array}{lll}\text { UPLR } & 4 . & \text { IV-13 } \\ \text { UWML } & 19 .(\mathrm{a}) & \text { III-18 } \\ \text { UWML } & 18 .(\mathrm{c}) & \\ \text { UMSCR } & 2.4 .1 . & \text { III-18 } \\ \text { UWML } & 19 .(\mathrm{b}) & \text { IV-67 } \\ \text { UMSCR } & 2.6 .2 . & \text { III-18 } \\ \text { UWML } & 21 . & \text { IV-68 } \\ \text { UPLR } & 6 . & \text { III-19 } \\ \text { UPLR } & 7 . & \text { IV-14 } \\ \text { UWML } & 18 ., 19 . & \text { IV-25 } \\ \text { UPLR } & 5 . & \text { III-18 }\end{array}$

UWML 20 III-19

UMSCR 2.12.7. IV-74

UPLR $11.17 . \quad$ IV-42

UWML 12.7. III-16

UWML 18.

$\begin{array}{lll}\text { UMSCR } & 2.10 . & \text { IV }-73 \\ \text { UMSCR } & 2.19 .2 . & \text { IV }-77 \\ \text { UMSCR } & 2.3 .5 . & \text { IV-66 } \\ \text { UMSCR } & 2.13 .4 . & \text { IV-72 } \\ \text { UMSCR } & 1.11 . & \text { IV-63 } \\ \text { UUPR } & 2 . & \text { IV-85 } \\ \text { UUPR } & 2 . & \text { IV-85 }\end{array}$


Determination of sell-by date

Diapers, non-rectangular, textile

Dimension lumber, softwood

Director

Dish cloths

Dish towels, woven textile

Disinfectants

Display card package

Distributed by

Documentation for retail labeling, gasoline-alcohol blends

See also Delivery Ticket

Drapes

Dressed, surfaced lumber, definition

Drinking water, labeling exemptions

Drugs, prescription and insulincontaining

Dry detergents, soap powders, household cleaners

Dry quart, dry pint, peck

Dual declaration exemption in advertisements

Dual quantity declaration, area measure

Dual quantity declaration, length measure

Dual quantity declaration, liquid measure

Dual quantity declaration, weight Duties of Director

\begin{tabular}{|c|c|c|}
\hline UODR & 3.3 . & IV -105 \\
\hline UPLR & 10.9.2.(i) & IV-35 \\
\hline UMSCR & 2.9 & IV -70 \\
\hline UWML & 1.6. & III-11 \\
\hline UWL & 1.3. & III-25 \\
\hline URNTE & 2.6 & IV-114 \\
\hline UPLR & 10.9.2.(h) & IV -35 \\
\hline UPLR & $10.9 .2 .(h)$ & IV-35 \\
\hline UUPR & 2. & IV-85 \\
\hline UPLR & 10.1. & IV -29 \\
\hline UPLR & 5. & IV -13 \\
\hline UMSCR & 2.19 .2 & IV-77 \\
\hline UPLR & 10.9.2.(f) & IV -35 \\
\hline UMSCR & 2.9.1.1. & IV -70 \\
\hline UPLR & 11.10 . & IV -40 \\
\hline UPLR & 11.21 . & IV -42 \\
\hline UUPR & 2. & IV-85 \\
\hline UPLR & 6.5.(f) & IV -16 \\
\hline UWML & 21. & III-19 \\
\hline UPLR & 6.7 .5 & IV -19 \\
\hline UPLR & 6.7.4. & IV -19 \\
\hline UPLR & 6.7.3. & IV -19 \\
\hline UPLR & 6.7.2. & IV -18 \\
\hline UWML & 12. & III-15 \\
\hline
\end{tabular}


Economy size, economy pack, budget pack

Effective date of:

regulation open dating

unit price regulation

voluntary registration regulation

weighmaster law

weights and measures law

method of sale regulation

packaging and labeling regulation

type evaluation regulation

Eggs

Eggs, labeling exemptions

Encapsulated seed

$\begin{array}{lll}\text { UPLR } & 13.3 . & \text { IV-49 } \\ \text { UODR } & 10 . & \text { IV-107 } \\ \text { UUPR } & 7 . & \text { IV-87 } \\ \text { URVRS } & 12 . & \text { IV-98 } \\ \text { UWL } & 26 . & \text { III-30 } \\ \text { UWML } & 28 . & \text { III-20 } \\ \text { UMSCR } & 5 . & \text { IV-80 } \\ \text { UPLR } & 15 . & \text { IV-50 } \\ \text { URNTE } & 6 . & \text { IV-114 } \\ \text { UPLR } & 10.2 . & \text { IV-30 } \\ \text { UPLR } & 11.14 . & \text { IV-41 } \\ \text { UPLR } & 10.10 . & \text { IV-37 } \\ \text { UWML } & 11.5 . & \text { III-15 } \\ \text { UWL } & 2 . & \text { III-25 } \\ \text { UPLR } & 8.1 . & \text { IV-27 } \\ \text { UPLR } & 9.1 . & \text { IV-29 } \\ \text { UPLR } & 11.22 .(b) & \text { IV-43 }\end{array}$

Encourage economic growth

Enforcing officer

IV -43

Equipment minimums for sevice agency

Equity among buyers and sellers

Establish labeling requirements

Establish standards of fill

Establish unit pricing

requirements

URVRS 5 .

IV-97

UWML

11.5 .

III-15

UWML

12.4 .

III-15

UWML

12.4 .

III-15

UWML $\quad 12.4$.

III-15

Evaluation of qualifications of applicants

Evidence

UWL

5.

III-25

UWML

13.3.

III-17

Evidence of qualifications

Examination and calibration of

UWL

24.

III-20

service agency standards

URVRS

4.

III-25

Execution of weight certificate

UWL

9.

IV -98

11.

III-27 
Exemptions

Exemptions for

individual serving size packages

random packages

small confections

uniform weight packages of cheese

Exemptions to dual quantity declarations labeling open dating

Expiration of weighmaster license Expression of month and day, in open dating

Expression of the year, in open dating

$\begin{array}{lll}\text { UWML } & 12.5 . & \text { III-25 } \\ \text { UPLR } & 11.4 . & \text { IV-38 } \\ \text { UPLR } & 11.2 . & \text { IV-38 } \\ \text { UPLR } & 11.3 . & \text { IV-38 } \\ \text { UPLR } & 11.2 . & \text { IV-38 } \\ \text { UPLR } & 11.1 . & \text { IV-38 } \\ \text { UPLR } & 11 . & \text { IV-38 } \\ \text { UODR } & 8 . & \text { IV-107 } \\ \text { UWL } & 8 . & \text { III-26 } \\ \text { UODR } & 3.4 .4 . & \text { IV-105 } \\ & & \\ \text { UODR } & 3.4 .5 . & \text { IV-106 }\end{array}$

- F -

Face cloths

Face cord of firewood

Facilitation of value comparisons

Factors for date determination, in open dating

False weight certificate

False weighing by weighmaster

Falsifying weight certificate

Federal Fair Packaging and Labeling Act

Federal Food, Drug, and Cosmetic Act

Federal requirements for packages

Fee for serviceperson registration

Felt roofing materials

Fence wire products

Film and sheeting, polyethylene, nonconsumer

Film and sheeting, consumer, polyethylene

$\begin{array}{lll}\text { UPLR } & 10.9 .2 .(\mathrm{h}) & \text { IV-35 } \\ \text { UMSCR } & 2.3 .4 . & \text { IV-66 } \\ \text { UWML } & 12.14 . & \text { III-17 } \\ \text { UODR } & 6 . & \text { IV-107 } \\ \text { UWL } & 19 . & \text { III-29 } \\ \text { UWL } & 19 . & \text { III-29 } \\ \text { UWL } & 20 . & \text { III-29 } \\ \text { UPLR } & 6.1 . \text { ftnote } & \text { IV-14 } \\ \text { UMSCR } & 2 . \text { ftnote } & \text { IV-65 } \\ \text { UMSCR } & 1.3 . f t n o t e & \text { IV-59 } \\ \text { UPLR } & 11.8 . & \text { IV-39 } \\ & & \\ \text { URVRS } & 3 . & \text { IV-96 } \\ \text { UMSCR } & 2.6 . & \text { IV-67 } \\ \text { UMSCR } & 2.1 . & \text { IV-65 } \\ \text { UMSCR } & 2.12 .5 . & \text { IV-73 }\end{array}$


Film, camera, labeling exemptions

Film, foil, and other rolls of wrapping

Fines under weighmaster law

Fines under weights and measures law

Fireplace and stove wood

Firewood

Firmly established general consumer usage/trade custom

First conviction/weights and measures law

First offense under weighmaster law

Fishing lines and reels

Fitted sheets

Fixture covers, textile

Flags, textile

Flat cars, covered hopper cars, refrigerator cars

Flat sheets

Flour, corn meal, and hominy grits

Flour, labeling exemptions

Fluid dairy products, ice cream, frozen desserts

Fluid milk products

Fluid ounce

Fluid ounce, liquid quart, liquid pint

Foil, film and other rolls of wrapping

Food and sandwich bags, consumer, polyethylene

Food products

Food wrap, consumer, polyethylene

Foot, yard, inch

Four feet, 4 sq feet, 4 pounds, 1 gallon, or more

Fractions, inch-pound

Fractions, metric

Free area, consumer package

$\begin{array}{lll}\text { UPLR } & 11.22 . & \text { IV-42 } \\ \text { UUPR } & 2 . & \text { IV-85 } \\ \text { UWL } & 20 ., 19 . & \text { III-29 } \\ \text { UWML } & 22 . & \text { III-19 } \\ \text { UMSCR } & 2.3 . & \text { IV-65 } \\ \text { UMSCR } & 2.3 . & \text { IV-65 } \\ \text { UPLR } & 6.4 . & \text { IV-15 } \\ \text { UWML } & 221 . & \text { III-19 } \\ \text { UWL } & 19 . & \text { III-29 } \\ \text { UPLR } & 11.29 . & \text { IV-45 } \\ \text { UPLR } & 10.9 .2 .(\mathrm{a}) & \text { IV-34 } \\ \text { UPLR } & 10.9 .2 .(\mathrm{i}) & \text { IV-35 } \\ \text { UPLR } & 10.9 .2 .(\mathrm{f}) & \text { IV-35 } \\ \text { UMSCR } & 3.4 .4 . & \text { IV-80 } \\ \text { UPLR } & 10.9 .2 .(\mathrm{b}) & \text { IV-34 }\end{array}$

UMSCR

1.4.

IV-60

UPLR

11.15 .

IV-41

UPLR

11.9 .

IV-39

UMSCR

1.6.

UPLR

6.5.2.

IV-61

IV -16

UPLR

6.5.(b)

IV -15

UUPR

2.

IV-85

UMSCR

2.12.4.

IV-74

UMSCR

1.

UMSCR

2.12.2.

IV -59

IV-73

UPLR

$6.5 .(c)$

IV-16

UPLR

6.7.6.

IV-19

UPLR

6.10.(b)

IV-23

UPLR

6.10.(a)

IV-23

UPLR

IV-28 
Freezer boxes

Freight cars, tare weights

Frozen desserts, ice cream, fluid dairy products

Frozen yogurt, ice cream, and ice milk

Fruit and vegetable juices and drinks

Fruit juice beverages

Fruits and vegetables

Fruits (small) and berries

Frustration of value comparison

Full, when-packed, minimum, giant

Furniture scarves, textile

Gallon

Garbage can liners

Gasoline-alcohol blends

Generic term

Generic terms for meat cuts

Giant, full, when-packed, minimum

Glass containers, reusable, returnable

Glass or plastic containers of milk

Glassware, allowable differences

Glazing compounds, sealants, putty

Good distribution practice

Good manufacturing practice

Good packaging practice

Government employee as weighmaster

Grade of softwood lumber, definition
UPLR $\quad$ 10.8.2(a)(1) IV-32

UMSCR 3.4 .

IV -79

$\begin{array}{lll}\text { UPLR } & \text { 11.9. IV-39 }\end{array}$

$\begin{array}{lll}\text { UMSCR } & 1.7 .1 . & \text { IV-62 }\end{array}$

$\begin{array}{lll}\text { UUPR } & 2 . & \text { IV-85 }\end{array}$

UPLR $11.10 . \quad$ IV-40

UUPR $2 . \quad$ IV-85

UMSCR 1.1. IV-59

UPLR 13.2.(d), IV-49

13.1.(c). IV -47

UPLR 6.12., IV-24

6.11.1. IV -24

UPLR 10.9.2.(f) IV-35

- G -

$\begin{array}{lll}\text { UPLR } & 6.5 .(\mathrm{b}) & \text { IV-15 } \\ \text { UPLR } & 10.8 .2(\mathrm{a})(3) & \text { IV-33 } \\ \text { UMSCR } & 2.19 . & \text { IV-77 } \\ \text { UPLR } & 3.1 . & \text { IV-13 } \\ \text { UMSCR } & 1.10 . & \text { IV-62 } \\ \text { UPLR } & 6.12 ., & \text { IV-24 } \\ & 6.11 .1 . & \text { IV-24 } \\ \text { UPLR } & 11.6 . & \text { IV-39 } \\ \text { UPLR } & 11.9 .(\mathrm{d}) & \text { IV-40 } \\ \text { UMSCR } & 3.2 .1 . & \text { IV-78 } \\ \text { UMSCR } & 2.7 . & \text { IV-69 } \\ \text { UWML } & 12.15 . & \text { III-17 } \\ \text { UPLR } & 12.1 .2 . & \text { IV-46 } \\ \text { UWML } & 12.15 . & \text { III-17 } \\ \text { UPLR } & 12.1 .1 . & \text { IV-45 } \\ \text { UWL } & 7 . & \text { III-26 } \\ \text { UMSCR } & 2.9 .1 .9 . & \text { IV-71 }\end{array}$


Gram, kilogram, or milligram Grant exemptions

Gusset in bags
UPLR

6.6.(a)

12.5 .

UPLR

10.8.1.(a)
IV-16

III-15

IV-31
Hair preparations

Half-gallon and half-pint containers

Half-pint and half-gallon containers

Halves, quarters, eighths, sixteenths, thirty-seconds

Hand lettering permitted, consumer packages nonconsumer packages

Handbook 130

Handbook 133

Handbook 44

Handbook 67

Handbooks 105-1, 105-2, 105-3

Handicraft threads

Hardwood lumber

Heating fuel

Height of numbers and letters, consumer pkgs.

Hindrance of official in performance of duties

Hold order

Hominy grits, flour, and corn meal

House-type cars, tank cars, covered hopper cars

Household cleaners, detergents, soap powders, disinfectants
UUPR

UPLR

11.9.(a)

IV-85

UPLR

11.9.(a)

IV-39

UPLR

6.10.(b)

IV-39

UPLR

8.1.

9.1 .

UPLR

$5 ., 6 ., 7 .$,

$8 ., 9 ., 10$.

III-1

UWML

UW ML

12.13.

UPLR

12.2 .

UWML

URNTE

4.

UWML

2.1 .

UPLR

12.13 .

12.2 .

URNTE

2.1 .

UPLR

10.9.5.(a)

UMSCR

2.11 .

UWML

18.

UPLR

8.2.1.,

Table 1.

IV-29

UWML

22.

III-19

UWML

13.2.

III-17

UMSCR

1.4.

IV -60

UMSCR

3.4.4.

IV -80

UUPR

2.

IV-85 
Ice cream and similar frozen products

Ice cream, frozen desserts, fluid dairy products

Ice milk, frozen yogurt, ice cream

Identity

Identity of firewood sof twood lumber

Imitation fruit juice beverages Impersonating a weighmaster Imprisonment under; weighmaster law weights and measures law Inch, foot, yard

Inch-pound and metric declarations, combined

$\begin{array}{lll}\text { UMSCR } & 1.7 .1 . & \text { IV-62 } \\ \text { UPLR } & 11.9 . & \text { IV-39 } \\ \text { UMSCR } & 1.7 .1 . & \text { IV-62 } \\ \text { UWML } & 18 . & \text { II-18 } \\ \text { UMSCR } & 2.3 .2 . & \text { IV-65 } \\ \text { UMSCR } & 2.9 .2 . & \text { IV-71 } \\ \text { UPLR } & 11.10 . & \text { IV-40 } \\ \text { UWL } & 17 . & \text { III-28 } \\ \text { UWL } & 19 ., 20 . & \text { II-29 } \\ \text { UWML } & 22 . & \text { III-19 } \\ \text { UPLR } & 6.5(\mathrm{c}) & \text { IV-16 } \\ & & \\ \text { UPLR } & 6.11 .2 . & \text { IV-24 } \\ & & \\ \text { UPLR } & 6.7 .1 . & \text { IV-18 } \\ \text { UPLR } & 6.5 . & \text { IV-16 } \\ \text { UPLR } & 7.4 . & \text { IV-25 } \\ \text { UWL } & 19 . & \text { III-29 } \\ \text { UWL } & 19 . & \text { III-29 } \\ & & \text { III-17 } \\ \text { UWML } & 13.3 . & \text { III-16 } \\ \text { UWML } & 12.12 ., & \text { III-19 }\end{array}$

Inch-pound system, prescribed units weight, measure-consumer weight, measure-nonconsumer Incorrect weighing by weighmaster Incorrect weight certificate Incorrect weight, measure, package, or commodity

Incorrect weights and measures

Individual serving size packages, labeling exemption

Individual wrappings not to be sold individually

Industrial thread

UPLR 11.4. IV-38

Industrial use

Information required on packages

UPLR

1.(a)

UPLR

10.9.5.(d)

IV-11

UPLR

2.3.

IV-37

UWML

19.

IV-12

III-18 
Injunction under weights and measures law Inspection of commercial weights and measures Inspect packaged commodities

Inspect weights and measures for sale Inspector's tag

Installed insulation Institutional purchases Institutional supplies Institutional use Instrumentality for deception

Insulation

Insulin-containing and prescription drugs

Intrastate Commerce

Introductory offers

Investigations

UWML $23 . \quad$ III-20

UWML $\quad 12.10 \quad$ III-16

UWML 12.13. III-16

UWML 12.9. III-16

UPLR 2.6. IV-12

UMSCR 2.13.4. IV-75

UWML 12.11. III-16

UWML 12.11. III-16

UPLR 2.3. IV-12

UPLR 13.1.(c), IV-47

13.2.(d), IV-49

13.3.(c) IV-49

$\begin{array}{lll}\text { UMSCR } & \text { 2.13. IV-75 }\end{array}$

UPLR 11.21. IV-42

UWML 12.15. III-17

UPLR 12.1.2. IV-46

UPLR 13.2. IV-48

UWML 12.6. III-16

Invoices or records of price promotions

Issue regulations

UPLR 13.1.(d) IV-48

Issue stop-use, stop-sale, hold, and removal orders

UWML 12.3 .

III-15

UWML 13.2.

III-17

Jams, jellies, preserves, and peanut butter

UUPR 2.

IV-85

Juices and drinks, fruit and vegetable

UUPR 2.

IV-85

Kerosene, ASTM D3699

Kiln drying

Kilogram, gram, or milligram

Kindling logs, boards, timbers as fuel
UMSCR

2.18 .

IV-77

UMSCR

2.11 .

UPLR

6.6.(a)

IV-73

IV-16

UMSCR

2.3.1.1.

IV-65 
1 and $\mathrm{L}$

Label

Labeling exemptions

Labeling requirements

Lacquers, labeling exemptions

Largest whole unit consumer declarations nonconsumer declarations

Lawn and trash bags, consumer, polyethylene

Length measure, dual quantity declaration

Less than 1 foot, $1 \mathrm{sq}$ foot, 1 pound, 1 pint

Lettering style or type, consumer package

License

application

fees for weighmaster

period, weighmaster renewal, weighmaster requirements

Licensed public weighmaster

Lignite Coal

Limited licenses of weighmasters

Lines of print or type

Liquefied petroleum gas cylinder tare weights

Liquid detergents

Liquid measure, dual quantity declaration

Liquid quart, liquid pint, fluid ounce

Liquid soups and condensed liquid soups

List of registered servicepersons

Liter or milliliter

Loaf of bread

Location of quantity declaration, consumer package nonconsumer package

$\begin{array}{lll}\text { UPLR } & 6.6 .1 .(b) & \text { IV-17 } \\ \text { UPLR } & 2.5 . & \text { IV-12 } \\ \text { UPLR } & 11 . & \text { IV-38 } \\ \text { UWML } & 12.4 . & \text { III-15 } \\ \text { UPLR } & 11.23 . & \text { IV-43 }\end{array}$

$\begin{array}{lll}\text { UPLR } & 6.2 . & \text { IV-14 } \\ \text { UPLR } & 7.2 . & \text { IV-25 } \\ \text { UMSCR } & 2.12 .3 . & \text { IV-74 } \\ \text { UPLR } & 6.7 .4 . & \text { IV-19 } \\ \text { UPLR } & 6.7 .1 . & \text { IV-18 }\end{array}$

$\begin{array}{lll}\text { UPLR } & \text { 8.1.2. IV-27 }\end{array}$

UWL 4.4 III-25

UWL $\quad 6 . \quad$ III-26

UWL $8 . \quad$ III-26

UWL 8.

UWL $3 . \quad$ III-25

UWL 1.1 III-25

UMSCR 2.14. IV-76

$\begin{array}{lll}\text { UWL } & 7 . & \text { III-26 }\end{array}$

UPLR 6.3.2. IV-14

UMSCR 2.15. IV-76

UUPR 2. IV-85

$\begin{array}{lll}\text { UPLR } & 6.7 .3 . & \text { IV-19 }\end{array}$

UPLR 6.5.(b) IV-15

UUPR 2. IV-85

URVRS $11 . \quad$ IV-98

UPLR 6.6.(b) IV-17

UMSCR 1.2. IV-59

UPLR 8.1.1. IV-27

UPLR 7.2. IV-25


Long shelf-life food, definition

Loose fill cellulose insulation noncellulose insulation

UODR

2.4 .

IV-104

Loss or gain of moisture

UMSCR

2.13.2.

IV-75

UMSCR

2.13.1.

IV -75

UWML

12.15 .

UPLR

12.1.2.

III-17

UPLR

12.1.1.

IV -45

Lot of a commodity

Lowfat milk, skim milk, cultured milk, cream milk

UMSCR 1.6

IV-61

LPG cylinder tare weights

UMSCR

2.15 .

IV-76

Lumber, hardwood

UMSCR

2.11 .

IV-73

\section{- M -}

Machine vended commodities

Magnitude of permitted variations

Maintain traceability to NBS

Maintenance of commercial weights and measures

Malfeasance: weighmaster law

UMSCR

IV-78

UPLR

UWML

12.2 .

IV-46

UWML

12.1 .

III-15

UWL

11.1 .

III-15

III-29

Manner of expressing date, in open dating

UODR

3.4 .

IV-105

Manufactured for and packed by

4.3

IV-106

Margarine, butter, and oleomargarine

Margarine/labeling exemptions

Mark incorrect weights and measures

UPLR

5.

IV-13

UMSCR

1.3.

IV -59

UPLR

11.19.

IV -42

UWML

12.12 .

III-16

Matched, patterned, shiplapped lumber

Mattress covers

UMSCR

2.9 .

IV-70

UPLR

10.9.2.(a)

IV -33

Mattress pads

UPLR

$10.9 .2 .(d)$

IV-33

Mattress pads, sleeping bags, pillows, cushions

UPLR

11.26 .

IV-44

Measure combined with weight, count, or size

UPLR

6.4.1.(b)

IV-15 
Measure containers under $\mathrm{H}-44$

UPLR

11.9.(c)

IV-39

Measure packaged commodities

UWML

12.13 .

III-16

Measurement of container-type commodities

UPLR $\quad 10.8$.

IV -31

Meat cuts, generic terms

Meat sales by carcass, side or primal cut

UMSCR 1.10 .

IV -62

UMSCR 1.11 .

IV-63

Meat, poultry, and seafood

Meat, poultry, seafood

Meter, centimeter, or millimeter

Method of sale regulation

Metric and inch-pound declarations, combined

UMSCR $\quad 1.5$

IV -60

UUPR

2.

UPLR

UWML

6.6.(c)

IV -85

IV -17

III-13

6.9

III-18

UPLR

6.11 .2 .

IV-24

Metric and inch-pound systems permitted

UPLR

7.1.

IV -25

Metric system, prescribed units

UPLR

6.8 .

IV -21

Metric units, weight, measure, nonconsumer consumer

UPLR

7.5 .

IV-26

UPLR

6.6 .

IV-16

Metric/inch-pound conversion factors

Metrological certification

$\begin{array}{lll}\text { UPLR } & \text { Appendix } & \text { IV-51 } \\ \text { UWML } & 11.3 . & \text { III-15 }\end{array}$

Milk, lowfat milk, skim milk, cultered milk, cream

Milk, package labeling exemptions

Milk-type containers

Milligram, gram, or kilogram

Milliliter or liter

$\begin{array}{lll}\text { UMSCR } & 1.6 . & \text { IV-61 } \\ \text { UPLR } & 11.9 . & \text { IV-39 } \\ \text { UPLR } & 11.10 & \text { IV-40 } \\ \text { UPLR } & 6.6 .(\mathrm{a}) & \text { IV-16 } \\ \text { UPLR } & 6.6 .(\mathrm{b}) & \text { IV-17 } \\ \text { UPLR } & 6.6 .(\mathrm{c}) & \text { IV-17 } \\ \text { UMSCR } & 2.9 . & \text { IV-70 } \\ \text { UMSCR } & 2.9 .1 .13 . & \text { IV-71 } \\ \text { URVRS } & 5 . & \text { IV-97 } \\ \text { UPLR } & \text { Table 1 } & \text { IV-29 }\end{array}$

Millimeter, centimeter, or meter

Millwork items individually assembled, softwood

Minimum dressed sizes, softwood lumber

Minimum equipment of service agency

Minimum height of numbers and letters, consumer 
Minimum, giant, full, when-packed

UPLR

6.11.1.,

IV-24

6.12 .

IV-24

Misdemeanor under weights and measures law

UWML

22.

III-19

Misrepresentation of:

pricing

quantity

UWML

16.

III-18

UWML

15 .

III-18

Moisture loss

UWML

12.15 .

III-17

UPLR

12.1.2.

IV -45

Month and day or day of week in open dating

UODR

IV-105

Motor fuel lableing

Motor oils, labeling exemptions

Movie film, labeling exemptions

Multi-unit package

UMSCR

2.19 .

UPLR

11.25 .

IV-77

UPLR

11.22 .

IV -44

UPLR

2.8 .

IV -42

Multi-unit soft-drink bottles

UPLR 11.12 .

IV -12

IV -30

IV -41

Name and address of manufacturer, packer, or

distributor

Napkins, textile

National Bureau of Standards

National Type Evaluation Program Net quantity

Net Weight

Next smaller whole unit

Nominal dimensions of softwood lumber

Non-rectangular diapers, textile

Nonconsumer package declaration of identity
UPLR

UPLR

URNTE

5.

10.9.2.(e)

2.1.,2.4.,

2.5 .

UWML

$2 ., 3 ., 4$.,

5.,6.,7.,

8.,9.,10.,

12.1 .

URNTE 2.1 .

UPLR $\quad 6.3$.

1.2 .

6.3.1.

UPLR

UPLR

6.2.(a)(2)

UMSCR

2.9.3.(a)

UPLR

UPLR

UPLR 10.9.2.(i)

2.3.

4.
IV -13

IV-34

IV -113

IV-114

III-12

III-13

III-14

III-15

IV-14

III-11

IV-14

IV -14

IV -71

IV-35

IV -12

IV -13 
Nonfood products

Nonpromotional matter on consumer commodity

Nonrectangular textile products

Normal business hours

Numbers and letters,

minimum height, consumer pkg

proportions, consumer pkg
UMSCR 2 .

IV -65

UPLR

2.6.

UPLR

10.9.2.(j)

IV -12

UWML

13.1 .

IV -35

III-17

UPLR

Table 1.,

IV -29

UPLR

8.2.1.

8.2.2.

IV -28

IV -28

- $\mathbf{0}-$

Oath of public weighmaster

Obstruction of official duties

Offenses and penalties, weighmaster law weights and measures law

Oils, paint, labeling exemptions

Oleomargarine, margarine and butter
UWL

UTML

9.

22.

UWL

UWML

19.

UPLR

22.

11.23 .

UMSCR

1.3.

III-26

III-19

III- 29

III-19

IV -43

One meter, 1 sq. meter, 1 kilogram, 1 liter, or more

UPLR

6.8.2.

IV-21

One-draft weighing by weighmaster

Open carriers not obscuring label information

UWL

13.

III-27

Open dating requirements

Open multi-unit package

UPLR

$1(\mathrm{e})$

IV-11

UWML

9.

12.4 .

III-14

UPLR

10.4.ftnote

III-15

Optional licensing as weighmasters

UWL

16.

III-28

Oral examination for weighmaster license

Ordinary and customary exposure

Other milk products

UWL

5.

III-25

UPLR

12.1.2.

IV -45

UMSCR

1.7.

IV-61 


\section{$-\mathbf{P}-$}

\section{Package}

for industrial use, institutional use, or wholesale distribution identity labeling of consumer commodity of nonconsumer commodity standards of fill with no fixed pattern of weight

Packaged commodities sold by count

Packaged commodity

Packaged seed

Packages with labeling specified under Federa Law

Packaging and labeling requirements

Packaging variations

Paints and kindred products, labeling exemptions

Pans, boxes, bags, cups, containers

Paper products, sanitary

Parallel identity declaration: consumer package

Parallel quantity declaration: consumer package

Participating Laboratory

Pasteurized Milk Ordinance of U.S. P.H.S.

Patterned lumber, definition

Peanut butter, jams, jellies, preserves

Peat and peat moss

Peck, dry-quart, dry-pint

Pelletized seed

Penalties: weights and meas law weighmaster Law $\begin{array}{lll}\text { UWML } & 1.9 . & \text { III-11 } \\ \text { UPLR } & 2.1 . & \text { IV-11 }\end{array}$

UPLR 2.3. IV-12

UWML 19. III-18

UWML $19 . \quad$ III-18

UPLR 2.2. IV-12

UPLR 2.3. IV-12

UWML 12.4. III-15

UPLR $\quad 2.4$

UPLR 11.28. IV-44

UWML 11.2. III-15

UPLR $10.10 . \quad$ IV-37

$\begin{array}{lll}\text { UPLR } & \text { 11.8. }\end{array}$

UWML 5.

III -13

UPLR $12.1 . \quad$ IV-45

UPLR 11.23. IV-43

UPLR $10.8 .1 . \quad$ IV-31

UUPR 2. IV-85

UPLR 3.1.1. IV-13

UPLR 8.1.5. IV-28

URNTE 2.4. IV-113

UMSCR 1.7. IV-61

UMSCR 2.9.1.7. IV-71

UUPR 2. IV-85

UMSCR 2.4. IV-66

UPLR 6.5.(f) IV-16

$\begin{array}{lll}\text { UPLR } & 10.10 . & \text { IV-37 }\end{array}$

UWML $22 . \quad$ III-19

UWL $19 . \quad$ III-29 
Penny candy, labeling exemptions Perforated roll-type commodities Performance of services in the household

Period of weighmaster license

Periods following symbols

Perishable food, definition

Permanent injunction

Person

Personal possessions

Pet food

Petroleum products

Physical standards

Pickles, pickle relish

Pile of firewood

Pillowcases

Pillows, cushions, comfor ters, mattress pads

Pint, quart, and half-gallon containers

Placed-in-service report

Placement of date, in open dating

Plastic or glass containers of milk

Plastics, ashpalt paints, and coatings

Platform size of scale used by weighmaster

Plugs, cuts, and twists of tobacco and cigars

Plural forms of symbols

Ply, count

Policy, voluntary registration regulation

Polyethylene products

Pot holders, textile

Poultry, meat, seafood
11.3.

6.9 .

IV -38

UPLR

2.2 .

8.

IV-23

UPLR

UWL

UPLR

6.5 .1 .

IV-12

III-26

IV -16

UODR

2.2 .

IV-103

UWML

23.

III-20

UWML

UPLR

1.7.

2.7 .

UUDR

2.7 .

UPLR

2.2 .

UUPR

2.

III-11

IV-12

IV-104

IV-12

IV-85

UPLR

6.5.(b),

IV-15

UWML

6.6.(b)

IV -17

UMSCR

3.

UMSCR

1.8 .

2.3.4.

III-12

UPLR

10.9 .2 .

IV-62

IV-66

IV-33

UPLR

11.26.

IV-44

UPLR

11.9.(b)

IV -39

URVRS

8.

IV-97

UODR

5.

IV-106

UPLR

11.9.(d)

IV-40

UMSCR

2.2 .

IV-65

UWL

13.

III-27

UPLR

11.5 .

IV -39

UPLR

6.5.1.

IV-16

UPLR

6.9 .

IV-23

URVRS

1.

IV-95

UMSCR

2.12 .

UPLR

$10.9 .2 .(i)$

IV -73

UUPR

2.

IV -35

UMSCR
IV-85

IV-60 
Power to issue regulations

UWL

2.

III-25

Powers and duties of local officials

Powers of director

Pre-planters of seed

UWML

14.

III-17

UWML

12.

III-15

Precious metals

UPLR

10.10 .

IV -37

UMSCR

2.16 .

IV -76

Precision calibration

Preemption of local, county, and municipal ordinances

UWML

11.3.

III-15

Prefabricated utility buildings

Prepackaged, definition

Prescribe appropriate terms or units

UODR

9.

UMSCR

2.5 .

IV-107

UODR

2.5 .

IV-67

UWML

12.14.

III-16

Prescribed units, inch-pound system metric system

UPLR

6.7.

IV -18

UPLR

6.8 .

IV-21

Prescription and insulin-containing drugs

Presealing weight certificate

Presentation of price

UPLR

11.21 .

IV -42

UWL

20.

UMSCR

3.1 .

III-29

Preserves, jams, jellies, and peanut butter

UUPR

2.

IV -85

Pressurized containers and aerosols

UPLR

10.3 .

IV -30

Presumptive evidence

Prevention of unfair dealing

Price advantage by reason of the size of package

UWML 24.

III-20

UWML

11.2 .

III-15

Price lower than ordinary and customary price

UPLR 13.3.

IV -49

UPLR

13.1.

IV -46

Price marked based on price per weight or measure

$\begin{array}{lll}\text { UPLR } & 2.1 . & \text { IV-11 } \\ \text { UWML } & 16 . & \text { III-18 } \\ \text { UWML } & 20 . & \text { III-19 } \\ \text { UPLR } & 13.1 . & \text { IV-46 } \\ \text { UUPR } & 5 . & \text { IV-86 } \\ \text { UMSCR } & 1.9 . & \text { IV-62 }\end{array}$


Prohibition of terms in sale of firewood

Primary standards

Principal display panel area calculation

Principal place of business

Privileges and responsibilities of serviceperson

UMSCR

2.3.4.

IV -66

UWML

1.4 .

III-11

UPLR

2.8 .

IV -12

UPLR

8.2 .

IV-28

UPLR

5.

IV-13

URVRS 7 .

IV-97

Prohibited acts as weighmaster

UWL

17.

III-28

Prominance and placement, consumer packages nonconsumer packages

Promotion of uniformity

Proper installation

Proportion of numbers and letters, consumer packages

UPLR

8.

IV -27

UPLR

9.1.

IV -29

UWML

11.4 .

III-15

UWML

11.1 .

III-15

$\begin{array}{lll}\text { UPLR } & \text { 8.2.2. } & \text { IV-28 }\end{array}$

Protection of consumers

Public weighing

Publication of lists of registered service persons

UWML 11.5

$\begin{array}{lll}\text { UWML } & 11.5 . & \text { III-15 } \\ \text { UWL } & 17 . & \text { III-28 }\end{array}$

URVRS $11 . \quad$ IV-98

UPLR 2.2. IV-12

UPLR 2.1. IV-11

Put up in advance of sale

Putty, calking compounds, sealants

$\begin{array}{lll}\text { UMSCR } & \text { 2.7. IV } 69\end{array}$

Qualification of declaration prohibited

Qualifications: for weighmaster for weighmaster applicant

Qualifying term

Quality representation

Quality misrepresentation

UPLR

6.12 .

IV-24

Quantity of contents

UWL

3.

III-25

UWL

5.

III-25

UPLR

6.11.1.

IV -24

UWML

18.

III-18

UWML

15 .

III-18

Quantity of:

firewood, packaged or from bulk

UWML

19.

III-18

sod or turf

UMSCR

2.3.3.

IV-66

UMSCR

2.8.3.

IV-69

softwood lumber

2.9.3.

IV-71

roofing materials

UMSCR

2.6.2.2.

IV-68

Quart, pint, and half-gallon containers

Quilts

UPLR

11.9.(b)

IV -39

UPLR

10.9.2.(d)

IV-34 
$\mathrm{R}$-value, insulation

Rack of firewood

Railroad car tare weights

Random package

labeling exemptions

Random weight package

Ready-wound bobbins of thread

Reasonable variations

Rebuttable presumption of evidence

Reciprocal acceptance of weight certificates

Record keeping of weighmaster applications

Records required

for price promotions

in open dating

Rectangular container, area of PDP calculation

Refrigerator cars, house-type cars, tank cars

Regional grading rules for softwood lumber

Registered sevice agency, definition

Registered serviceperson, definition

Registration as serviceperson

Registration certificate

Registration fee for servicepersons

Registration of servicepersons requirements
UMSCR

2.13.

IV -75

UMSCR

2.3.4.

IV-66

UMSCR

3.4 .

IV-79

UPLR

2.4.,

IV-12

6.7.1.prov.

IV -18

6.8. proviso

IV -21

UPLR

11.2.

IV -38

11.27.

IV -44

UPLR

6.7.1.prov.

IV -18

6.8.proviso

UWML

20.

IV -21

III-19

UPLR 10.9.5.(d) IV-37

UWML $\quad 12.15$.

III-17

UWML

24.

III-20

UWL

15.

III-28

UWL

5.

III-25

UPLR

13.1.(d),

IV -47

UODR

13.2.(e)

IV -49

IV-107

UPLR

8.2.(a)

IV-28

UMSCR

3.4.4.

IV -80

UMSCR

2.9.1.13.

IV-71

URVRS

2.2 .

IV-96

URVRS

2.1.

IV-96

URVRS

4.

IV-96

URVRS

6.

IV-97

URVRS

3.

IV-96

UWML

8.

III-14 
Regular price

Regulations unaffected by repeal of statute

Reject incorrect weights and measures

Relish, pickle

Relishes and condiments

Remnant textile packages

Removal of tag, seal, or mark from weight or measurement

Removal order

Removers, paint, labeling exemptions

Renewal of weighmaster license

Repeal of conflicting laws: weights and measures law weighmaster law

Representation of softwood lumber

Representation, ad, or offering of firewood

Required entries on weight certificate

Requirements for type evaluation

Resins, paint, labeling exemptions

Reasonable period for consumption

Responsibilites and privileges of serviceperson

Responsibility for advertisement of sale for sell by date

Retail sale price representations

Retail sales agencies

Retail tray pack display containers

Returnable glass containers

Reusable glass containers

Revocation of certificate of registration

$\begin{array}{lll}\text { UPLR } & 13.1 .(\mathrm{b})(4) & \text { IV-47 } \\ \text { UWML } & 27 . & \text { III-20 } \\ \text { UWML } & 12.12 . & \text { III-16 } \\ \text { UMSCR } & 1.8 . & \text { IV-62 } \\ \text { UUPR } & 2 . & \text { IV-85 }\end{array}$

UPLR 10.9.2.(k) IV-35

UTML $22 . \quad$ III-19

UWML 13.2. III-17

$\begin{array}{lll}\text { UPLR } & 11.23 . & \text { IV }-43\end{array}$

UWL $8 . \quad$ III-26

UWML $26 . \quad$ III-20

UWL $24 . \quad$ III-30

$\begin{array}{lll}\text { UMSCR } & \text { 2.9.1.12. IV-71 }\end{array}$

$\begin{array}{lll}\text { UMSCR } & \text { 2.3.1.3. } & \text { IV-65 }\end{array}$

UWL 10,11. III-27

UWML $10 . \quad$ III-14

\begin{tabular}{|c|c|c|}
\hline $\begin{array}{l}\text { UPLR } \\
\text { UODR }\end{array}$ & $\begin{array}{l}11.23 \\
3.3 .1\end{array}$ & $\begin{array}{l}\text { IV-43 } \\
\text { IV }-105\end{array}$ \\
\hline URVRS & 7. & IV-97 \\
\hline UODR & 3.2 .2 . & IV-104 \\
\hline UODR & 3.3 .2 . & IV-105 \\
\hline UPLR & 13. & IV -46 \\
\hline UPLR & 2.2. & IV -12 \\
\hline UPLR & $1(d)$ & IV-11 \\
\hline UPLR & 11.6. & IV-39 \\
\hline UPLR & 11.6. & IV-39 \\
\hline URVRS & 10. & IV-98 \\
\hline
\end{tabular}


Revocation of conflicting regulations: packaging and labeling method of sale type evaluation

Revocation of weighmaster license

Rice

Roll-type commodities metric system

Rolls of

felt and roofing material

fence wire products

wrapping

$\begin{array}{lll}\text { UPLR } & 14 . & \text { IV-50 } \\ \text { UMSCR } & 4 . & \text { IV-80 } \\ \text { URNTE } & 5 . & \text { IV-114 } \\ \text { UWL } & 18 . & \text { III-28 } \\ \text { UUPR } & 2 . & \text { IV-85 } \\ \text { UPLR } & 6.7 .7 . & \text { IV-19 } \\ \text { UPLR } & 6.8 .3 . & \text { IV-22 } \\ \text { UMSCR } & 2.6 . & \text { IV-68 } \\ \text { UMSCR } & 2.1 . & \text { IV-65 } \\ \text { UUPR } & 2 . & \text { IV-85 } \\ & & \\ \text { UMSCR } & 1.2 . & \text { IV-59 } \\ \text { UMSCR } & 2.6 . & \text { IV-67 } \\ \text { UMSCR } & 2.7 . & \text { IV-69 } \\ \text { UMSCR } & 2.9 . & \text { IV-70 } \\ \text { UMSCR } & 2.9 .1 .5 . & \text { IV-70 } \\ \text { UPLR } & 6.11 .3 . & \text { IV-24 } \\ \text { UPLR } & 10.9 .2 .(8) & \text { IV-34 }\end{array}$

Rolls, biscuits, or buns

Roofing and roofing material

Rope calk

Rough lumber

definition, softwood

Rounding

Rugs

SAE viscosity number

Salad dressing

Sale after expiration

of best-if-used-by date

of sell-by date

Sale from bulk

$\begin{array}{lll}\text { UPLR } & 11.25 . & \text { IV-44 } \\ \text { UUPR } & 2 . & \text { IV-85 } \\ & & \\ \text { UODR } & 4.2 . & \text { IV-106 } \\ \text { UDDR } & 3.2 . & \text { IV-104 } \\ \text { UWML } & 1.8 ., & \text { III-11 } \\ & 18 . & \text { III-18 } \\ & & \text { IV-63 }\end{array}$

Sale of meat by carcass, side or primal cut

UODR $3 . \quad$ IV-104

and date determination

Sale of semi-perishable and long life food

Sales invoice for firewood

Sandwich and food bags, consumer, polyethylene

Sanitary paper products

$\begin{array}{lll}\text { UODR } & 4 . & \text { IV-106 } \\ \text { UMSCR } & 2.3 .5 . & \text { IV-66 } \\ & & \\ \text { UMSCR } & 2.12 .4 . & \text { IV-74 } \\ \text { UUPR } & 2 . & \text { IV-85 }\end{array}$


Scale used by weighmaster

Seafood, meat, and poultry

Seal of public weighmaster

Sealants

Search warrant

Secondary standards

Seed tapes, coated seed

Seizure of incorrect or unapproved items weights and measures

Sell by date, definition placement, wording

Semi-perishable food, definition

Separability provision weights and measures law weighmaster law

Serviceperson and service agency registration

Sewing threads, handicraft threads, yarns

Shaving preparations

Sheeting and film, polyethylene, consumer polyethylene, nonconsumer

Sheets

Shingles and roofing materials

Shiplapped lumber, definition

Shipping containers solely for transportation

Shortening and cooking oils

Single item exemptions

Single strength fruit juice beverage

Single-draft weighing by weighmaster

Skim milk, cultured milk, cream, milk, lowfat milk

Sleeping bags, pillows, cushions, etc.

$\begin{array}{lll}\text { UWL } & 12 ., 13 . & \text { III-27 } \\ \text { UMSCR } & 1.5 . & \text { IV-60 } \\ \text { UUPR } & 2 . & \text { IV-85 } \\ \text { UWL } & 9 . & \text { III-26 } \\ \text { UMSCR } & 2.7 . & \text { IV-69 } \\ \text { UWML } & 13.1 . & \text { III-17 } \\ \text { UWML } & 1.5 . & \text { III-11 } \\ \text { UPLR } & 10.10 . & \text { IV-37 } \\ \text { UWML } & 13.3 . & \\ \text { UWML } & 12.12 . & \text { III-17 } \\ \text { UODR } & 2.1 . & \text { III-16 } \\ \text { UODR } & 3.4 .2 . & \text { IV-103 } \\ \text { UODR } & 2.3 . & \text { IV-105 }\end{array}$

$\begin{array}{lll}\text { UWML } & 25 . & \text { III-20 } \\ \text { UWL } & 23 . & \text { III-29 }\end{array}$

UWML 8.

UPLR 10.9.5. IV-36

UUPR 2. IV-85

UMSCR 2.12.1. IV-73

UMSCR 2.12.5. IV-74

UPLR 10.9 .2 IV-33

UMSCR 2.6. IV-67

UMSCR 2.9.1.8. IV-71

UPLR 1(b) IV-11

UUPR 2. IV-85

UUPR 4.4 IV-86

UPLR 11.10 IV-40

UWL $13 . \quad$ III-27

UMSCR 1.6. IV-61

UPLR $\quad 11.26 . \quad$ IV-44 
Slip covers, textile

Small cigars and cigarettes

Small confections, labeling exemptions

Small fruits and berries

Small package exemptions

Soap powders, detergents, household cleaners

Sod and turf definition

Soft drinks

Soft-drink bottles

Softwood lumber

Softwood lumber sizes

Solid fuel products

Solvents, paint, labeling exemptions

Soups, condensed

Sour cream, yogurt, cottage cheese

Special police powers

Species group as identity of firewood of softwood lumber

Species of softwood lumber, definition

Specific consumer and nonconsumer package requirements

Specifications and tolerances

Square meter or square centimeter

Square of roofing

Square yard, square foot, square inch

Square, oblong, rectangular containers

Stale bread

$\begin{array}{lll}\text { UPLR } & 10.9 .2 .(\mathrm{i}) & \text { IV-35 } \\ \text { UPLR } & 11.7 . & \text { IV-39 } \\ \text { UPLR } & 11.3 . & \text { IV-38 } \\ \text { UMSCR } & 1.1 . & \text { IV-59 } \\ \text { UUPR } & 3 . & \text { IV-86 } \\ \text { UPLR } & 11.16 . & \text { IV-41 }\end{array}$

UUPR 2.

IV-85

UMSCR 2.8 .

IV -69

UMSCR

2.8.2.1.

IV -69

UUPR

2.

IV-85

UPLR

11.11 .

IV -40

UMSCR

2.9 .

IV-70

UMSCR Table 1., IV-72

2.9 .

IV -70

UMSCR

2.14 .

IV-76

UPLR

11.23 .

IV -43

UUPR

2.

IV-85

UMSCR

1.7.

IV-61

UWML

13.

III-17

UMSCR

2.3.2.

IV-65

UMSCR

2.9.1.11.

IV-71

UMSCR

2.9.1.10.

IV-71

UPLR

10.

IV-29

UWML

4.

III-12

UPLR

6.6.(d)

IV-17

UMSCR

2.6.1.2.

IV-68

UPLR

6.5.(d)

IV-16

UPLR

10.8.1.(b)

IV -32

UMSCR

1.2 . 
Standards of fill for packages

Standards of weight, measure, or count

State purchases

State residency

State weights and mesures division

Stated quantity of contents

Stemware, tumblers, allowable differences

Stenciled tare weights on freight cars

Stop commercial vehicles

Stop-sale order, stop-use order

Stove and fireplace wood

Stuffed meat or poultry products

Style of lettering, consumer package

Subsequent conviction

Suitability for intended use

Supplementary declarations

Surfaced, dressed lumber, definition

Suspension of: certificate of registration weighmaster license

Symbols and abbreviations, consumer packages nonconsumer packages metric, consumer packages metric,nonconsumer packages Syrups, table and topping

Systems of weights and measures

$\begin{array}{lll}\text { UWML } & 12.4 . & \text { III-15 } \\ \text { UWML } & 12.4 . & \text { III-15 } \\ \text { UWML } & 12.11 . & \text { III } 16 \\ \text { UWL } & 3 . & \text { II-25 } \\ \text { UWML } & 11 . & \text { III-15 } \\ \text { UWML } & 12.15 . & \text { III-17 } \\ \text { UMSCR } & 3.2 .1 . & \text { IV-78 } \\ \text { UMSCR } & 3.4 . & \text { IV-79 } \\ \text { UWML } & 13.4 . & \text { III-17 } \\ \text { UWML } & 13.2 . & \text { III-17 } \\ \text { UMSCR } & 2.3 . & \text { IV-65 } \\ \text { UMSCR } & 1.5 . & \text { IV-60 } \\ \text { UPLR } & 8.1 .2 . & \text { IV-27 } \\ \text { UWML } & 22 . & \text { III-19 } \\ \text { UWML } & 11.1 . & \text { III-15 } \\ & & \\ \text { UPLR } & 6.11 ., & \text { IV-24 } \\ & 6.11 .1 . & \text { IV-24 } \\ \text { UMSCR } & 2.9 .1 .1 . & \text { IV-70 } \\ \text { URVRS } & 10 . & \text { IV-98 } \\ \text { UWL } & 18 . & \text { III-28 } \\ \text { UPLR } & 6.5 .1 . & \text { IV-16 } \\ \text { UPLR } & 7.4 .1 . & \text { IV-26 } \\ \text { UPLR } & 6.6 .1 . & \text { IV-17 } \\ \text { UPLR } & 7.6 . & \text { IV-27 } \\ \text { UUPR } & 2 . & \text { IV-85 } \\ \text { UWML } & 2 . & \text { III-12 }\end{array}$

Table syrups

Tablecloths or bedsheets metric system

Tablecloths, textile

Tank cars, covered hopper cars, flat cars

Tea, coffee, and cocor

$\begin{array}{lll}\text { UUPR } & 2 . & \text { IV-85 } \\ \text { UPLR } & 6 \cdot 7 \cdot 7 .(\mathrm{d}) & \text { IV-20 } \\ \text { UPLR } & 6.8 .3 .(\mathrm{b})(3) & \text { IV-23 } \\ \text { UPLR } & 10.9 .2 .(\mathrm{e}) & \text { IV-34 } \\ & & \\ \text { UMSCR } & 3.4 .4 . & \text { IV-80 } \\ \text { UUPR } & 2 . & \text { IV-85 }\end{array}$


Technical requirements

$$
\text { for devices }
$$

Telephone directory

Temporary injunction

Terms of capacity declarations for containers

Terms, weight, liquid measure, dry, count

Test weights and measures

Testing of city or county standards

Textile packages, variety package, exemption

Textile products, threads, yarns

Textiles, variations from declared dimensions

Thinners, labeling exemptions

Thirds, fractions, inch-pound

Throws

Timbers of softwood lumber, definition

Timbers, logs, boards as fuel

Tint base paint, labeling exemptions

Tobacco and cigars, labeling exemptions

Toilet water and colognes

Toothpaste

Topping syrups

Towels

Traceability

Trade area

Trade custom

Trademark

\begin{tabular}{|c|c|c|}
\hline UWML & 4. & III-12 \\
\hline UPLR & 5. & IV -13 \\
\hline UWML & 23. & III-20 \\
\hline UPLR & 10.8 .3 & IV -33 \\
\hline UPLR & $\begin{array}{l}\text { 6.4., } \\
7.3 .\end{array}$ & $\begin{array}{l}\text { IV }-15 \\
\text { IV }-25\end{array}$ \\
\hline UWML & 12.9 & III-16 \\
\hline UWML & 12.8 & III-16 \\
\hline UPLR & 10.9 .4 & IV -36 \\
\hline UPLR & 10.9 & IV -33 \\
\hline UPLR & 10.9 .3 & IV -36 \\
\hline UPLR & 11.23 & IV -43 \\
\hline UPLR & $6.10 .(b)(2)$ & IV -23 \\
\hline UPLR & $10.9 .2 .(d)$ & IV -33 \\
\hline UMSCR & 2.9 .1 .3 & IV-70 \\
\hline UMSCR & 2.3 .1 .1 & IV -65 \\
\hline UPLR & 11.23.(b) & IV -43 \\
\hline UPLR & 11.5. & IV -39 \\
\hline UUPR & 2. & IV -85 \\
\hline UUPR & 2. & IV -85 \\
\hline UUPR & 2. & IV -85 \\
\hline UPLR & $10.9 .2 .(h)$ & IV-35 \\
\hline UWML & $\begin{array}{l}3 ., \\
12.1\end{array}$ & $\begin{array}{l}\text { III-12 } \\
\text { III-15 }\end{array}$ \\
\hline UPLR & 13.1. & IV -46 \\
\hline UPLR & 6.4 & IV -15 \\
\hline UPLR & $10.9 .5 .(c)$ & IV -36 \\
\hline
\end{tabular}


Trash and lawn bags, consumer, polyethylene

Truckload of firewood

Tumblers, stemware, allowable differences

Turf and sod definition

Twists, euts, and plugs, of tobacco and cigars

Type evaluation

Type evaluation requirements

Type of scale used by weighmaster

Type size, labeling

$\begin{array}{lll}\text { UMSCR } & 2.12 .3 . & \text { IV-74 } \\ \text { UMSCR } & 2.3 .4 . & \text { IV-66 } \\ \text { UMSCR } & 3.2 .1 . & \text { IV-78 } \\ \text { UMSCR } & 2.8 . & \text { IV-69 } \\ \text { UMSCR } & 2.8 .2 .2 . & \text { IV-69 } \\ \text { UPLR } & 11.5 . & \text { IV-39 } \\ \text { URNTE } & 2.2 . & \text { IV-113 } \\ \text { UWML } & 10 . & \text { III-14 } \\ \text { UWL } & 12 . & \text { III-27 } \\ \text { UPLR } & 8.2 .1 ., & \text { IV-28 } \\ & 8.2 .2 . & \text { IV-28 }\end{array}$

Unapproved weight, measure, package or commodity

Unavoidable deviations

Unfair or decptive dealing

Uniform Laws and Regulations

Uniform Open Dating Regulation

Uniform Packaging and Labeling Regulation

Uniform Regulation for the Method of Sale

Uniform Regulation for National Type Evaluation

Uniform Retail Meat Identity Standards

Uniform Unit Pricing Regulations

Uniformity in weights and measures requirements

Unit of measure, method of sale, precious metals

UWML

13.3.

III-17

UWML

12.15 .

III- 17

UPLR

12.1.1.

IV -45

UWML

11.2 .

III-15

UWML

5., 6., 7.,

III- 13

UWML

8., 9., 10 .

III-14

9.

III-14

UWML

5.

III-13

UWML

6.

III-13

UWML

10.

III-14

UMSCR

1.10 .

IV -62

UWML

7.

III-13

UWML

11.4 .

III-15

UMSCR

2.16.2.

IV-76

UUPR

5.

6.

IV 86

UUPR

IV-86

UWML

20.

III-19 
Unit pricing requirements

United States citizen

Units of quantity for peat and peat moss

Units of two or more meanings

Units of weight for peat and peat moss

Unreasonable shortage

Upper and lower case letters

Use of tested and approved scale by weighmaster

Utility cloths

$\begin{array}{lll}\text { UWML } & 12.4 ., & \text { III-15 } \\ \text { UWL } & 7 . & \text { III-13 } \\ & 3 . & \text { III-25 } \\ \text { UMSCR } & 2.4 .2 . & \text { IV-67 } \\ \text { UPLR } & 6.5 .2 . & \text { IV-16 } \\ \text { UMSCR } & 2.4 .2 .1 . & \text { IV-67 } \\ \text { UPLR } & 12.1 .1 . & \text { IV-45 } \\ \text { UPLR } & 6.5 .1 . & \text { IV-16 } \\ \text { UWL } & 12 . & \text { III-27 } \\ \text { UPLR } & 10.9 .2 .(b) & \text { IV-34 }\end{array}$

Validity of prosecutions under weighmaster law

Value size, economy size, economy pack

Variable weights and sizes, labeling exemptions

Variations:

above the declared quantity

from declared quantity textiles

bark mulch

resulting from exposure

to be allowed

Variety packages

Variety textile packages, exemption

Varnishes, labeling exemptions

Vegetables and fruits

Vehicle

Volume at various temperatures

Voluntary product standard 20-70

Voluntary registration of servicepersons
UWL

UPLR

UPLR

UPLR

UPLR

UPLR

UPLR

UPLR

UPLR

UPLR

UPLR

UPLR

UUPR

UWL

UPLR

UMSCR

URVRS

UWML
22.

13.3.

11.27.

12.1.1.

12.1.1.

10.9.3.

10.11 .

12.1.2.

12.

10.6 .

10.9 .4 .

11.23 .

2.

1.2 .

6.6.(b),

6.5.(b)

2.9.1.13.

4.

8.
III-29

IV-49

IV-44

IV -45

IV -45

IV-36

IV-37

IV -45

IV-45

IV-30

IV-36

IV -43

IV-85

III-25

IV-17

IV-15

IV-71

III-14
IV-86

Warrant

UWML

13.1.,

III-17

Wearing apparel

UPLR

13.3.,13.5.

III-17

IV-33 
Weigh packaged commodities

Weighmaster license:

$$
\text { period }
$$

renewal

Weighmaster qualifications

Weighmaster's weight certificate

Weight

Weight certificate

Weight combined with measure, count, or size

Weight: dual quantity declaration

Weights and measures, definition

Weights and measures for sale

Weights and measures officer

as weighmaster

Weights and measures:

basic units

systems

Wheat flour, labeling exemptions

When-packed, minimum, giant, full

Whole units of weight

Wire fencing

Wire gage

Wood as fuel

Wood for fireplaces and stoves

Wrapping, not gift wrap

Written authorization

$\begin{array}{lll}\text { UWML } & 12.13 . & \text { III-16 } \\ \text { UWL } & 8 . & \text { III-26 } \\ \text { UWL } & 8 . & \text { III-26 } \\ \text { UWL } & 3 . & \text { III-25 } \\ \text { UWL } & 10 . & \text { III-27 } \\ \text { UWML } & 1.2 . & \text { III-11 } \\ \text { UWL } & 10 . & \text { III-27 } \\ \text { UPLR } & 6.4 .1 .(a) & \text { IV-15 } \\ \text { UPLR } & 6.7 .2 . & \text { IV-18 } \\ \text { UWML } & 1.1 . & \text { III-11 } \\ \text { UWML } & 12.9 . & \text { III-16 }\end{array}$

UWL

16.

III-28

UW ML

2.

III-12

UWML

2.

III-12

UPLR

11.15 .

IV -41

UPLR

6.11.1.,

IV-24

6.12 .

IV-24

UMSCR

1.9 .

IV-62

UMSCR

2.1.

IV-65

UMSCR

2.1 .

IV-65

UMSCR

2.3 .

2.3.

2.

IV-65

IV-65

UUPR

IV -85

UWML 22 .

III-19

\section{- X,Y,Z -}

\author{
Yard, foot, inch \\ Yarns \\ Yogurt, frozen \\ Yogurt, sour cream, \\ cottage cheese \\ ZIP Code
}

$\begin{array}{lll}\text { UPLR } & 6.5 .(c) & \text { IV-16 } \\ \text { UPLR } & 10.9 .5 .(b) & \text { IV }-36 \\ \text { UMSCR } & 1.7 .1 . & \text { IV-62 } \\ & & \\ \text { UMSCR } & 1.7 . & \text { IV-61 } \\ \text { UPLR } & 5 . & \text { IV-13 }\end{array}$




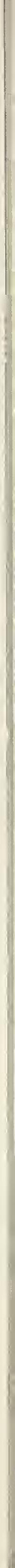


NBS-114A IREV. 2-8C)

U.S. DEPT. OF COMM.

BIBLIOGRAPHIC DATA

SHEET (See in structions)

1. PUBLICATION OR REPORT NO.

NBS / HB-130-1987
2. Performing Organ. Report Nod 3. Publication Date

Sept. 1986

4. TITLE AND SUBTITLE

Uniform Laws and Regulations, Handbook 130-1987

5. AUTHOR(S)

Carroll S. Brickenkamp, Editor

6. PERFORMING ORGANIZATION (If joint or other than NBS, see instructions)

NATHONAL BUREAU OF STANDARUS

U.S. DEPARTMENT OF COMMERCF

GAITHERSBURG, MD 20899

7. Contract Grant No.

8. Type of Report \& Period Covered

Final

9. SPONSORING ORGANIZATION NAME AND COMPLETE ADDRESS (Street, City. Stote, ZIP)

Same as above

10. SUPPLEMENTARY NOTES

Superseding Handbook 130-1986

$\square$ Document describes a computer program; SF-185, FIPS Software Summary, is attached.

11. ABSTRACT (A 200-word or less foctual summory of most significant informotion. If document includes a significant bibliogrophy or literoture survey. mention it here)

This handbook, revised annually, compiles the uniform laws and regulations developed by the Committee on Laws and Regulations of the National Conference on Weights and Measures (NCWM). The compilation itself was approved by the NCWM in 1979, and this edition includes amendments adopted by the Conference at its annual meeting in 1986. The title of the handbook and the titles of the laws and regulations compiled in it were changed at the 1983 annual meeting of the NCWM. A new index for the entire handbook has been added to this year's edition.

The NCWM recommends adoption and promulgation by the states of these uniform laws and regulations as updated in this handbook.

12. KEY WORDS (Six to twelve entries; alphabetical order; capitalize only proper names; and separate key words by semicolons) Basic weights and measures law; method of sale of commodities; open dating; packaging and labeling; pattern approval regulation; regulation of servicepersons; type evaluation; unit pricing; weighmaster law. 13. AVAILABILITY

X Unlimited

$\square$ For Official Distribution. Do Not Release to NTIS X Order From Superintendent of Documents, U.S. Govemment Printing Office, Washington. D.C.
20402.

14. NO. OF

PRINTED PAGES

178

15. Price

$\square$ Order From National Technical Information Service (NTIS), Springfield, VA. 22161 



\section{Periodical}

Journal of Research-The Journal of Research of the National Bureau of Standards reports NBS research and development in those disciplines of the physical and engineering sciences in which the Bureau is active. These include physics, chemistry, engineering, mathematics, and computer sciences. Papers cover a broad range of subjects, with major emphasis on measurement methodology and the basic technology underlying standardization. Also included from time to time are survey articles on topics closely related to the Bureau's technical and scientific programs. Issued six times a year.

\section{Nonperiodicals}

Monographs-Major contributions to the technical literature on various subjects related to the Bureau's scientific and technical activities.

Handbooks-Recommended codes of engineering and industrial practice (including safety codes) developed in cooperation with interested industries, professional organizations, and regulatory bodies.

Special Publications-Include proceedings of conferences sponsored by NBS, NBS annual reports, and other special publications appropriate to this grouping such as wall charts, pocket cards, and bibliographies.

Applied Mathematics Series-Mathematical tables, manuals, and studies of special interest to physicists, engineers, chemists, biologists, mathematicians, computer programmers, and others engaged in scientific and technical work.

National Standard Reference Data Series-Provides quantitative data on the physical and chemical properties of materials, compiled from the world's literature and critically evaluated. Developed under a worldwide program coordinated by NBS under the authority of the National Standard Data Act (Public Law 90-396).

NOTE: The Journal of Physical and Chemical Reference Data (JPCRD) is published quarterly for NBS by the American Chemical Society (ACS) and the American Institute of Physics (AIP). Subscriptions, reprints, and supplements are available from ACS, 1155 Sixteenth St., NW, Washington, DC 20056.

Building Science Series-Disseminates technical information developed at the Bureau on building materials, components, systems, and whole structures. The series presents research results, test methods, and performance criteria related to the structural and environmental functions and the durability and safety characteristics of building elements and systems.

Technical Notes-Studies or reports which are complete in themselves but restrictive in their treatment of a subject. Analogous to monographs but not so comprehensive in scope or definitive in treatment of the subject area. Often serve as a vehicle for final reports of work performed at NBS under the sponsorship of other government agencies.

Voluntary Product Standards-Developed under procedures published by the Department of Commerce in Part 10, Title 15, of the Code of Federal Regulations. The standards establish nationally recognized requirements for products, and provide all concerned interests with a basis for common understanding of the characteristics of the products. NBS administers this program as a supplement to the activities of the private sector standardizing organizations.

Consumer Information Series-Practical information, based on NBS research and experience, covering areas of interest to the consumer. Easily understandable language and illustrations provide useful background knowledge for shopping in today's technological marketplace.

Order the above NBS publications from: Superintendent of Documents, Government Printing Office, Washington, DC 20402.

Order the following NBS publications-FIPS and NBSIR's-from the National Technical Information Service, Springfield, .VA 22161.

Federal Information Processing Standards Publications (FIPS PUB)-Publications in this series collectively constitute the Federal Information Processing Standards Register. The Register serves as the official source of information in the Federal Government regarding standards issued by NBS pursuant to the Federal Property and Administrative Services Act of 1949 as amended, Public Law 89-306 (79 Stat. 1127), and as implemented by Executive Order 11717 (38 FR 12315, dated May 11, 1973) and Part 6 of Title 15 CFR (Code of Federal Regulations).

NBS Interagency Reports (NBSIR)-A special series of interim or final reports on work performed by NBS for outside sponsors (both government and non-government). In general, initial distribution is handled by the sponsor; public distribution is by the National Technical Information Service, Springfield, VA 22161, in paper copy or microfiche form. 
